\title{
Advances towards Multi-Hazard Analysis by Hybrid Simulation of Buildings in Fire and Fire Following Earthquake
}

\author{
by \\ Zhimeng Yu
}

A thesis submitted to the Faculty of Graduate and Postdoctoral Affairs in partial fulfillment of the requirements for the degree of

Master of Applied Science

in

Civil Engineering

Carleton University

Ottawa, Ontario

(C) 2019, Zhimeng Yu 


\section{Abstract}

Hybrid simulation is an innovative testing technique which takes both advantages: the efficiency in numerical modelling and accuracy of physical test. This research presents a framework for assessing the risks of large-scale structures in fire and fire following earthquake through hybrid simulation. Full interactions between the thermal and mechanical behaviour of the structures are considered in the assessment. In the proposed framework, the element of the prototype structure that is exposed to the sequence of fire loads is selected as physical domain for physical test while the remainder structure as numerical domain is numerically modelled. An illustrative example of the building exposed to fire hazard is presented to demonstrate the hybrid fire simulation methodology. For the multi-hazard risk, a numerical study on the performance of a 4-storey steel moment resisting frame subjected to fire following earthquake is also presented in this research. The results show that the sequential combination multi-hazard effect of fire following earthquake causes more severe damage to the example building when correspond to the case of damage due to fire hazard alone. The results from the fire following earthquake numerical simulation example contribute to the development of the multi-hazard hybrid simulation technique in future studies. 


\section{Acknowledgements}

The author would like to gratefully acknowledge her supervisors Dr. David Lau and Dr. Jeffrey Erochko for their tireless and tremendous support and guidance throughout this work, and for all their efforts to help secure the funding. The author would also like to thank Professor Heng Khoo and Professor Ehab Zalok for their countless help on this thesis. The author greatly acknowledges Professor Murat Saatcioglu and Professor Ehab Zalok for taking time reviewing the thesis and providing valuable suggestions. Special thanks to all the colleagues for their contributions to this work. The author would like to thank for the supports of all her family and friends. 


\section{Table of Contents}

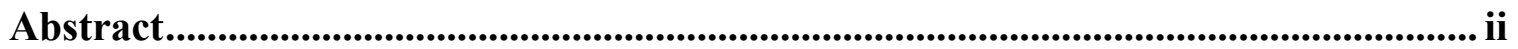

Acknowledgements .................................................................................................... iii

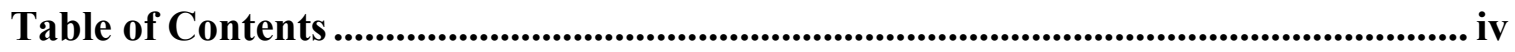

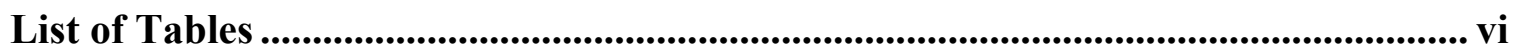

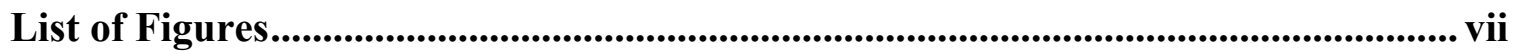

List of Appendix ........................................................................................................................... $\mathrm{x}$

1 Chapter: Introduction ..................................................................................................... 1

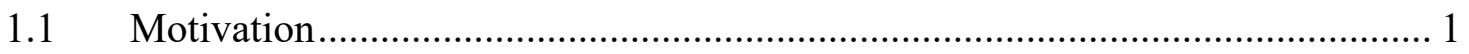

1.2 Research Objectives and Scope ......................................................... 7

2 Chapter: Background and Literature Review ..................................................... 9

2.1 Steel Material Properties at Elevated Temperature ................................... 9

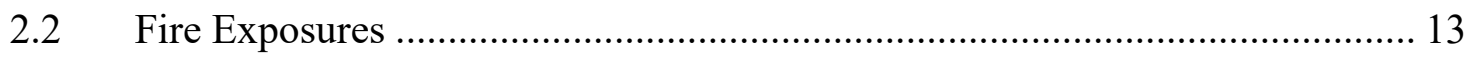

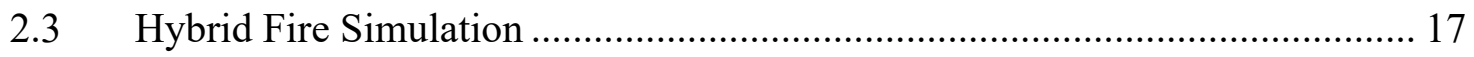

2.4 Review of Steel Structures Subjected to Fire Following Earthquake.............. 24

3 Chapter: Proposed Framework for Hybrid Fire Simulation ................................... 26

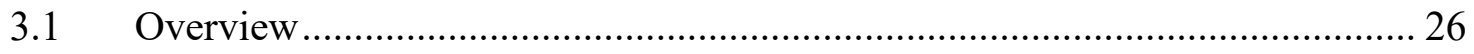

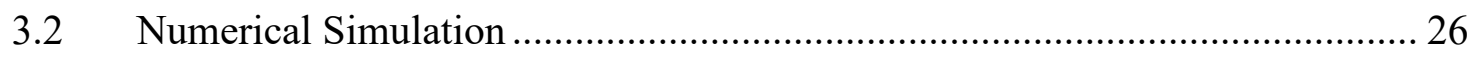

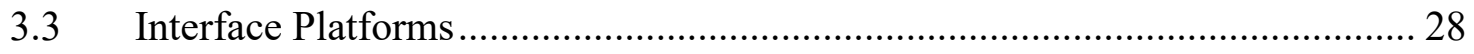




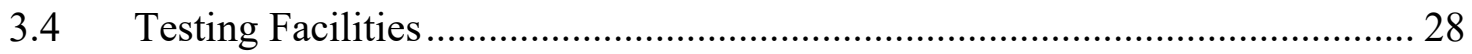

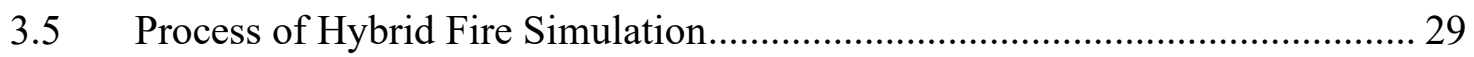

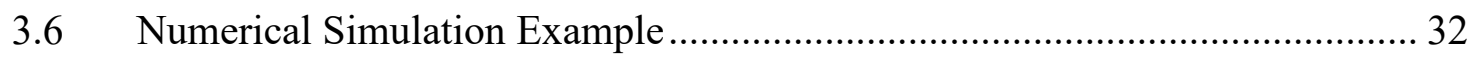

4 Chapter: Numerical Study on the Performance of a Steel Building Subjected to

Fire Following Earthquake .................................................................................................. 36

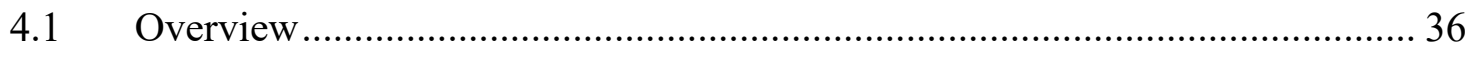

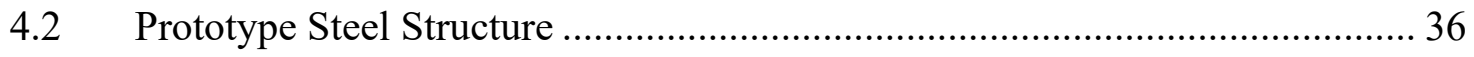

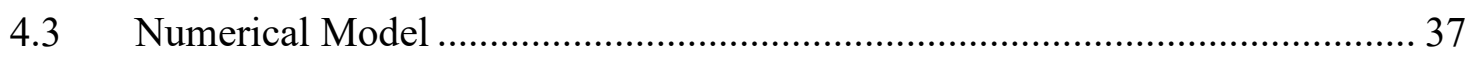

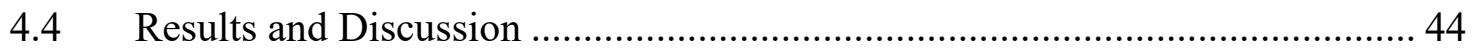

5 Chapter: Summary, Conclusions, and Future Research ……………...................... 54

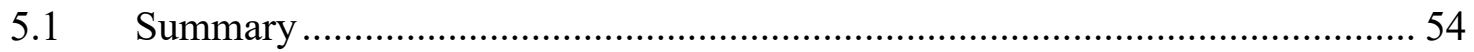

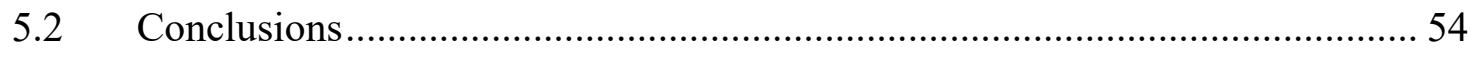

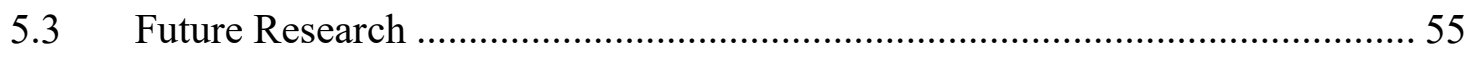

Appendix A: Calculation of Properties of Unprotected Steel Temperature Exposed

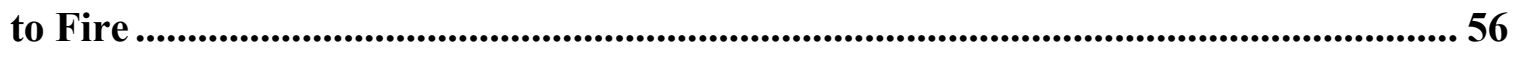

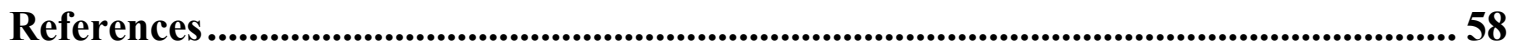




\section{List of Tables}

Table 1.1 Structural performance levels and illustrative damage (ASCE/SEI 41-17, 2017)

Table 2.1 Formulations for calculating stress-strain relationship for carbon steel at elevated temperatures in Eurocode $3(\mathrm{CEN}, 2005)$.................................................... 9

Table 2.2 Reduction factors for stress-strain relationship of carbon steel at elevated

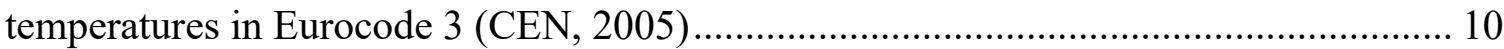

Table 2.3 Summary of the previous researches on HFS (Yu et al, 2019)....................... 21

Table 3.1 Thermal properties of steel under elevated temperature (Wang et al, 2018).... 33

Table 4.1 Sections, storey heights and storey masses for the building (Kildashti and

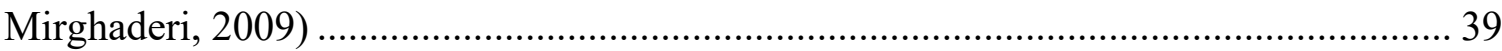

Table 4.2 Periods and natural frequencies of the model............................................ 39

Table 4.3 Base shear of the building under five earthquakes .................................... 45

Table A.1 Section factor for different sections......................................................... 57 


\section{List of Figures}

Figure 1.1 (a) Fire after Northridge earthquake event in 1994, photographer unkown (b) burning city after Kobe earthquake in 1995, photographer unkown 2

Figure 1.2 Performance-based design procedure demonstrated in Eurocode 3

(CEN,2005). 5

Figure 1.3 Performance curve for evaluating structural performance levels in earthquake engineering. 6

Figure 2.1 Reduction factors for the stress-strain relationship of carbon steel at elevated temperatures in Eurocode 3 (CEN, 2005) 11

Figure 2.2 Stress-strain relationship for carbon steel at elevated temperatures in Eurocode 3 (Memari, 2016) 11

Figure 2.3 Thermal conductivity of structural steel at elevated temperatures (CEN, 2005) 12

Figure 2.4 Specific heat of structural steel at elevated temperatures.............................. 12

Figure 2.5 Elongation coefficient of structural steel at elevated temperatures (CEN, 2005)

Figure 2.6 Typical time-temperature curve for fire in compartment (Buchanan, 2017) .. 14

Figure 2.7 A comparison between ISO 834 (CEN, 2002) standard fire curve and

Eurocode parametric fire curve (CEN, 2002) assuming $\Gamma=1.0$ (Memari, 2016) .............. 15

Figure 2.8 Hybrid fire simulation framework proposed by Korzen (1999 and 2002)..... 22

Figure 2.9 Hybrid fire simulation framework proposed by Mostafaei (2013) ................. 22

Figure 2.10 Hybrid fire simulation framework proposed by Whyte et al (2014) ............ 23

Figure 2.11 Hybrid fire simulation framework proposed by Wang et al (2018) ............. 23

Figure 2.12 Fire scenarios in multi-storey steel moment resisting frames (Memari, 2016) 25

Figure 3.1 (a) Column furnace at NRC (b) wall furnace at NRC (c) floor furnace at NRC

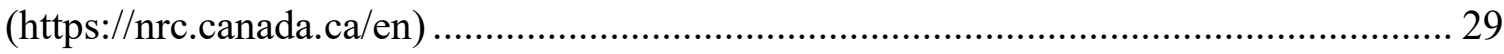

Figure 3.2 (a) Example of fire load and fire scenario (b) demonstration of initial boundary conditions in HFS (c) the process of HFS from step 4 to step 8 31 
Figure 3.3 Demonstration of the process and information exchange of the HFS numerical study. 32

Figure 3.4 (a) Reduction factors for strength degradation of steel under elevated temperature (Wang et al, 2018) (b) stress-strain relationships of steel under elevated

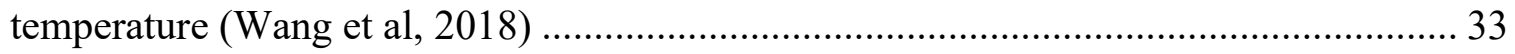

Figure 3.5 Steel temperature and fire temperature history in unit of Kelvin ................... 34

Figure 3.6 Deformation and temperature contour of the complete structure after heating

Figure 3.7 Comparison example of the vertical and lateral displacement and temperature information exchange at one interface node for complete structure model and hybrid model 35

Figure 4.1 Design details of the prototype structure (Jin and El-Tawil, 2004) ............... 37

Figure 4.2 Configuration of the numerical model in ABAQUS ................................... 38

Figure 4.3 Bilinear stress-strain relationships for the numerical model ........................ 40 Figure 4.4 Normalized ground motions from ATC (a) Northridge ground motion (b) El Centro ground motion (c) Kobe ground motion (d) Loma Prieta ground motion (e) Chi-Chi

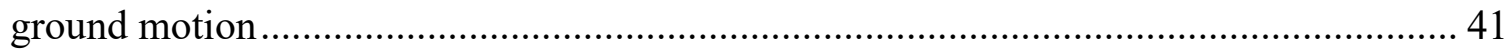

Figure 4.5 Design response spectrum and five earthquake spectrums scaled to the MCE hazard level ..... 42

Figure 4.6 Time temperature curve for parametric fire and steel temperature in beams and columns 43

Figure 4.7 Three considered fire hazard scenarios on the first storey of the building (a) fire located in the two left bays (b) fire located in the two middle bays and (c) fire located in

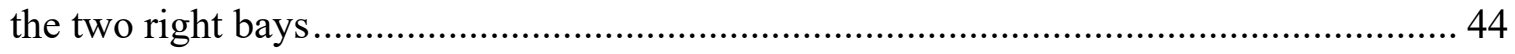

Figure 4.8 Maximum interstorey drift ratio of the building under fire hazards............... 47

Figure 4.9 Residual interstorey drift ratio of the building under fire hazards ................ 47

Figure 4.10 Maximum interstorey drift ratio of the building under earthquake hazards.. 48

Figure 4.11 Residual interstorey drift ratio of the building under earthquake hazards .... 48

Figure 4.12 Maximum interstorey drift ratio of the building under FFE hazards ........... 49

Figure 4.13 Residual interstorey drift ratio of the building under FFE hazards ............. 49

Figure 4.14 Maximum interstorey drift ratio of the building under FFE hazards ........... 50 
Figure 4.15 Residual interstorey drift ratio of the building under FFE hazards .............. 50

Figure 4.16 Maximum interstorey drift ratio of the building under FFE hazards ........... 51

Figure 4.17 Residual interstorey drift ratio of the building under FFE hazards .............. 51

Figure 4.18 Maximum interstorey drift ratio of the building under FFE hazards ............ 52

Figure 4.19 Residual interstorey drift ratio of the building under FFE hazards ............... 52

Figure 4.20 Moment curvature relationship of a beam with RBS on the first floor ........ 53

Figure 4.21 Moment curvature relationship of an exterior column on the first floor ....... 53

Figure A.1 Specific heat of steel calculated based on Eurocode 3 (CEN, 2005) ............ 57 


\section{List of Appendix}

Appendix A: Calculation of Properties of Unprotected Steel Temperature Exposed to

Fire

56 


\section{Chapter 1: Introduction}

\subsection{Motivation}

The current practice of structural design in dealing with the effects and actions from multiple hazards is the silo approach (NBC, 2015), which is to design structures against each hazard individually. However, design against one hazard can have impact on design against other hazard effects, e.g. wind and earthquake, since they are both considered as lateral loads. Furthermore, hazards may come in sequence, such as fire triggered by rupture of gas pipes after a major earthquake event or subsequent aftershocks. In this potential combination hazards of earthquake and fire, the risk of collapse of the building systems could be more than the cases of separate individual hazards of earthquake and fire alone. This is because earthquakes can have a significant impact on the integrity performance of the fire protection systems in buildings (Braxtan and Pessiki, 2011). Such extreme fire following earthquake events had been reported to have inflicted heavy casualties and economy losses e.g. the fire following the San Francisco earthquake in 1906, Northridge earthquake in 1994 (Figure 1.1a) and Kobe earthquake Japan in 1995 (Figure 1.1b) (Khorasani, 2015). Hence, further development on the design of structures against such devastating multi-hazard events is crucial. 


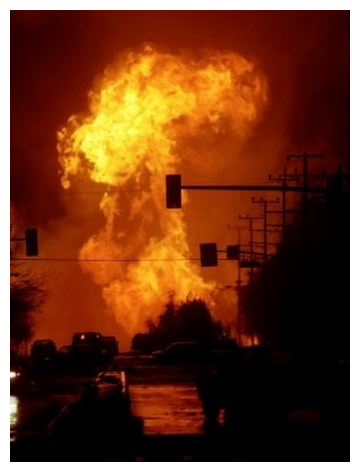

(a)

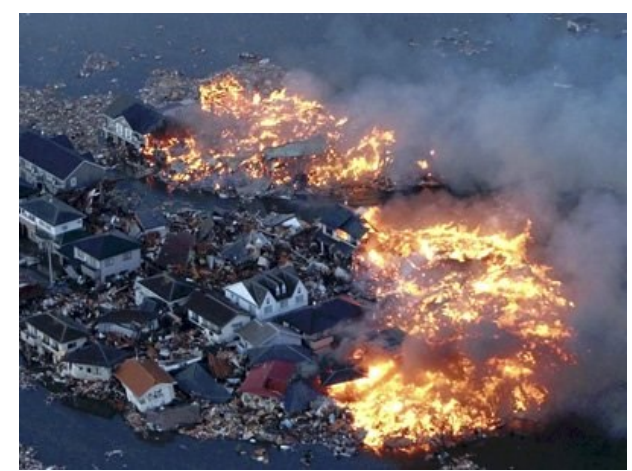

(b)

Figure 1.1 (a) Fire after Northridge earthquake event in 1994, photographer unknow (b) Burning city after Kobe earthquake in 1995, photographer unknow.

At present, the widely adopted structural design approach is based on prescriptive procedures, which requires practitioners design structures by following the code provisions and the performance of the design structures is only implied. In structural fire engineering, most of the building codes stipulate methods for determining structural resistance in fire, e.g. ASCE/SFPE 29-05 (ASCE/SFPE, 2007). While the prescriptive design methods are standardized and have been widely used in design practice in the past, it is recognized that they have limitations. The design resulting from prescriptive-based design method may be overly conservative, and prescriptive-based design approach is generally not applicable or difficult to be adopted for design with new types of modern structures and construction materials that are outside the existing accepted norms.

In recent development of design methodology, the trend of moving forward is the design approach is stepping forward from prescriptive code-based design to performancebased design. In performance-based seismic design framework, the performance of the design structures is explicitly specified to meet target performance objectives at multiple levels as shown in Table 1.1. In the structural fire design codes, e.g. Eurocode 3 (CEN, 2005), the performance-based fire design procedure is demonstrated in Figure 1.2 (CEN, 
2005). In the latest National Building Code of Canada (2015), the performance-based design is stated as "Alternative Solutions" that will achieve at least the minimum level of performance described in Division B. To follow the "Alternative Solutions" design process, additional design calculations and analyses are required to verify the adopted "Alternative Solutions" one comparable in meeting the safety and performance goals in the design structures as would be under the prescriptive method.

While design of majority of buildings is carried out by following prescriptive codebased design approach, more effective and efficient design and performance in earthquake resistance of buildings can be achieved by performance-based design approach. The techniques of hybrid simulation for assessment of system level performance of structures will provide the insights towards achieving the goal of performance-based design objectives. 


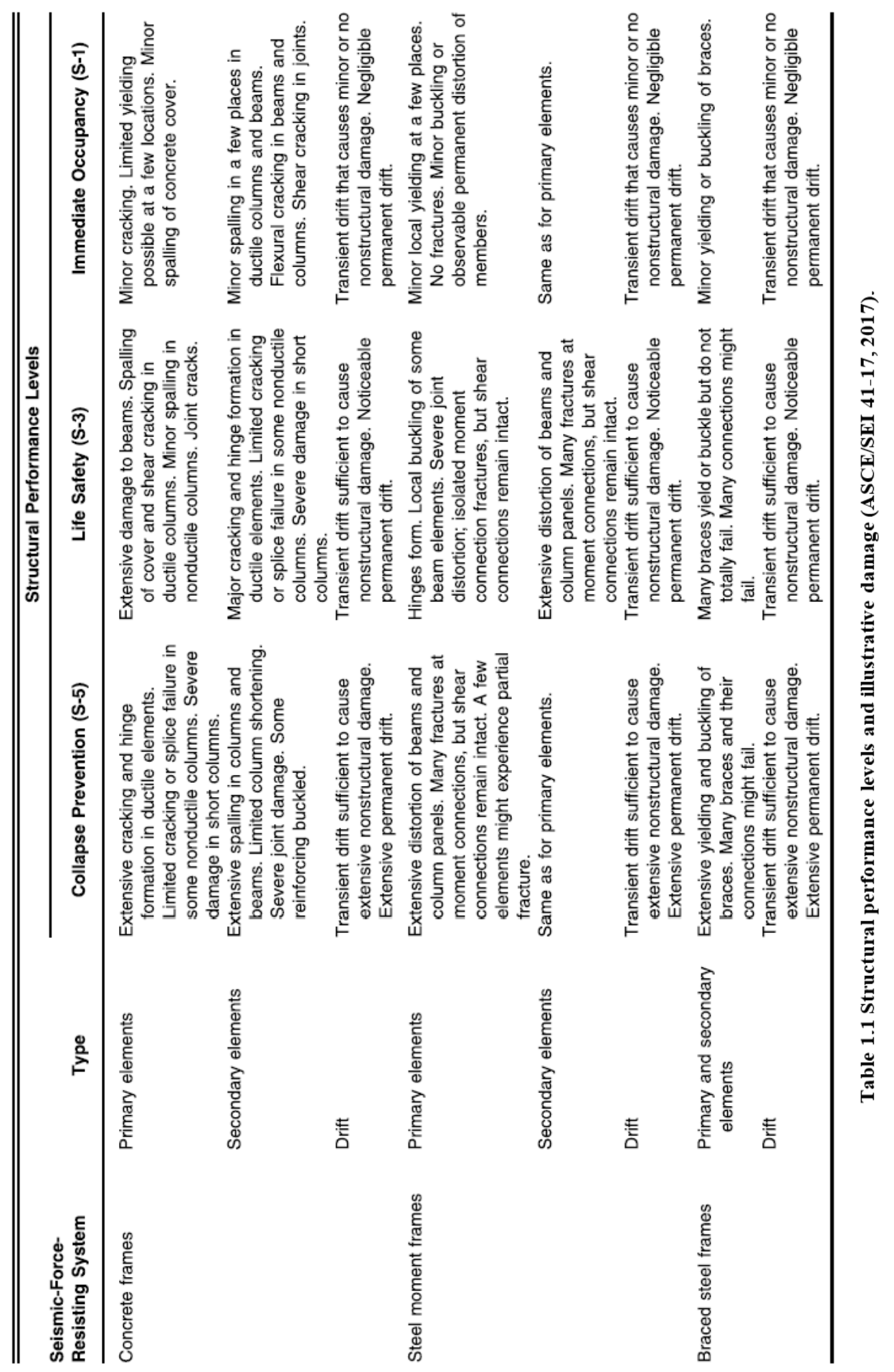




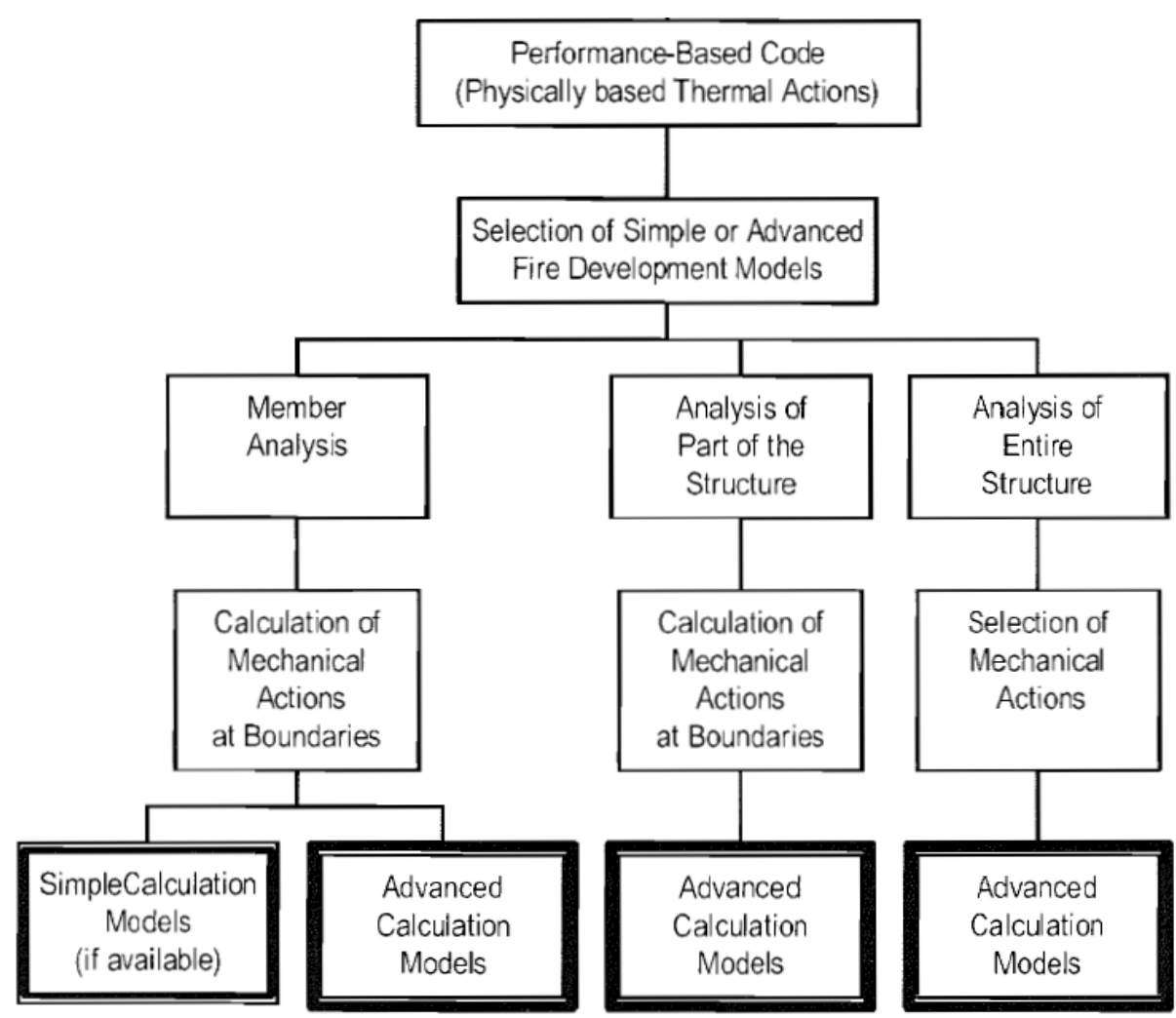

Figure 1.2 Performance-based design procedure demonstrated in Eurocode 3 (CEN, 2005).

To provide sufficient and reliable information for performance-based design for both fire safety and seismic resistance, it is necessary to understand the global behaviour of the design structures under different load conditions. For this purpose, numerical simulation is the typically accepted approach. For example, in performance-based earthquake engineering, the performance of the design structures can be plotted as the performance curve shown in Figure 1.3. As the structure experiences progressive damage towards ultimate failure of collapse, plastic hinge formation and load redistribution between the structural members of the structural system, the accuracy of the numerical model may be questionable because of the challenges in accurately modelling the complex nonlinear behaviour in a large-scale modern structure. Therefore, it is considered more accurate to obtain the complex behaviour and performance of a complex structure by physical test, 
ideally by full-scale or large size testing to avoid the size effect of scaled test specimen. In fire safety engineering, similar issues on the accuracy of modelling technique for capturing the complicated temperature dependent material properties behaviour, nonlinear behaviour in structures under elevated temperature and temperature cycles, as well as the challenge of modelling, complex structural configurations and the interaction with the fire effects. In current fire safety engineering and fire design of structures, the understanding on the behaviour and fire resistance rating of structures is mostly based on standard fire tests, in which simple structural component or assembly with idealized boundary conditions is subjected to elevated temperature represented by standard fire curves, e.g. CAN/ULCS101, ASTM E119, or ISO 834 (CAN/ULC 2014, ASTM 2016 and ISO 2014). The interaction effects between the structural members are ignored. A reliable measure to capture the entire structural behaviour exposed to fire is by conducting full-scale fire tests, yet only a few cases have been carried out in pilot studies (Izzuddin and Moore 2008, Kim et al 2014). They are prohibitively expensive and impractical to be conducted on a routine basis, for the reasons of the demanding requirements on the testing facilities and availability of necessary equipment, as well as the high cost of construction of the fullscale prototype structures.

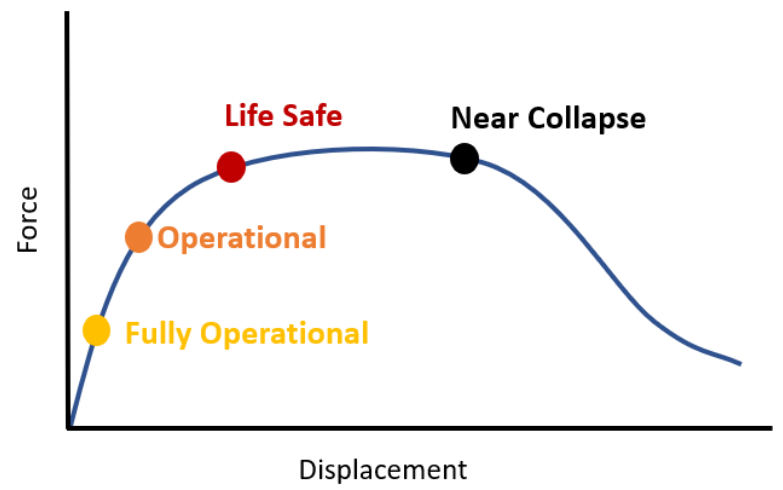

Figure 1.3 Performance curve for evaluating structural performance levels in earthquake engineering. 


\subsection{Research Objectives and Scope}

In light of the need for improving the design of structures against fire or fire following earthquake (FFE) as discussed in section 1.1, it is necessary to develop a more efficient, reliable and economical testing technique alternative to full-scale fire tests to obtain better understanding on the performance of the complete structural systems under fire and FFE. For this purpose, a new fire testing approach referred to as hybrid fire simulation (HFS) based on the recently developed methodology of hybrid simulation in earthquake engineering is proposed in this research, which combines physical testing and numerical modelling. In the hybrid simulation technique, the critical part of the structure which is expected to experience high nonlinearities is physically tested in the laboratory; meanwhile, the remaining part of the structure is numerically modelled by finite elements (McCrum and Williams, 2016).

The following key objectives are highlighted:

- Extend the hybrid simulation technology to fire safety engineering and fire following earthquake multi-hazard applications by introducing full thermal and mechanical interactions.

- Demonstrate the proposed hybrid fire simulation framework by conducting a simulation example in a purely numerical environment as a rehearsal before the carrying out the actual hybrid fire simulation test. 
- Investigate the performance of a 4-storey steel building subjected to fire following earthquake by using numerical analyses, as the first step towards the application of hybrid simulation on fire following earthquake multi-hazard scenario. 


\section{Chapter 2: Background and Literature Review}

\subsection{Steel Material Properties at Elevated Temperature}

The thermal and mechanical temperature dependent material properties of structure steel are important considerations in advanced simulation of steel structures in fire. These properties vary in a large range as the steel deteriorates on strength and stiffness with temperature increases.

Temperature dependent constitutive model is required in modelling mechanical response of steel structures under elevated temperatures. Such models of structural steel material are provided by Eurocode $3(\mathrm{CEN}, 2005)$. The variation of temperature dependent mechanical material properties of steel, e.g. modulus of elasticity, yield stress and proportional limit, can be calculated by the formulations given in Table 2.1 (CEN, 2005). The corresponding reduction factors are shown in Table 2.2 and Figure 2.1 (CEN, 2005).

\begin{tabular}{|c|c|c|}
\hline Strain range & Stress $\sigma$ & Tangent modulus \\
\hline$\varepsilon \leq \varepsilon_{\mathrm{p}, \theta}$ & $\varepsilon E_{\mathrm{a}, \theta}$ & $E_{\mathrm{a}, \theta}$ \\
\hline$\varepsilon_{\mathrm{p}, \theta}<\varepsilon<\varepsilon_{\mathrm{y}, \theta}$ & $f_{\mathrm{p}, \theta}-c+(b / a)\left[a^{2}-\left(\varepsilon_{\mathrm{y}, \theta}-\varepsilon\right)^{2}\right]^{0.5}$ & $\frac{b\left(\varepsilon_{\mathrm{y}, \theta}-\varepsilon\right)}{a\left[a^{2}-\left(\varepsilon_{\mathrm{y}, \theta}-\varepsilon\right)^{2}\right]^{0.5}}$ \\
\hline$\varepsilon_{\mathrm{y}, \theta} \leq \varepsilon \leq \varepsilon_{\mathrm{t}, \theta}$ & $f_{\mathrm{y}, \theta}$ & 0 \\
\hline$\varepsilon_{\mathrm{t}, \theta}<\varepsilon<\varepsilon_{\mathrm{u}, \theta}$ & $f_{\mathrm{y}, \theta}\left[1-\left(\varepsilon-\varepsilon_{\mathrm{t}, \theta}\right) /\left(\varepsilon_{\mathrm{u}, \theta}-\varepsilon_{\mathrm{t}, \theta}\right)\right]$ & - \\
\hline$\varepsilon=\varepsilon_{\mathrm{u}, \theta}$ & 0,00 & $\varepsilon_{\mathrm{i}, \theta}=0,15$ \\
\hline Parameters & $\varepsilon_{\mathrm{p}, \theta}=f_{\mathrm{p}, \theta} / E_{\mathrm{a}, \theta}$ & \\
\hline Functions & $a^{2}=\left(\varepsilon_{\mathrm{y}, \theta}-\varepsilon_{\mathrm{p}, \theta}\right)\left(\varepsilon_{\mathrm{y}, \theta}-\varepsilon_{\mathrm{p}, \theta}+c / E_{\mathrm{a}, \theta}\right)$ \\
& $b^{2}=c\left(\varepsilon_{\mathrm{y}, \theta}-\varepsilon_{\mathrm{p}, \theta}\right)_{E_{\mathrm{a}, \theta}+c^{2}}$ \\
& $c=\frac{\left(f_{\mathrm{y}, \theta}-f_{\mathrm{p}, \theta}\right)^{2}}{\left(\varepsilon_{\mathrm{y}, \theta}-\varepsilon_{\mathrm{p}, \theta}\right) E_{\mathrm{a}, \theta}-2\left(f_{\mathrm{y}, \theta}-f_{\mathrm{p}, \theta}\right)}$ \\
\hline
\end{tabular}

Table 2.1 Formulations for calculating stress-strain relationship for carbon steel at elevated temperatures in Eurocode 3 (CEN, 2005). 


\begin{tabular}{|c|c|c|c|}
\hline \multirow{3}{*}{$\begin{array}{c}\text { Steel } \\
\text { Temperature }\end{array}$} & \multicolumn{3}{|c|}{$\begin{array}{l}\text { Reduction factors at temperature } \theta_{\mathrm{a}} \text { relative to the value of } f_{\mathrm{y}} \text { or } E_{\mathrm{a}} \\
\text { at } 20^{\circ} \mathrm{C}\end{array}$} \\
\hline & $\begin{array}{c}\text { Reduction factor } \\
\left.\text { (relative to } f_{\mathrm{y}}\right) \\
\text { for effective yield } \\
\text { strength }\end{array}$ & $\begin{array}{l}\text { Reduction factor } \\
\text { (relative to } f_{y} \text { ) } \\
\text { for proportional limit }\end{array}$ & $\begin{array}{l}\text { Reduction factor } \\
\text { (relative to } E_{\mathrm{a}} \text { ) } \\
\text { for the slope of the } \\
\text { linear elastic range }\end{array}$ \\
\hline & $k_{\mathrm{v}, 0}=f_{\mathrm{v}, \theta} / f_{\mathrm{v}}$ & $k_{\mathrm{n}, \theta}=f_{\mathrm{n}, \theta} / f_{\mathrm{v}}$ & $k_{\mathrm{f}, \theta}=E_{\mathrm{i}, \theta} / E_{\mathrm{a}}$ \\
\hline $20^{\circ} \mathrm{C}$ & 1,000 & 1,000 & 1,000 \\
\hline $100^{\circ} \mathrm{C}$ & 1,000 & 1,000 & 1,000 \\
\hline $200^{\circ} \mathrm{C}$ & 1,000 & 0,807 & 0,900 \\
\hline $300^{\circ} \mathrm{C}$ & 1,000 & 0,613 & 0,800 \\
\hline $400^{\circ} \mathrm{C}$ & 1,000 & 0,420 & 0,700 \\
\hline $500^{\circ} \mathrm{C}$ & 0,780 & 0,360 & 0,600 \\
\hline $600^{\circ} \mathrm{C}$ & 0,470 & 0,180 & 0,310 \\
\hline $700^{\circ} \mathrm{C}$ & 0,230 & 0,075 & 0,130 \\
\hline $800^{\circ} \mathrm{C}$ & 0,110 & 0,050 & 0,090 \\
\hline $900^{\circ} \mathrm{C}$ & 0,060 & 0,0375 & 0,0675 \\
\hline $1000^{\circ} \mathrm{C}$ & 0,040 & 0,0250 & 0,0450 \\
\hline $1100^{\circ} \mathrm{C}$ & 0,020 & 0,0125 & 0,0225 \\
\hline $1200^{\circ} \mathrm{C}$ & 0,000 & 0,0000 & 0,0000 \\
\hline
\end{tabular}

NOTE: For intermediate values of the steel temperature, linear interpolation may be used.

Table 2.2 Reduction factors for stress-strain relationship of carbon steel at elevated temperatures in Eurocode 3 (CEN, 2005). 


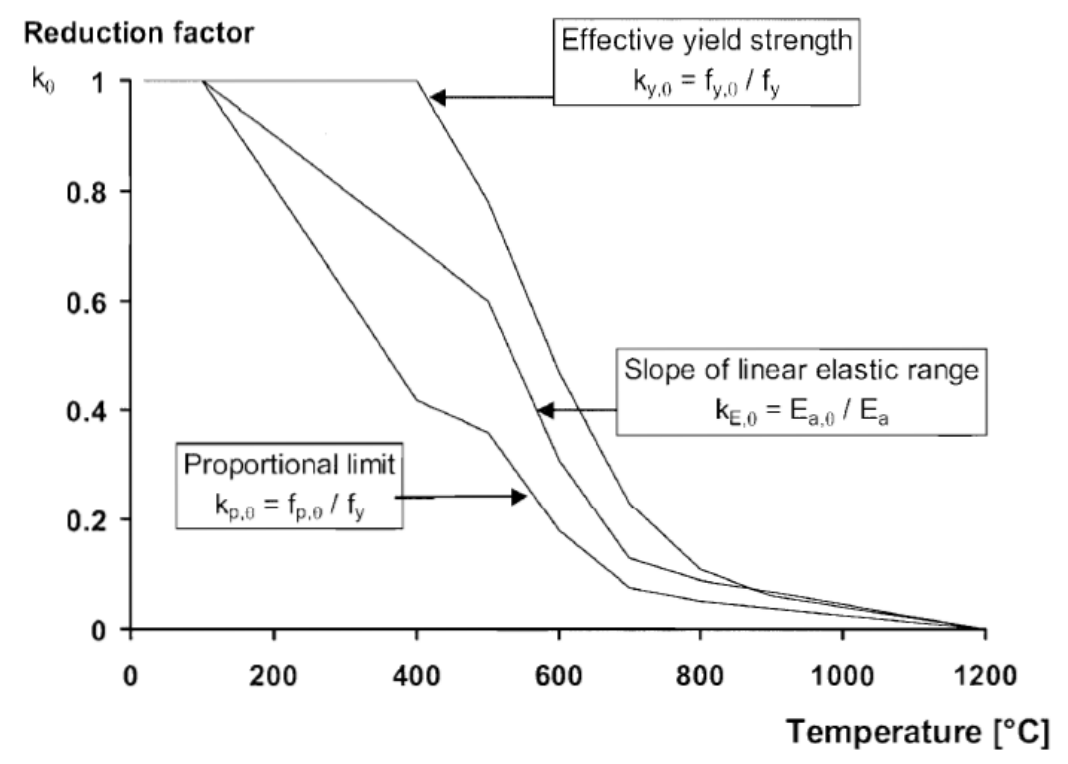

Figure 2.1 Reduction factors for the stress-strain relationship of carbon steel at elevated temperatures in Eurocode 3 (CEN, 2005).

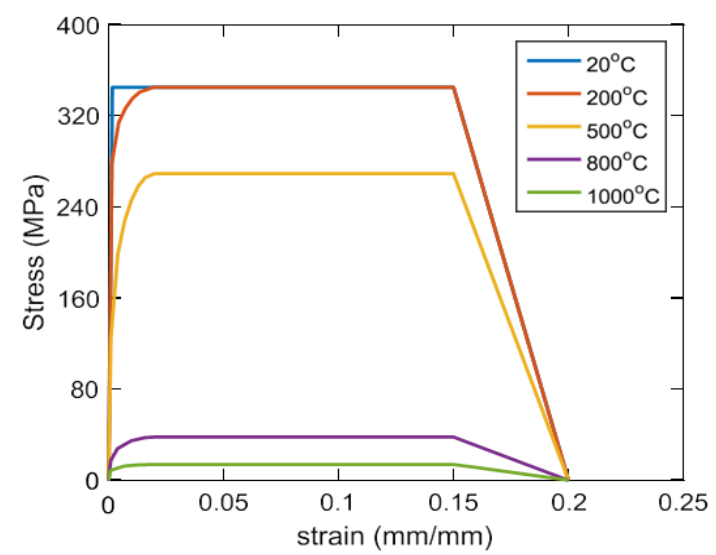

Figure 2.2. Stress-strain relationship for carbon steel at elevated temperatures in Eurocode 3 (Memari, 2016).

Thermal conductivity, specific heat, and density are important thermal parameters in predicting heat propagation within the steel structural members. The temperature dependent properties of thermal conductivity and specific heat as stipulated by empirical temperature dependent relationships in Eurocode 3 (CEN, 2005) are shown in Figure 2.3 and 2.4 , respectively. The density of structural steel is assumed constant at $7850\left(\mathrm{~kg} / \mathrm{m}^{3}\right)$ at all temperature variations. 
Thermal conductivity [ $\mathrm{W} / \mathrm{mK}$ ]

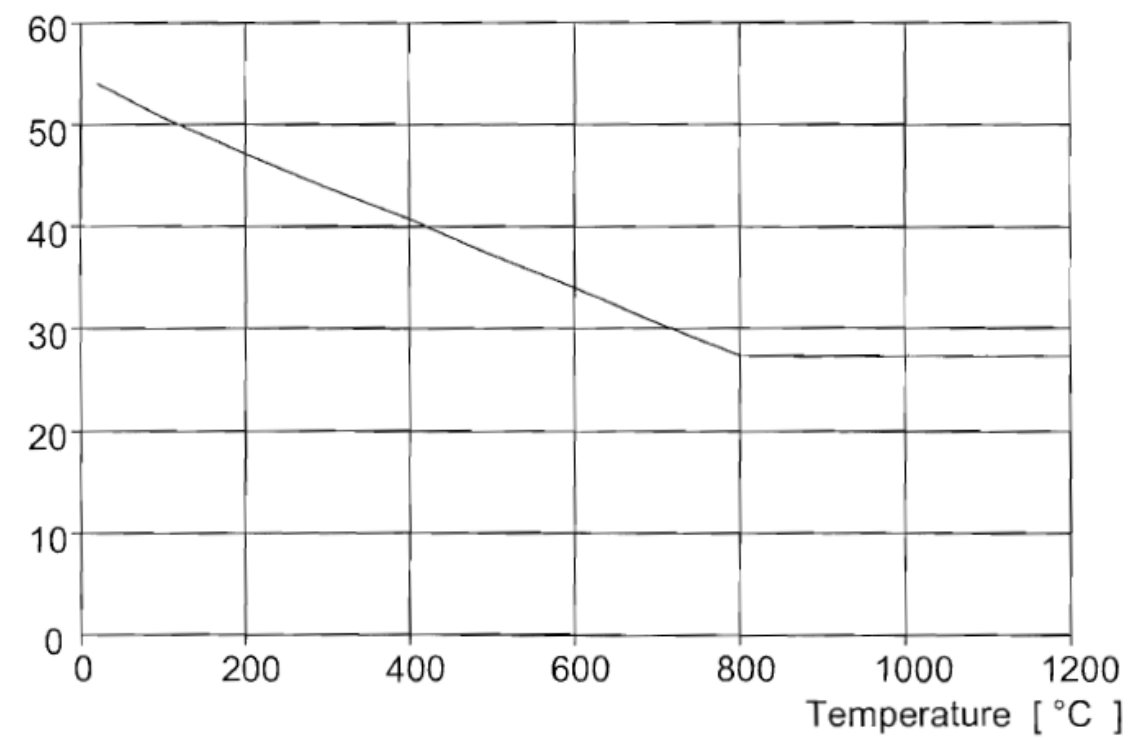

Figure 2.3 Thermal conductivity of structural steel at elevated temperatures (CEN, 2005).

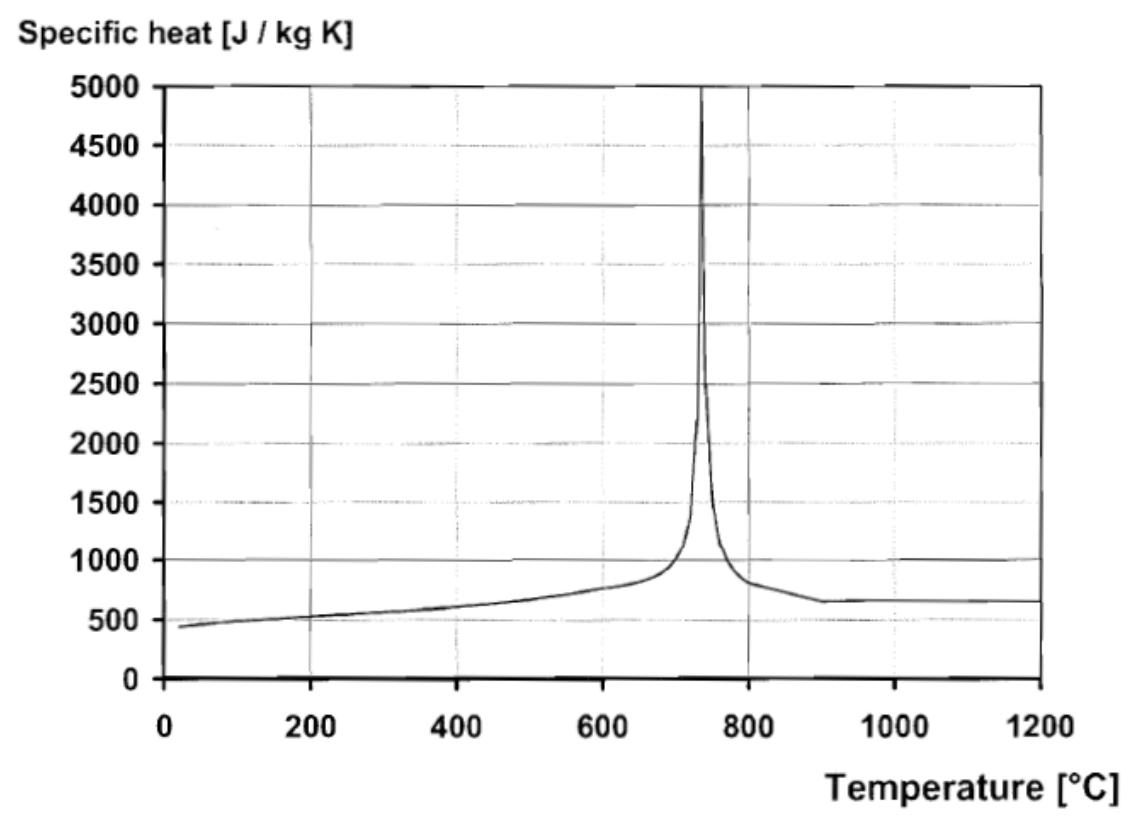

Figure 2.4 Specific heat of structural steel at elevated temperatures (CEN, 2005). 
Thermal expansion is defined as the tendency of material to expand and/or retract due to temperature change. Thermal expansion coefficient is expressed as the deformational property of structural steel material at elevated temperatures as shown in Figure 2.5 (CEN, 2005).

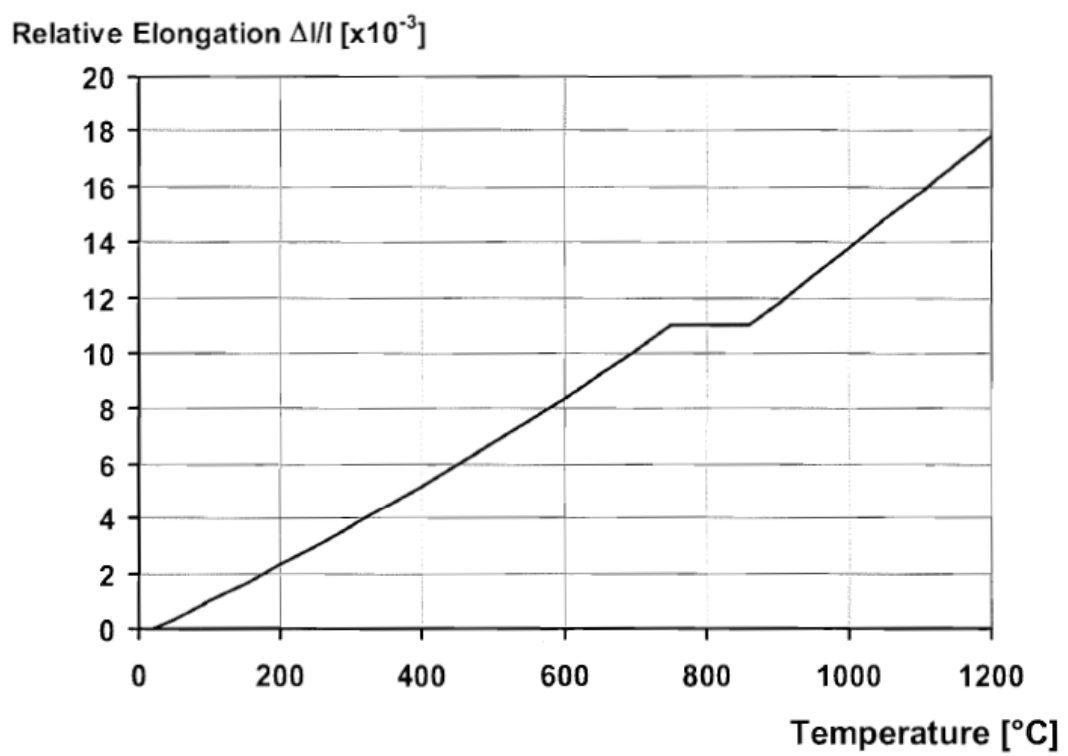

Figure 2.5 Elongation coefficient of structural steel at elevated temperatures (CEN, 2005).

\subsection{Fire Exposures}

Flashover condition occurs after fire ignition with sufficient fuel supply and ventilation in the fire compartment, in which all combustible materials exposed to fire are ignited. After the flashover point, the fire is considered as fully developed post-flashover fire as shown in Figure 2.6. The post-flashover fire is typically the only consideration phase of fire in design, which can cause significant deterioration in strength and stiffness of structural steel material, and consequently can increase the risk of collapse in a structural system (Buchanan, 2017). As a representation of the effect of post-flashover fires, e.g. 
standard fires, are widely adopted to evaluate the fire resistance behaviour of structural components and materials.

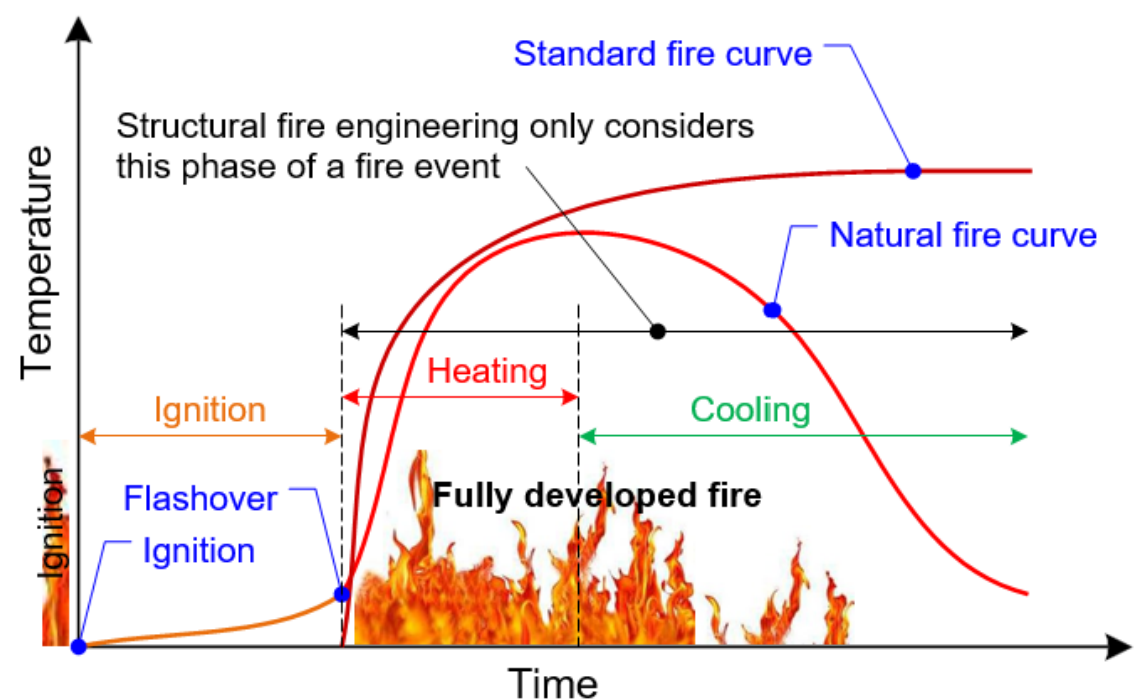

Figure 2.6 Typical time-temperature curve for fire in compartment (Buchanan, 2017).

The standard fires represent only the heating phase during the fire development in a burning compartment. It is assumed by using the standard fire curve in fire testing that there is consistent and sufficient fuel supply to keep the temperature rising in the fire compartment of the building exposed to fire which may not be realistic. One of the most commonly adopted standard fire is given in ISO 834 (CEN, 2002) as presented in Figure 2.7. The ISO 834 standard fire curve is given by the following equation:

$$
\Theta_{\mathrm{g}}=20+345 \log _{10}(8 \mathrm{t}+1)
$$

where $\Theta_{\mathrm{g}}$ is the gas temperature in the fire compartment $\left[{ }^{\circ} \mathrm{C}\right]$,

$\mathrm{t}$ is the time [min].

Alternatively, a more realistic fire load can be generated using parametric fire curve, which allows for the calculation of a time-temperature curve for various combination of ventilation condition, fuel, openings, and wall lining materials as defined 
in Eurocode 1 (CEN, 2002). This time-temperature curve considers three important phases of a realistic fire, i.e. heating stage, cooling phase, and a constant room temperature. The comparison of the standard fire ISO-834 and a parametric fire is shown in Figure 2.7 (Memari, 2016).

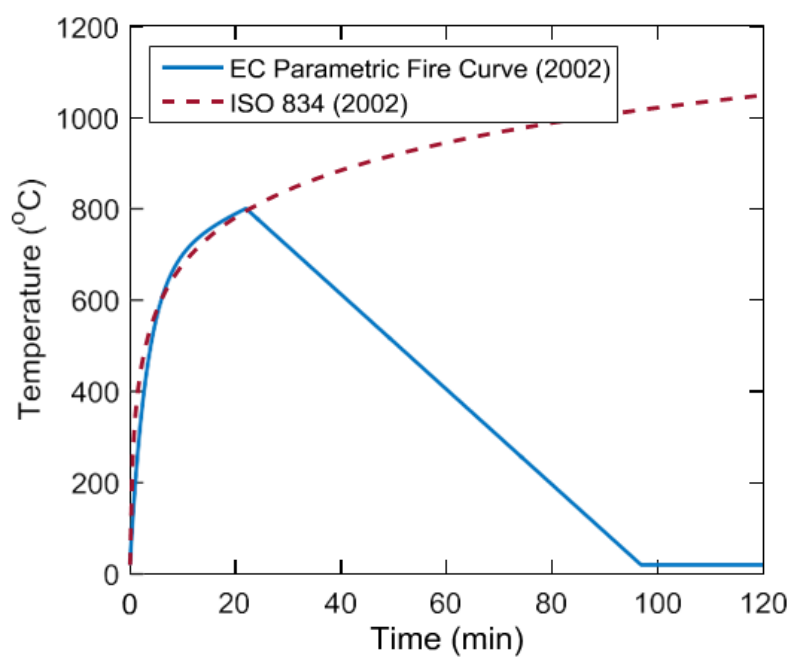

Figure 2.7 A comparison between ISO 834 (CEN, 2002) standard fire curve and Eurocode parametric fire curve (CEN, 2002) assuming $\Gamma=1.0$. (Memari, 2016).

The Eurocode parametric time-temperature curve are valid for fire compartments with a floor area up to $500 \mathrm{~m}^{2}$, without openings in the roof and for a maximum compartment height of $4 \mathrm{~m}(\mathrm{CEN}, 2002)$. The heating phase of the parametric fire curve is given by Equation 2.2:

$$
\Theta_{\mathrm{g}}=20+1325\left(1-0.324 \mathrm{e}^{-0.2 t^{*}}-0.204 \mathrm{e}^{-1.7 t^{*}}-0.472 \mathrm{e}^{-19 \mathrm{t}^{*}}\right)
$$

where $\Theta_{\mathrm{g}}$ is the gas temperature in the fire compartment $\left[{ }^{\circ} \mathrm{C}\right]$,

$$
\mathrm{t}^{*}=\mathrm{t} \cdot \Gamma[\text { hour }]
$$

$\mathrm{t}$ is time [hour],

$$
\begin{aligned}
& \Gamma=[\mathrm{O} / \mathrm{b}]^{2} /(0.04 / 1160)^{2}[-] \\
& \mathrm{b}=(\rho \mathrm{c} \lambda)^{1 / 2} \text { with the limits: } 100 \leq \mathrm{b} \leq 2200\left[\mathrm{~J} / \mathrm{m}^{2} \mathrm{~s}^{1 / 2} \mathrm{~K}\right]
\end{aligned}
$$


$\rho$ is density of boundary of enclosure $\left[\mathrm{kg} / \mathrm{m}^{3}\right]$,

c is specific heat of boundary of enclosure $[\mathrm{J} / \mathrm{kgK}]$,

$\lambda$ is thermal conductivity of boundary of enclosure $[\mathrm{W} / \mathrm{mK}]$,

$\mathrm{O}$ is opening factor: $\mathrm{A}_{v} \mathrm{~h}_{\mathrm{eq}}{ }^{1 / 2} / \mathrm{A}_{\mathrm{t}}\left[\mathrm{m}^{1 / 2}\right]$ with the limits: $0.02 \leq \mathrm{O} \leq 0.20$,

$A_{v}$ is total area of vertical openings on all walls $\left[\mathrm{m}^{2}\right]$,

$h_{\text {eq }}$ is weighted average of window heights on all walls [m],

$A_{t}$ is total area of enclosure (walls, ceiling and floor, including openings) $\left[\mathrm{m}^{2}\right]$.

The maximum temperature $\Theta_{\max }$ in the heating phase occurs at $\mathrm{t}^{*}=\mathrm{t}^{*} \max$,

where $\mathrm{t}^{*}{ }_{\max }=\mathrm{t}_{\max } \cdot \Gamma[$ hour $]$

$$
\mathrm{t}_{\max }=\max \left[\left(0.2 \cdot 10^{-3} \cdot \mathrm{q}_{\mathrm{t}, \mathrm{d}} / \mathrm{O}\right) ; \mathrm{t}_{\text {lim }}\right][\text { hour }]
$$

$\mathrm{q}_{\mathrm{t}, \mathrm{d}}$ is the design value of the fire load density related to the total surface area $A_{t}$ of the enclosure, whereby $q_{t, d}=q_{f, d} \cdot A_{f} / A_{t}\left[M J / m^{2}\right]$, with limits: $50 \leq q_{t, d} \leq 1000$ $\left[\mathrm{MJ} / \mathrm{m}^{2}\right]$

$\mathrm{q}_{\mathrm{f}, \mathrm{d}}$ is the design value of the fire load density related to the total surface area $\mathrm{A}_{\mathrm{f}}$ of the floor $\left[\mathrm{MJ} / \mathrm{m}^{2}\right]$,

$\mathrm{t}_{\text {lim }}=25 \mathrm{~min}$ for slow fire growth rate; $\mathrm{t}_{\mathrm{lim}}=20 \mathrm{~min}$ for medium fire growth rate and $\mathrm{t}_{\text {lim }}=15 \mathrm{~min}$ for fast fire growth rate.

The cooling phase in the parametric fire curve is given as follows:

$$
\begin{aligned}
& \Theta_{\mathrm{g}}=\Theta_{\max }-625\left(\mathrm{t} *-\mathrm{t} *{ }_{\max } \cdot \mathrm{x}\right) \text { for } \mathrm{t}^{*}{ }_{\max } \leq 0.5 \\
& \Theta_{\mathrm{g}}=\Theta_{\max }-250\left(3-\mathrm{t}^{*}{ }_{\max }\right)\left(\mathrm{t}^{*}-\mathrm{t}{ }^{*}{ }_{\max } \cdot \mathrm{x}\right) \text { for } 0.5<\mathrm{t} *_{\max }<2 \\
& \Theta_{\mathrm{g}}=\Theta_{\max }-250\left(\mathrm{t}^{*} \mathrm{t}^{*}{ }_{\max } \cdot \mathrm{x}\right) \text { for } \mathrm{t}^{*}{ }_{\max } \geq 2 \mathrm{~d}
\end{aligned}
$$

where $t^{*}$ is given by Equation 2.3a,

$$
\mathrm{t}^{*}{ }_{\max }=\left(0.2 \cdot 10^{-3} \cdot \mathrm{q}_{\mathrm{t}, \mathrm{d}} / \mathrm{O}\right) \cdot \Gamma
$$




$$
\mathrm{x}=1.0 \text { if } \mathrm{t}_{\max }>\mathrm{t}_{\text {lim }} \text {, or } \mathrm{x}=\mathrm{t}_{\lim } \cdot \Gamma / \mathrm{t}_{\max } \text { if } \mathrm{t}_{\max }=\mathrm{t}_{\text {lim }}
$$

Further details on the determination of the parametric fire curve are given in Eurocode 1 (CEN, 2002).

\subsection{Hybrid Fire Simulation}

An overview of the methodology of HFS is presented as follows. First, the fire scenario and fire load are defined for the prototype structure; then the part of the structure directly exposed to fire load is selected as the testing specimen for testing in a furnace (physical domain), while the remainder structure is numerically simulated (numerical domain). The responses are transferred between the two sub-domains through an interface platform in real-time. In the physical test domain of HFS, in addition to the fire effects, i.e. the temporal and spatial distribution of the fire loads, the test specimen is also subjected to the gravity and lateral loads from the rest of the structure as determined from the numerical model of the numerical domain of the structure. The temperature at interface node can be applied as predefined temperature field in the numerical model. After the fire starts, in each time step, the measured force from the physical domain will be fed back to the numerical simulation through the interface, and the finite element model of the numerical domain will start the thermomechanical analysis to calculate the structural response and send the mechanical response information i.e. displacement and rotation at the connection back to the physical specimen; and then move on to the next cycle until the end of the test.

Hybrid fire simulation has started to attract increasing attentions in recent years. However, there have only been limited number of studies on combining physical testing and numerical modelling in fire research (Yu et al, 2019). Table 2.3 shows a summary of 
previous hybrid fire simulation research. The first hybrid fire simulation can be found in literature was reported by Korzen et al (1999 and 2002), the proposed framework is shown in Figure 2.8. In their studies, an 8-storey steel frame building was chosen as the demonstrating structure. One column was physically tested in the gas furnace at BAM (Federal Institute for Materials Research and Testing) in Germany and the rest of the structure was represented by a predefined idealized model of the rest of the structure with a constant axial stiffness. The axial displacements and forces at the interface were exchanged through a 6-channel control system in the laboratory. Robert (Robert et al, 2010) at CERIB (Centre for Studies and Research of the Concrete Industry) in France conducted an HFS of a single-storey concrete frame, the physical domain was a concrete slab with three degrees-of-freedom controlled in total (one axial elongation and two rotational at the supports); whereas the numerical domain was represented by an elastic stiffness matrix. Later in 2013, Mostafaei (2013) successfully tested a column in a 6-storey reinforced concrete building in a gas furnace at NRC (National Research Council Canada) in Ottawa through HFS shown in Figure 2.9. In his study, the numerical domain was simulated by a 2D/3D finite element model in a special purpose finite element software SAFIR (Franssen et al. 2017). The calculated axial deformations and forces at the interface of the numerical domain were exchanged with the physical domain at the end of each time step. However, in this early HFS, the data transfer within the physical and numerical domains was not automated and required human interaction. The first fully computer-controlled hybrid fire simulation with a finite element model for the numerical domain was proposed by Whyte et al (2014). The proposed framework by Whyte et al (2014) is presented in Figure 2.10. In their research, a new OpenFresco (http://openfresco.berkeley.edu/) truss element with 
one temperature degree-of-freedom at each end node was developed, which can be adopted to realize one-way or two-way coupling between the sub-domains of the structure. The small-scale proof of concept HFS of a 2D elastic truss structure was carried out at ETH (Swiss Federal Institute of Technology) within the OpenSees (http://opensees.berkeley.edu/) and OpenFresco (http://openfresco.berkeley.edu/) frameworks (Whyte et al, 2014). A similar test was carried out by Schulthess et al (2016) using ABAQUS (SIMULIA, 2013) and an interface server. The most recently published research work on HFS was by Wang et al (2018) at University of Toronto. In their proposed method as demonstrated in Figure 2.11, fully automated and displacement control with proper error compensation scheme was realized and validated in a full-scale HFS through the UT-SIM interface platform (https://www.ut-sim.ca/).

There are other research works (Tondini et al 2012 and 2016, Sauca et al 2016, Mergny et al 2018, Khan et al 2018 and Qureshi et al 2018) carried out on hybrid fire simulation in a purely numerical environment, in which both the numerical and the physical domains are represented by computational models, incorporating with different control strategies and interface platforms.

It is noted, all the previous attempts on hybrid fire simulation discussed above typically have limitation of not considering the full interactions between the numerical and physical domains of the structure. This limitation is because of the lack of the necessary implementation tools for representing of the full boundary condition interface to consider the full mechanical and thermal interaction effects between the numerical and physical domains. Specifically, the mechanical degrees-of-freedom at the interface considered in previous research was limited to axial load. In terms of the thermal effects at the interface, 
e.g. heat conduction between the heated and adjacent structural elements, Whyte el al. (2014) adopted their newly developed element to send temperatures to the physical specimen. In this hybrid fire simulation investigation, Wang et al. (2018) applied a previously generated time-temperature history of the physical specimen on the numerical domain at the interface node. It is noted that, these two previous HFS framework can be used in HFS of structures only when the structural members are not sensitive to the temperature distribution within the cross sections, i.e. no flexural bending deformation behaviour and only uniform axial deformation can be considered.

In most typical structures, both flexural and axial deformation behaviours are important response mechanisms in the responses of the structure when exposed to fire and other load action effects. Therefore, near framework for HFS that takes into consideration of both flexural and axial behaviour with the corresponding thermal and mechanical boundary conditions information exchange between the numerical and physical domains at the interface is necessary. 


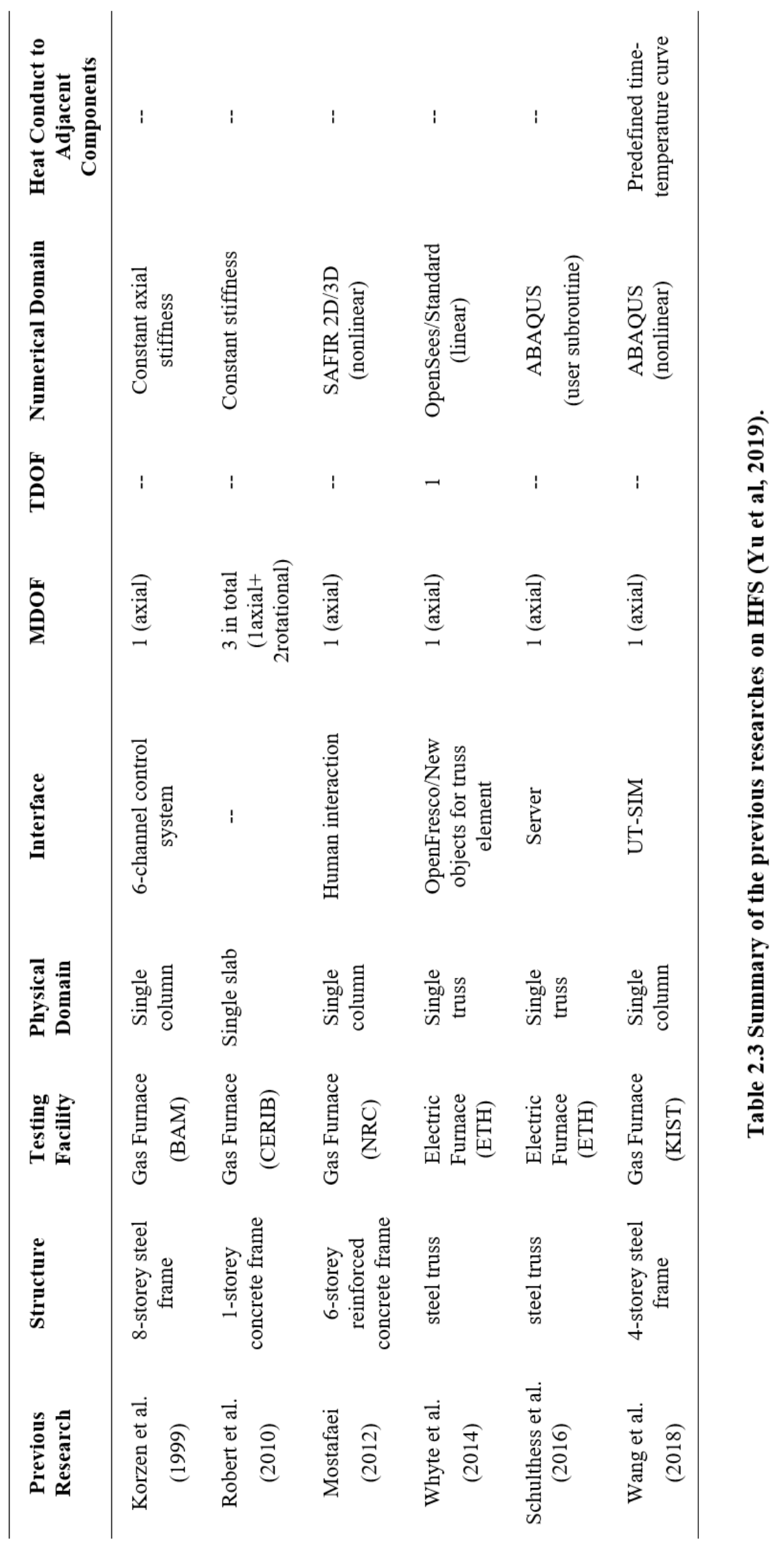


Experimental Substructure: Specimen

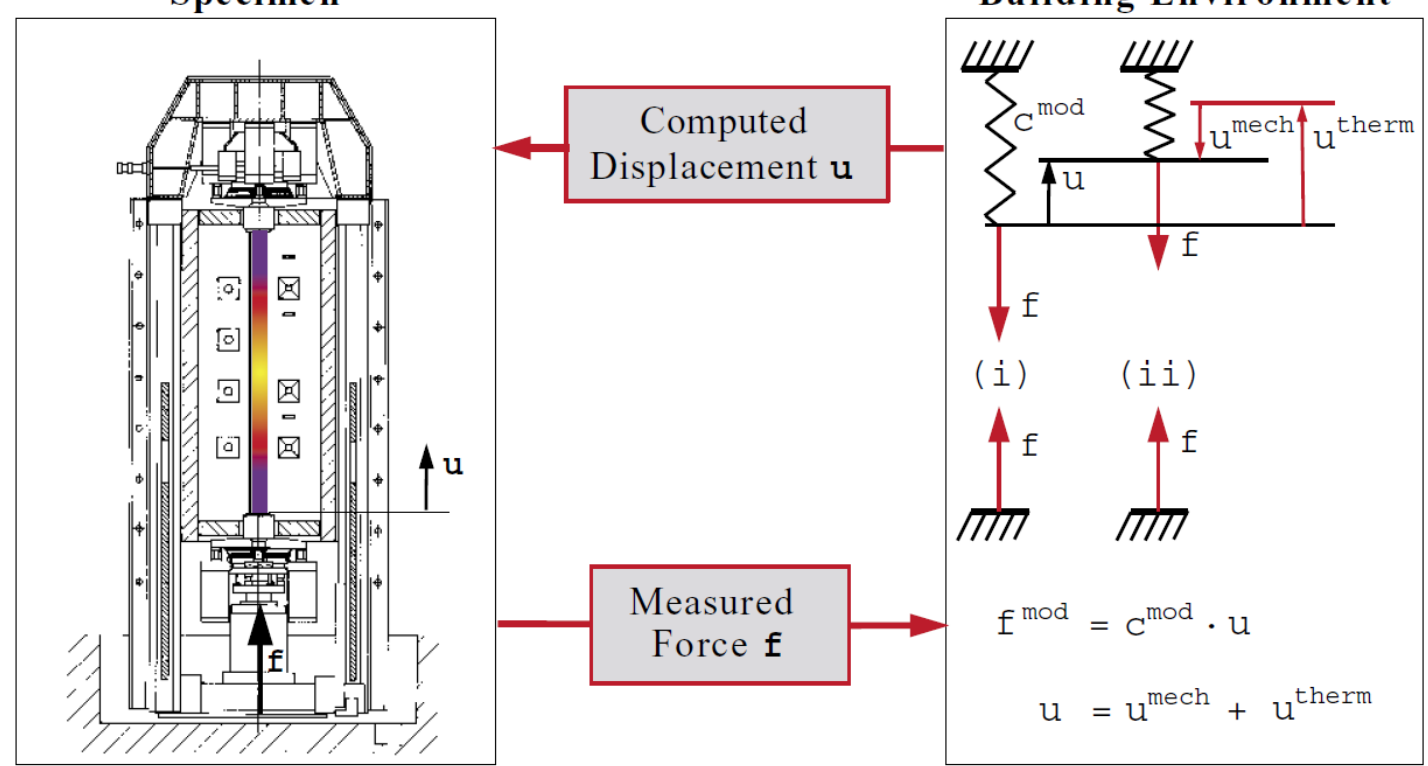

Simulated Substructure:

Building Environment

IIII

Figure 2.8 Hybrid fire simulation framework proposed by Korzen (1999 and 2002).

Numerical Simulation of the Rest of the Building

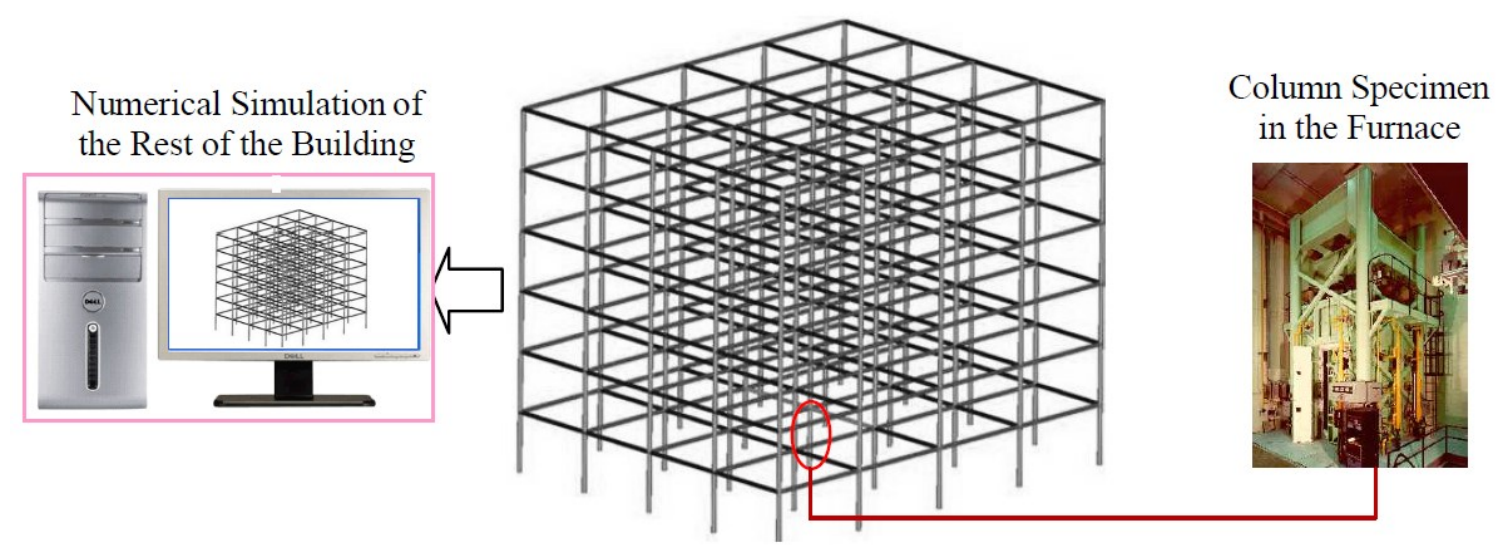

Figure 2.9 Hybrid fire simulation framework proposed by Mostafaei (2013). 


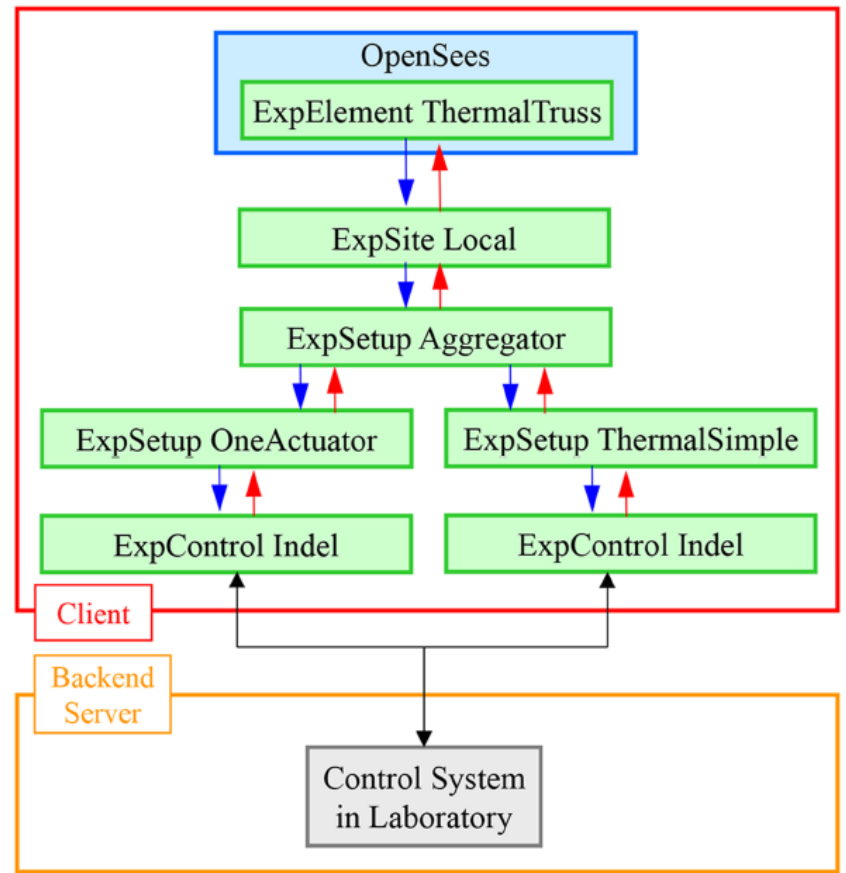

Figure 2.10 Hybrid fire simulation framework proposed by Whyte et al (2014).

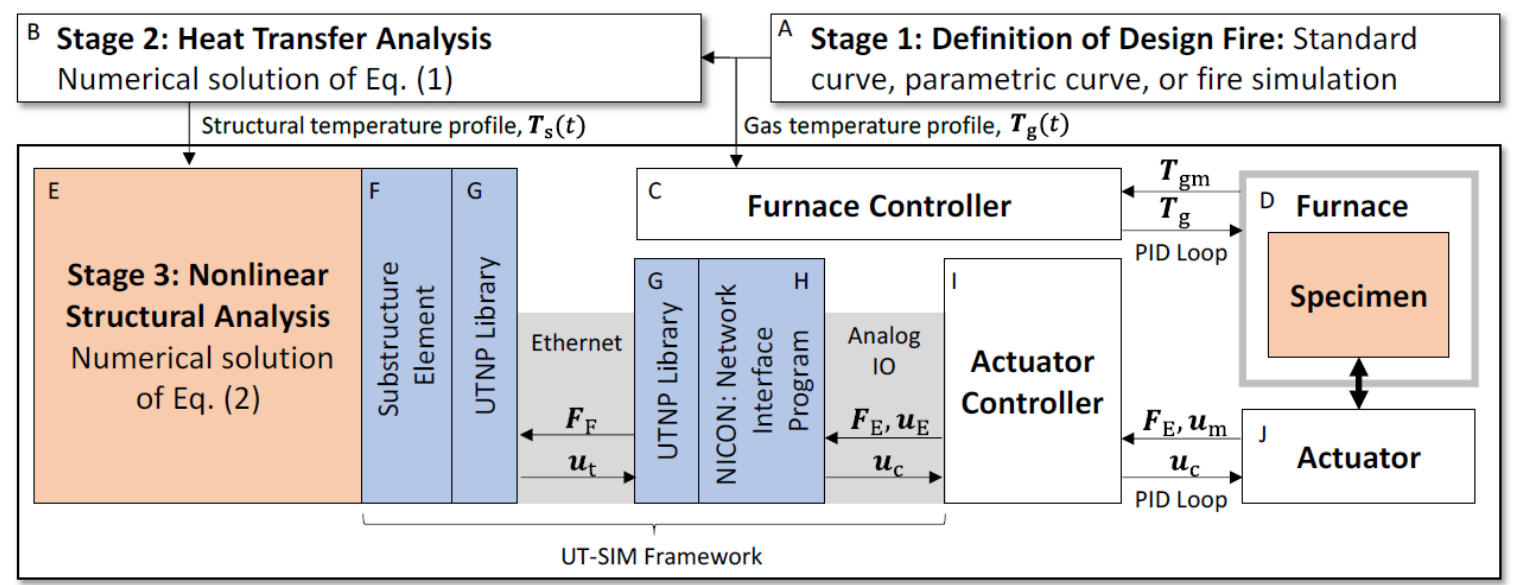

Figure 2.11 Hybrid fire simulation framework proposed by Wang et al (2018). 


\subsection{Review of Steel Structures Subjected to Fire Following Earthquake}

Today, limited number of studies on the response of steel structures under postearthquake fire hazard have been conducted. Della Corte et al. (2005) investigated the performance of steel moment resisting frames (SMRF) subjected to fire following earthquake by numerical models. The earthquake induced geometrical and mechanical damages in the structures were represented by applying a residual deformation and reducing the steel modulus of elasticity and yield strength in certain parts of the frames respectively (Della Corte et al, 2005). The finite element software OpenSees (http://opensees.berkeley.edu/) was chosen to model the structures and obtain the seismic response of the buildings using fiber beam-column element for capturing P-Delta effects. In addition, elastic-perfectly plastic hysteresis model was adopted in modelling the structural steel members. ISO-834 time-temperature curve was used for fire simulation considering uniform temperature distribution in fire compartment located on the first floor of the building. In this study, thermal and mechanical properties of steel were adopted according to Eurocode 3 (CEN, 2005). The fire program SAFIR (Franssen et al. 2017) was used to conduct post-earthquake fire simulations using thermal-mechanical analysis. It was observed that the seismic design philosophy can significantly affect the performance of steel MRFs under post-earthquake fires (Della Corte et al, 2005). It was recommended that fire safety codes should consider the location of buildings, seismic or non-seismic cases as a basis for structural fire design provisions (Della Corte et al, 2005).

Khorasani et al (2016) proposed a probabilistic framework for assessing buildings and communities subjected to fire following earthquake scenarios. The OpenSees and 
OpenSees for Fire (Usmani, 2012) frameworks were adopted and modified to cascade the time history and thermal analysis between the earthquake and fire modules in OpenSees.

Memari (2016) conducted extensive studies on multiple storey SMRFs subjected to fire following earthquake loading. Johnson and Cook (1985) damage model was used to consider the thermally induced damage in the SMRFs. ABAQUS (SIMULIA, 2013) was selected as the simulation tool to carry out three-step analyses: (1) static analysis with gravity load; (2) dynamic time history analysis to simulate the structure response under earthquakes and (3) uncoupled thermal stress analysis with predefined temperature profile obtained from a previously conducted heat transfer analysis. The considered fire load and scenarios in this study is shown in Figure. An important observation is that the postearthquake fire scenarios usually result in smaller interstorey drift ratio when compared to those resulting from the earthquakes (Memari and Mahmoud, 2018).
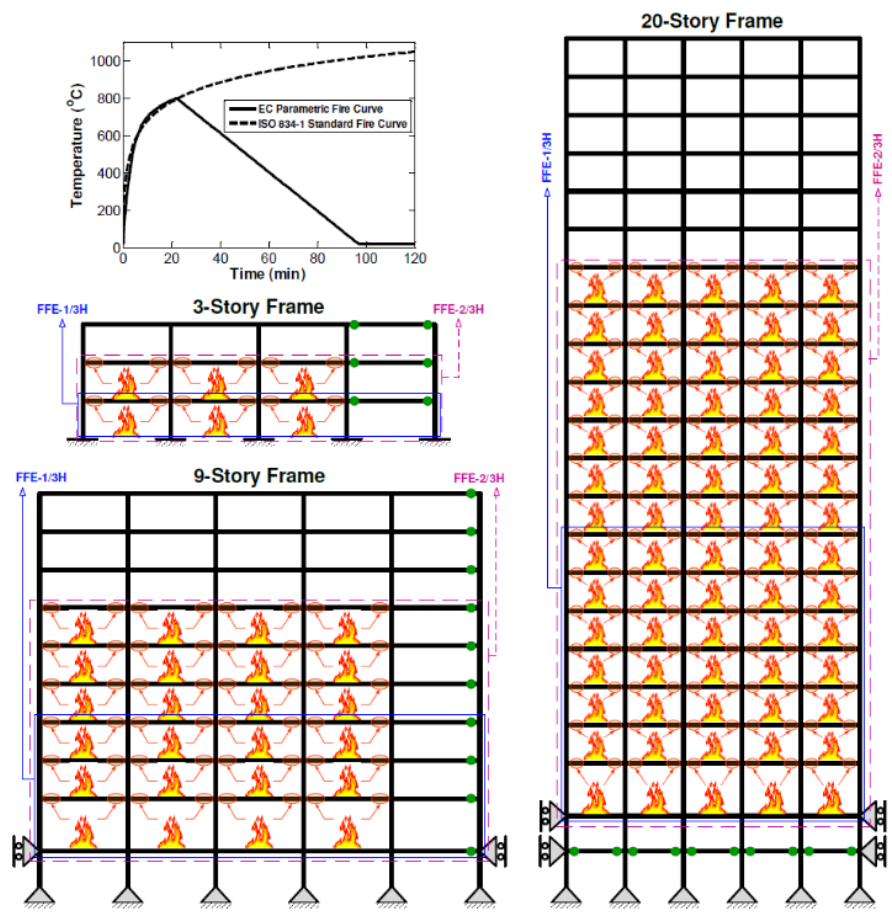

Figure 2.12 Fire scenarios in multi-storey steel moment resisting frames (Memari, 2016). 


\section{Chapter 3: Proposed Framework for Hybrid Fire Simulation}

\subsection{Overview}

In the proposed hybrid fire simulation method within the framework of performance-based design in fire safety engineering, a key requirement in capturing the complete structural behaviour is to account for the full interaction effects. The interactions between the two sub-domains i.e. physical and numerical, include the heat transferred from the fire to the structures, heat conduction as well as the forces, displacements, rotations induced by the elevated temperature. In addition, it is also necessary to update the mechanical boundary conditions in both the numerical and physical domains in real-time throughout the hybrid fire simulation to ensure full compatibility at the interface. The full interaction effects can be realized by coupling of the thermal analysis, mechanical analysis with thermal loading, high-performance testing facilities, and sufficient data exchange in the interface platforms. The details of an HFS protocol and simulation example considering full interaction effects are presented in this chapter.

\subsection{Numerical Simulation}

The numerical simulation part in the HFS framework can be divided into two types of analyses i.e. thermal analysis and mechanical analysis with thermal loading.

The thermal analysis aims at solving for the temperature profile in the structures exposed to fire, including (1) the convective and radiative heat transfer analysis from the fire to the surface of the structures by computational fluid dynamic (CFD); and (2) the conductive heat transfer within and among the structural elements using finite element 
analysis (FEA). A one-way coupled analysis approach between CFD and FEA can be adopted.

In the performance-based analysis, fire scenarios are chosen according to a number of factors e.g. the fuel type, the fuel consumption, the ventilation condition etc., which can be either represented by parametric fire curves or simulated by CFD software, e.g. Fire Dynamic Simulator developed by NIST (2013). Recognizing the complicity of the fire dynamic phenomenon in the convective and radiative heat transfer from the fire assume to the surface of the structures, it may be more convenient to use the fire load curves generated by CFD simulation as fire loads on the fire exposed structural members. After obtaining the temperature/heat flux profile at the surface of the structural elements by CFD, the conductive heat transfer is carried out to solve for the temperature gradient in the sections of the structural members using finite element (FE) software, e.g. SAFIR, OpenSees for Fire, ABAQUS (SIMULIA, 2013) etc.

In the mechanical analysis with thermal loading, typically by using specialized FE software packages or modules developed for fire engineering, the structural responses under the static and thermally induced mechanical loading are calculated. An assumption is adopted that if the structural responses do not affect the temperature profile, e.g. no total collapse occurred during the analysis, a one-way coupled analysis between thermal analysis and mechanical analysis can be used. The mechanical analysis is carried out sequentially after the thermal analysis based on the previously generated temperature profile in the structure. In the mechanical structural analysis within the proposed framework, the structure is subjected to the constant gravity load as well as the time variant forces, moments and the temperature gradient introduced from the physical domain at the 
interface node. The responses of the structure are calculated in the thermal-mechanical analysis are fed back to the physical specimen for the next cycle of HFS of the structure.

\subsection{Interface Platforms}

To include the full interactions for performance-based design as mentioned before, it is necessary to have the capability of sufficient information communication between the numerical and physical domains during the hybrid fire simulation. The implementation in the proposed framework is through the UT-SIM and OpenFresco interface platforms, which provide standard data exchange protocols. Both of these middleware platforms are originally developed for conducting seismic hybrid simulation for earthquakes, which includes force, displacement and rotation information exchange between the numerical and physical domains.

\subsection{Testing Facilities}

The National Research Council Canada (NRC) has conducted extensive fundamental research and innovative investigation on structural behaviour in fire. The $\mathrm{NRC}$ fire laboratory has a number of unique high-performance furnaces including a column furnace, a wall furnace and a floor furnace as shown in Figure 3.1 (https://nrc.canada.ca/en), which can carry out large-scale fire tests. The high-performance column furnace at $\mathrm{NRC}$ has the unique capability of conducting high temperature fire tests of full-scale specimens under controlled axial, lateral and rotational degrees-of-freedom and applied forces and moments. It is one of the best large-scale furnaces in the world that can carry out hybrid fire simulation with full mechanical loading effects. 


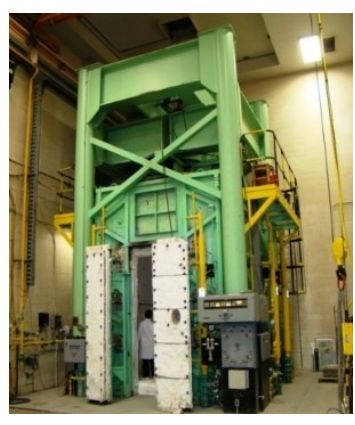

(a)

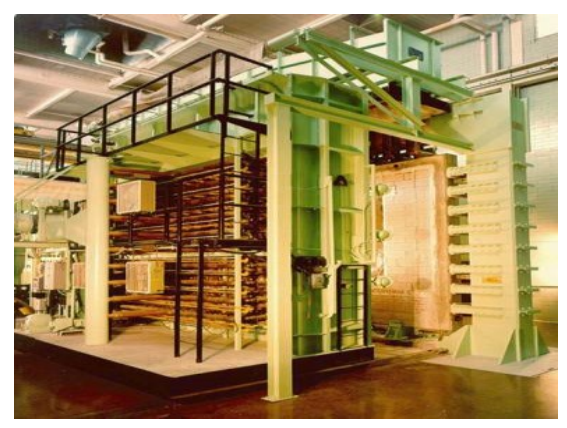

(b)

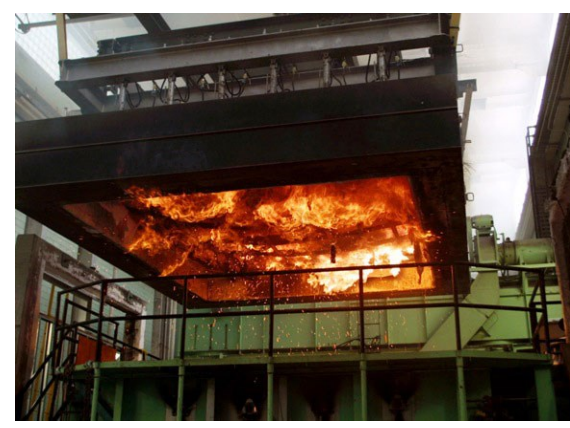

(c)

Figure 3.1 (a) Column furnace at NRC (b) wall furnace at NRC (c) floor furnace at NRC (https://nrc.canada.ca/en).

\subsection{Process of Hybrid Fire Simulation}

The procedures of carrying out hybrid fire simulation, as shown in Figure 3.2, are described as follows:

- Step 1: define the fire scenario and obtain the fire load for the entire structure as shown in Figure 3.2(a), e.g. by carrying out fire simulation in CFD software;

- Step 2: conduct the thermal analysis with gravity load for the complete structure at ambient temperature to determine the initial mechanical boundary conditions i.e. axial and lateral displacements, moments, for the numerical and physical domains at the interface, as demonstrated in Figure 3.2(b);

- Step 3: impose the previously calculated initial mechanical loads on both the numerically modelled structure and the test specimen in the fire test furnace, additional predefined temperature field history is applied in the numerical model at the interface nodes;

- Step 4: initiate the fire load to the test specimen in the furnace as shown in Figure 3.2(c); 
- Step 5: measure the mechanical responses at the interface node between the numerical and physical domains of the test structure at the end of the time step;

- Step 6: apply the obtained mechanical loads (transferred through the interface platform) on the numerical structure at the same degree-of-freedoms, then sequentially carrying out the thermomechanical analysis to calculate the structural response;

- Step 7: impose the obtained structural response of axial, lateral displacements and rotations at the interface node from previous step of the physical specimen;

- Step 8: repeat Step 5 to Step 7 until the end of the temperature-time history, or the cooling phase. 
Step 1: definition of fire scenario and loads:

e.g. dead load,

live load,

fire load (e.g. from CFD)
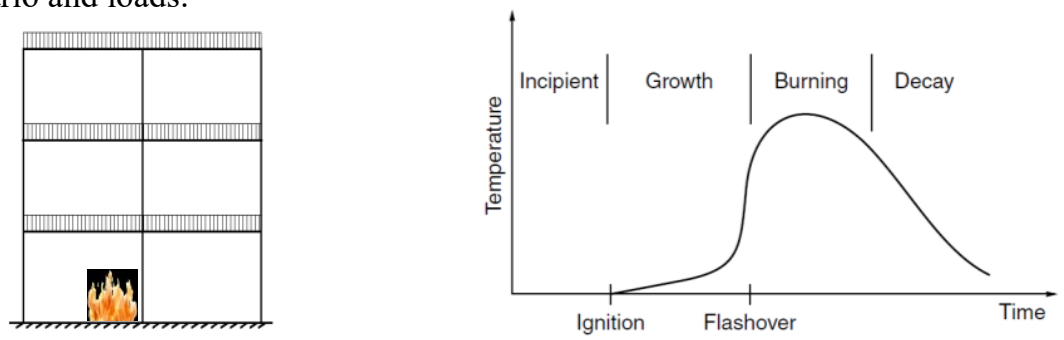

Time-temperature curve for full process of the fire development

(Buchanan, 2017)

(a)

Step $2 \&$ 3: determination of initial boundary conditions.

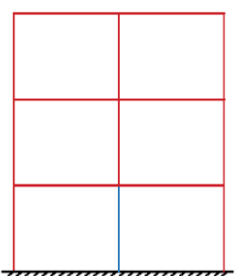

Entire Structure

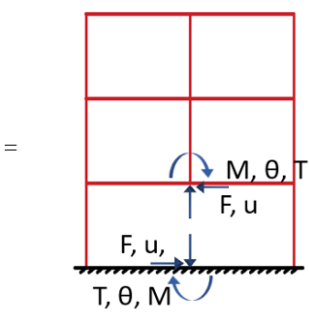

$=\quad$ Numerical Domain

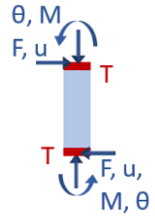

Physical Domain (b)

Step 4 to 8: hybrid fire simulation framework

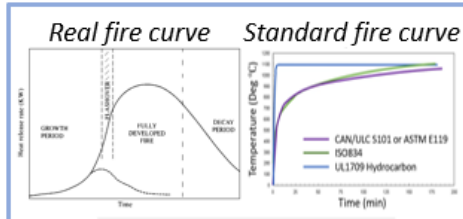

Fire Scenario \& Fire Load
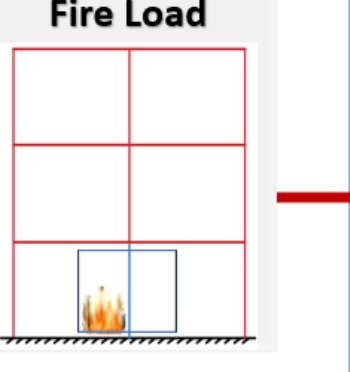

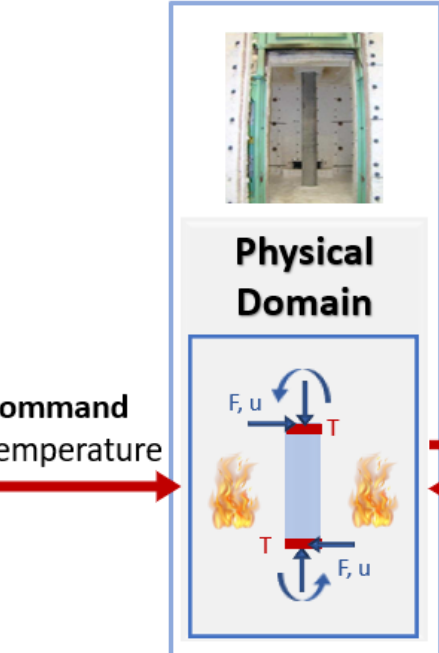

Physical

Domain

Feedback

Force

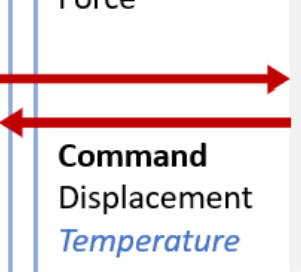

Temperature

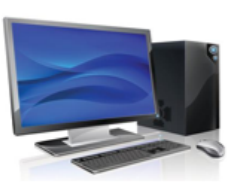

\section{Numerical}

Domain

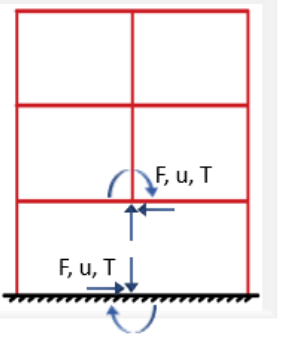

Figure 3.2 (a) Example of fire load and fire scenario (b) demonstration of initial boundary conditions in HFS (c) the process of HFS from step 4 to step 8. 


\subsection{Numerical Simulation Example}

To demonstrate the process of the proposed HFS, a numerical study is carried out. The computer software ABAQUS (SIMULIA, 2013) is used to carry out the numerical study, since it has comprehensive both thermal and mechanical analysis capacities. Both the numerical and physical domains in structure for HFS are represented by 3D analytical models in ABAQUS (SIMULIA, 2013). The information exchange i.e. temperature, force and displacement at each interface node is conducted as shown in Figure 3.3. A two-storey single bay steel frame is chosen as the prototype structure to study the feasibility of HFS. The bottom left column is selected as the physical domain yet represented by an ABAQUS (SIMULIA, 2013) model in this study. Beams and columns sizes are chosen as W14×74 and W18 $\times 65$ respectively. ASTM A992 grade 50 steel is adopted and the temperature dependent material property models are based on Eurocode 3 (CEN, 2005). The details of the thermal properties of steel in this model is shown in Table 3.1. The reduction factors and stress-strain relationships for strength degradation of steel under elevated temperatures are shown in Figure 3.4(a) and Figure 3.4(b), respectively.

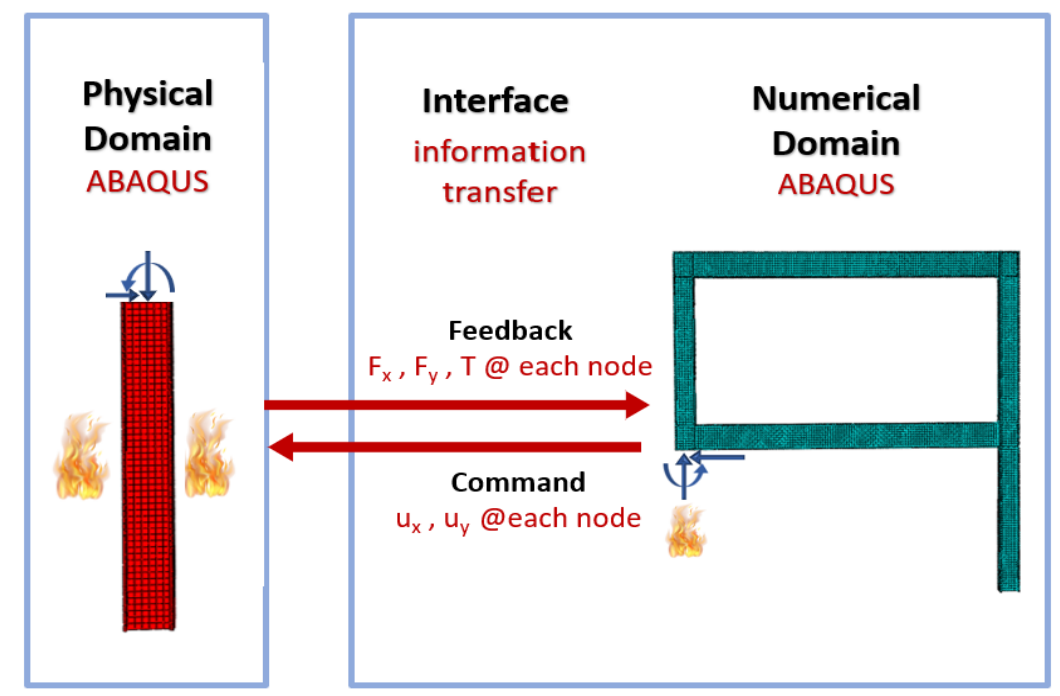

Figure 3.3 Demonstration of the process and information exchange of the HFS numerical study. 


\begin{tabular}{|c|c|c|}
\hline Thermal properties & Values & Temperature range $\left({ }^{\circ} \mathrm{C}\right)$ \\
\hline Density, $\rho\left(\mathrm{kg} / \mathrm{m}^{3}\right)$ & 7,580 & Constant \\
\hline \multirow[t]{4}{*}{ Specific Heat, $c(\mathrm{~J} / \mathrm{kg} / \mathrm{K})$} & $425+0.773 T-0.00169 T^{2}+2.22 \times 10^{-10} T^{3}$ & $20<T<600$ \\
\hline & $666+13002 /(378-T)$ & $600<T<735$ \\
\hline & $545+17820 /(T-731)$ & $735<T<900$ \\
\hline & 650 & $900<T<1,200$ \\
\hline Convection coefficient, $h_{c}\left(\mathrm{~W} / \mathrm{m}^{2} / \mathrm{K}\right)$ & 25 & Constant \\
\hline Emissivity, $\varepsilon$ & 0.5 & Constant \\
\hline \multirow[t]{2}{*}{ Conductivity, $k(\mathrm{~W} / \mathrm{m} / \mathrm{K})$} & $54-33.3 \times 10^{-3} T$ & $20<T<800$ \\
\hline & 27.3 & $800<T<1,200$ \\
\hline Stefan-Boltzmann constant, $\sigma\left(\mathrm{W} / \mathrm{m}^{2} / \mathrm{K}^{4}\right)$ & $5.67 \times 10^{-8}$ & Constant \\
\hline
\end{tabular}

Table 3.1 Thermal properties of steel under elevated temperature (Wang et al, 2018).
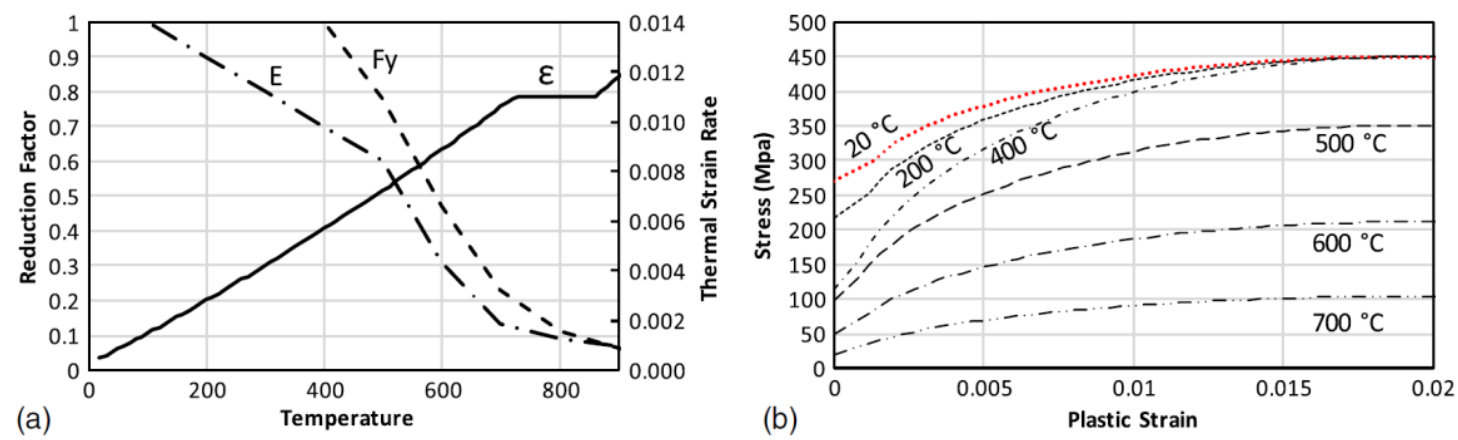

Figure 3.4 (a) Reduction factors for strength degradation of steel under elevated temperature (Wang et al, 2018) (b) stress-strain relationships of steel under elevated temperature (Wang et al, 2018).

Three models are built to carry out the demonstration study, i.e. the complete structure, physical domain and numerical domain. To observe the full thermal and mechanical interactions at the interface nodes, the fully coupled thermal stress analysis is adopted in this study, therefore, the heat transfer and thermal stress analysis is coupled in two-way in each time step. Same meshing and 20-node thermal-displacement coupled brick elements C3D20RT are used in the three models. Basic assumptions are applied to this study: only self weight of the steel frame is considered as the gravity load in the analyses; the hot column which is heated due to fire up to an hour, is assumed as unprotected yet the rest of the structure is well insulated, so that the fire represented by ISO-834 standard fire curve only attacks the physical domain of the structure, and the heat 
will transfer to the numerical domain through conduction. The surface temperature history of the heated steel column as shown in Figure 3.5 is solved using the step-by-step calculation method suggested in Eurocode 3 (CEN, 2005) for unprotected steel and assigned as temperature boundary condition. The temperature calculation details are shown in Appendix A.

In the complete structure model, it is observed that the heat conduction between the physical and numerical domains is not significant as shown in Figure 3.6. The top storey maximum vertical and lateral displacements are $53 \mathrm{~mm}$ and $45 \mathrm{~mm}$ respectively. Figure 3.7 presents the time history results of lateral and vertical displacement and temperature at one interface node at the top of the column expose to fire. The results of the complete and hybrid model show good agreement as shown in Figure 3.7.

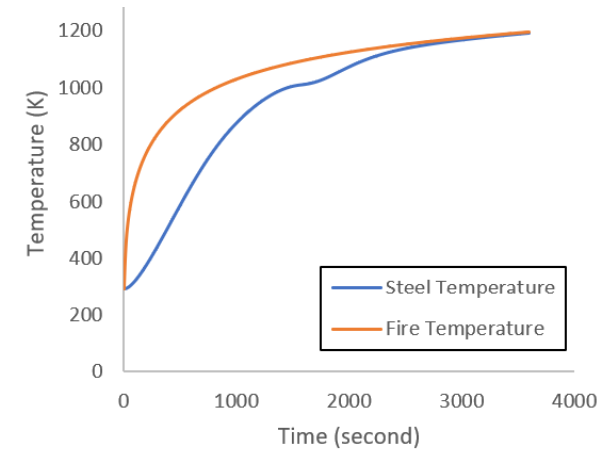

Figure 3.5 Steel temperature and fire temperature history in unit of Kelvin.

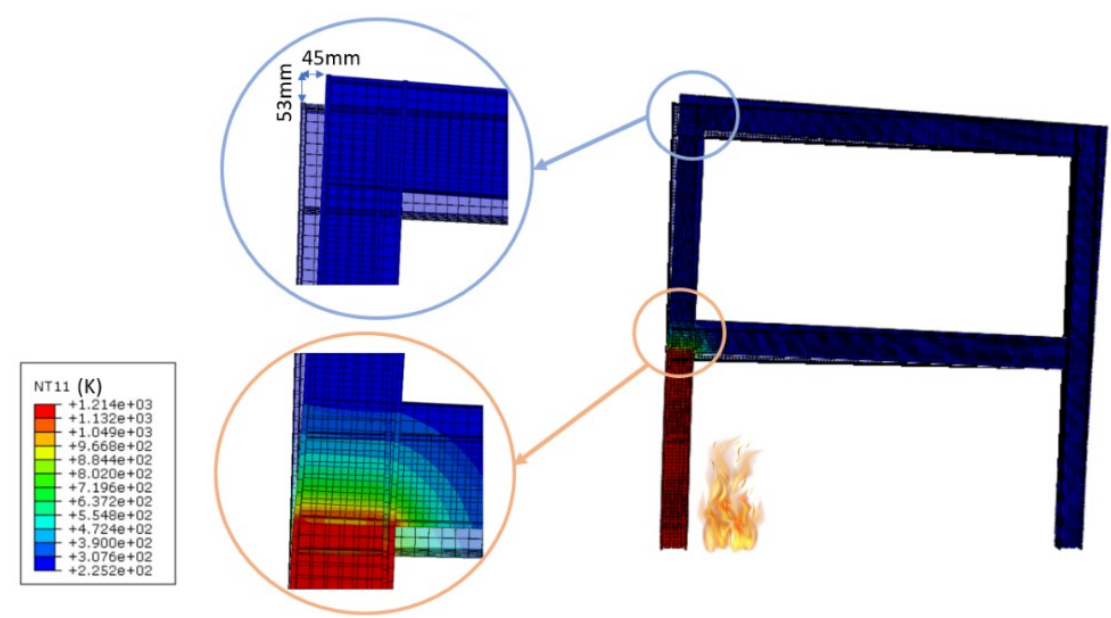

Figure 3.6 Deformation and temperature contour of the complete structure after heating. 


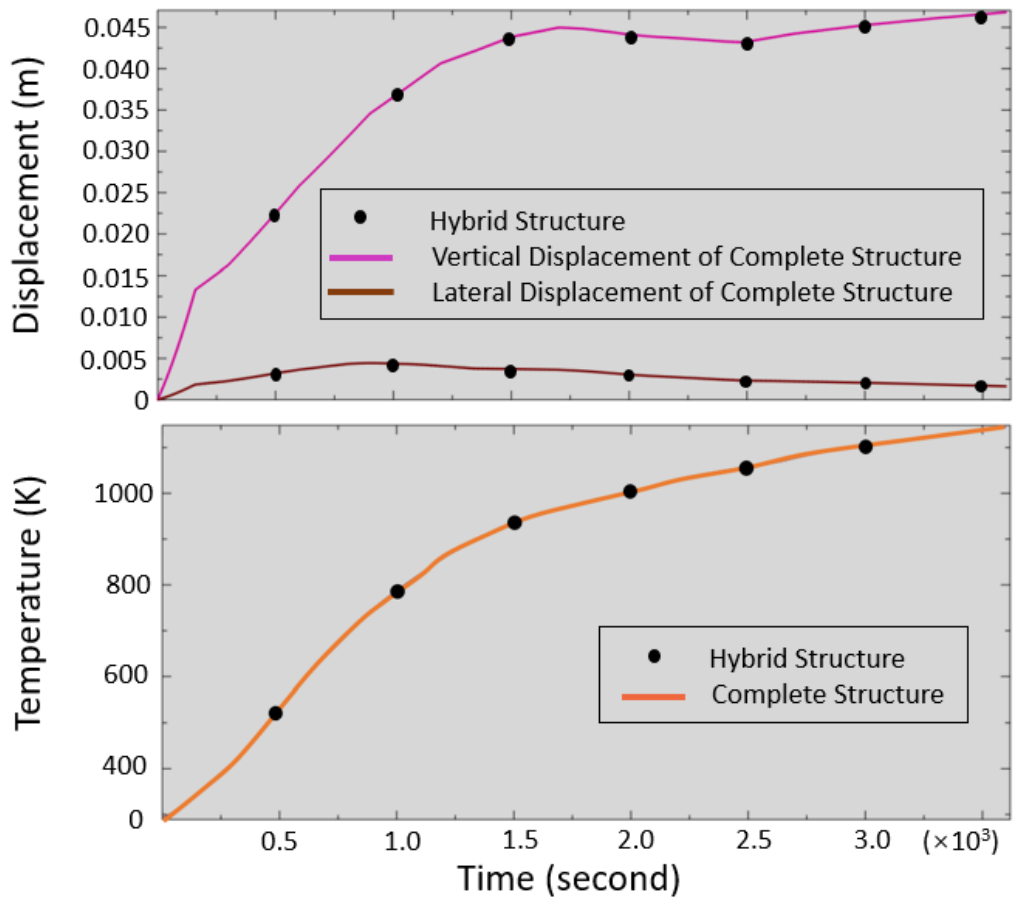

Figure 3.7 Comparison example of the vertical and lateral displacement and temperature information exchange at one interface node for complete structure model and hybrid model. 


\section{Chapter 4: Numerical Study on the Performance of a Steel Building Subjected to Fire Following Earthquake}

\subsection{Overview}

This chapter presents a study using finite element software ABAQUS (SIMULIA, 2013) to obtain insight into the effects of fire following earthquakes on a 4-storey steel moment resisting frame with reduced beam section (RBS) connections. The earthquake simulations are conducted using nonlinear time history analysis where the frames are subjected to a suite of far-field ground motions. With the damaged state of the structure at the end of the earthquake used as the initial condition for the fire analysis, an uncoupled thermal-mechanical analysis is performed with specified time-temperature curves applied on the heated elements exposed to fire. The results of the simulations can be used to reflect on the behavior of steel moment resisting frames under the combined loading conditions of earthquake and fire.

\subsection{Prototype Steel Structure}

The prototype 4-storey steel building with perimeter SMRFs using reduced beam section connections and interior gravity systems is designed based on FEMA-350 (2000) stipulations by Jin and El-Tawil (2004). The design details are provided by Kildashti and Mirghaderi (2009). Figure 4.1 (Jin and El-Tawil, 2004) shows the configuration of the frame, dimensions and cross sections of the beams and columns. In the design of RBS, a is taken as $75 \%$ as $b_{f}$, where $b_{f}$ is the width of the beam flange; $b$ equals to $85 \%$ of $d_{b}$, where $d_{b}$ is the depth of the beam; and c equals to $20 \%$ of $b_{f}$. 


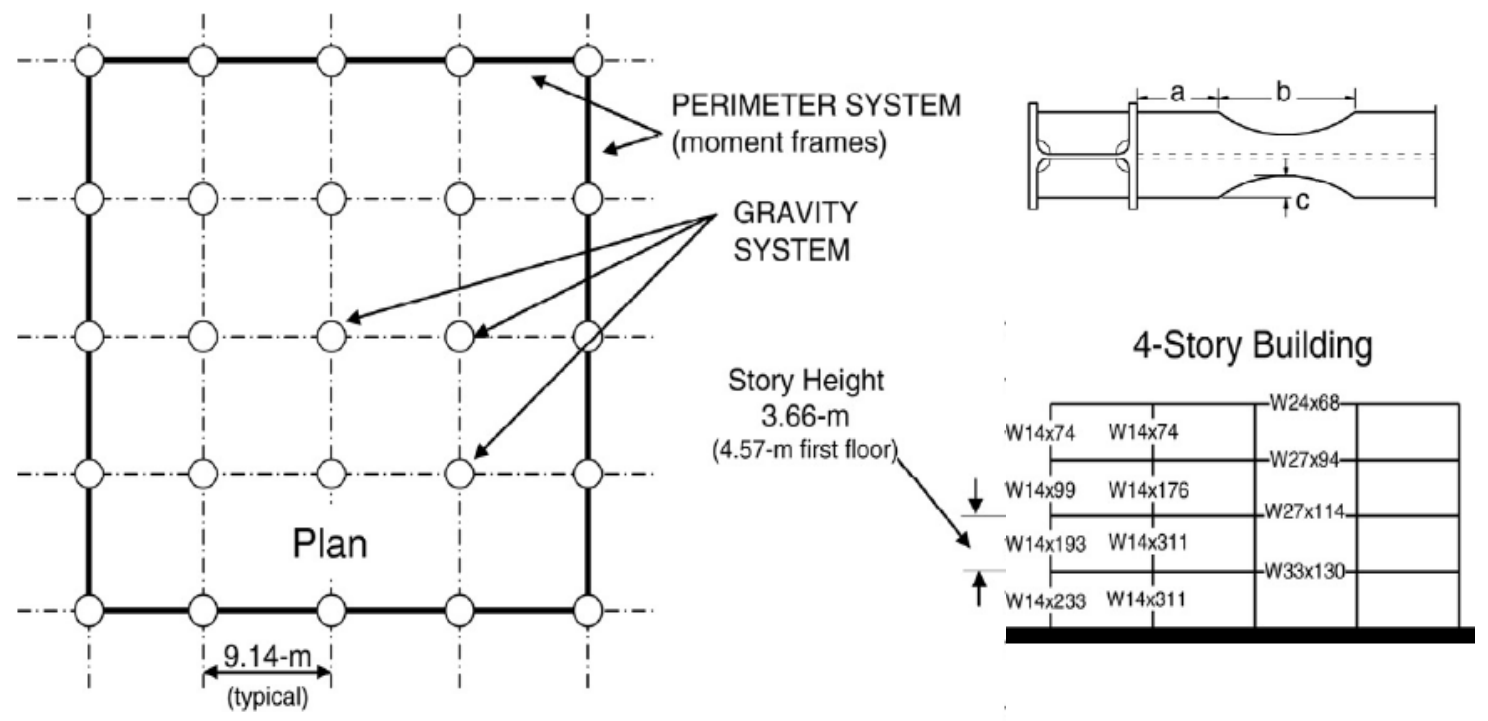

Figure 4.1 Design details of the prototype structure (Jin and El-Tawil, 2004).

\subsection{Numerical Model}

The finite element software ABAQUS (SIMULIA, 2013) is used for the development and analysis of the building model. Three types of scenarios are considered, i.e. fire hazard only, earthquake hazard only and post-earthquake fire hazard. A 3-step analysis procedure is performed to simulate the post-earthquake fire scenarios in the prototype structure. First, the frame is subjected to gravity loads by static analysis. Second, ground motion records are applied at the base of the model in a dynamic time history analysis to evaluate the earthquake response of the structure. Third, a static thermalmechanical analysis is conducted to simulate post-earthquake fires and the thermally induced stresses in the members of the building. 
As shown in Figure 4.2, the beams and columns are modeled using line elements and 2-node linear beam elements (B21) in the model. The flange width for the RBS in the model is simplified by taking the minimum width of the RBS as the constant beam flange width in the beam model. The seismic lumped masses are distributed among the beamcolumn joints of the frame. The gravity loads are divided into two parts. First, the gravity loads associated with the moment resisting frame (MRF) are applied as distributed vertical forces along the beams at each story level. Second, the gravity loads associated with the interior gravity systems associated with the tributary area resisted by the MRF are applied as concentrated loads to a column at the corresponding story levels. The representation of the gravity systems with the leaning columns is needed to account for the P-Delta effects of the building. The leaning columns are modeled using truss elements and are connected to the main MRF at the floor levels using rigid links. Diaphragms are modelled using truss elements with equivalent axial stiffness of the slabs. Rigid joint offsets are modelled at all beam-column joints.

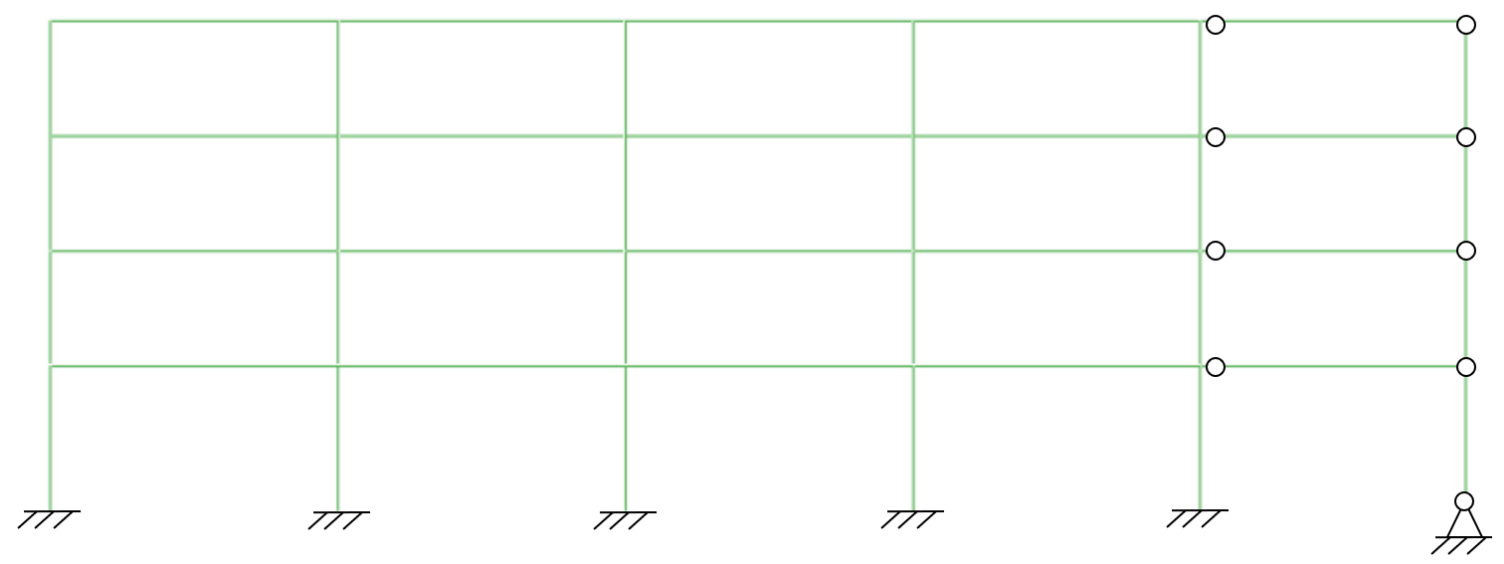

Figure 4.2 Configuration of the numerical model in ABAQUS.

The dead loads of $5.55 \mathrm{kPa}$ and $3.64 \mathrm{kPa}$, live load of $2.39 \mathrm{kPa}$ and $0.96 \mathrm{kPa}$ are assumed for floors and roof, respectively. The seismic load in the design and analyses is 
considered as $100 \%$ deal load in combination with $25 \%$ live load. The seismic masses and frame dimensions are shown in Table 4.1 (Kildashti and Mirghaderi, 2009). The first four periods and natural frequencies are shown in Table 4.2.

ASTM A572-50 grade steel with nominal yield strength of $345 \mathrm{MPa}$ and ultimate strength of $450 \mathrm{MPa}$ is implemented for the beams and columns. In the dynamic analysis, Rayleigh damping is used with $5 \%$ viscous damping for the 1 st and 4 th modes. Bilinear kinematic hardening model is used for earthquake analysis at $15{ }^{\circ} \mathrm{C}$ with a post yielding modulus as $2 \%$ of the elastic one. Temperature dependent thermal properties e.g. specific heat, conductivity, thermal expansion coefficient etc. are assigned to the model as the same value discussed in Section 3.5 in Chapter 3. Temperature dependent mechanical properties i.e. bilinear stress-strain relationship for steel in this model as shown in Figure 4.3, is modified based on Eurocode 3 constitutive models discussed in Chapter 2. One limitation of the material model used in ABAQUS in this study is that: no failure point in the material model is defined. Therefore, during the heating phase, the strength of the steel will degrade as the temperature increases, yet the strength will go back during the following cooling phase.

\begin{tabular}{llcccc}
\hline $\begin{array}{c}\text { Storey } \\
\text { no. }\end{array}$ & Beam type & $\begin{array}{c}\text { Interior } \\
\text { column type }\end{array}$ & $\begin{array}{c}\text { Exterior } \\
\text { column type }\end{array}$ & $\begin{array}{c}\text { Storey } \\
\text { height }(\mathrm{cm})\end{array}$ & $\begin{array}{c}\text { Storey } \\
\text { mass (ton) }\end{array}$ \\
\hline 4 & W24 $\times 68$ & W $14 \times 74$ & W14 $\times 74$ & 366 & 496 \\
3 & W $27 \times 94$ & W $14 \times 176$ & W $14 \times 99$ & 366 & 757 \\
2 & W27 $\times 114$ & W $14 \times 311$ & W14 14193 & 366 & 757 \\
1 & W33 $\times 130$ & W14 1411 & W14 $\times 233$ & 457 & 757 \\
\hline
\end{tabular}

Table 4.1 Sections, storey heights and storey masses for the building (Kildashti and Mirghaderi, 2009).

\begin{tabular}{ccccc}
\hline Mode number & 1 & 2 & 3 & 4 \\
\hline Period (second) & 1.08 & 0.39 & 0.23 & 0.14 \\
Frequencies (Hz) & 0.93 & 2.55 & 4.44 & 7.2 \\
\hline
\end{tabular}

Table 4.2 Periods and natural frequencies of the model. 


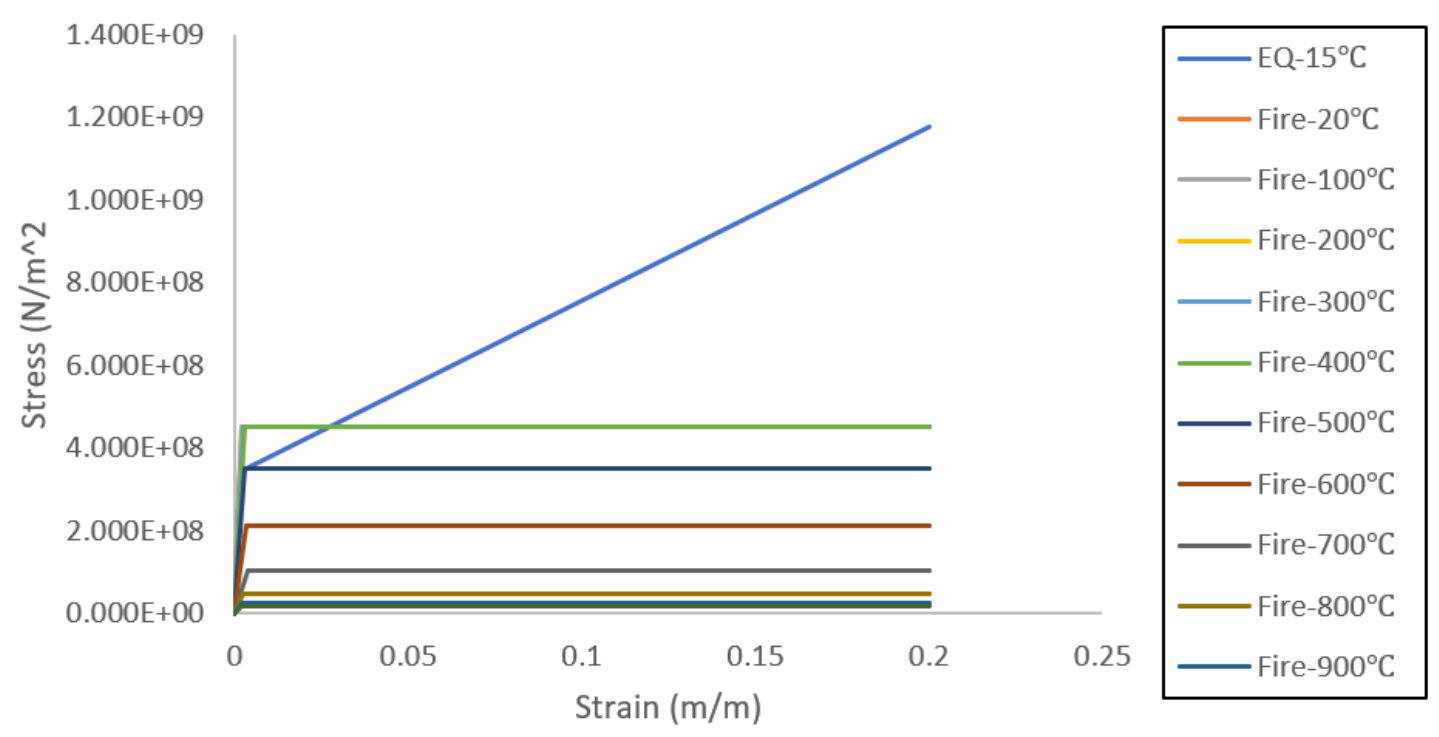

Figure 4.3 Bilinear stress-strain relationships for the numerical model.

Five far-field earthquake records as plotted in Figure 4.4 are selected in accordance with FEMA-P695 (2009). The earthquakes were scaled to a target spectral acceleration, $\mathrm{Sa}$, associated with a given code-defined period $(\mathrm{T})$ to remove the expected variability in spectral demand at that given period in the ground motions. To do so, individual earthquake records are normalized with respect to peak ground velocity $(\mathrm{PGV})$, and each set of records is collectively scaled to match the median spectral acceleration of the set to the maximum considered earthquake (MCE) response spectrum at the code-defined period of the structure (FEMA-P695, 2009). The MCE response spectrum allows the structure to be assessed based on the collapse prevention performance criterion for a seismic event with a $2 \%$ probability of being exceeded in 50 years (FEMA-P695, 2009). The MCE response spectrum is calculated based on the structure considered as a standard office building located in a region near Los Angeles with site class $\mathrm{C}$ following the stipulations in ASCE/SEI 7-16 (2017). The scaling factor applied to all five earthquakes is taken as 1.85. 
Figure 4.5 presents the design spectrum compared with the spectrums of the five earthquakes scaled to the MCE hazard level.

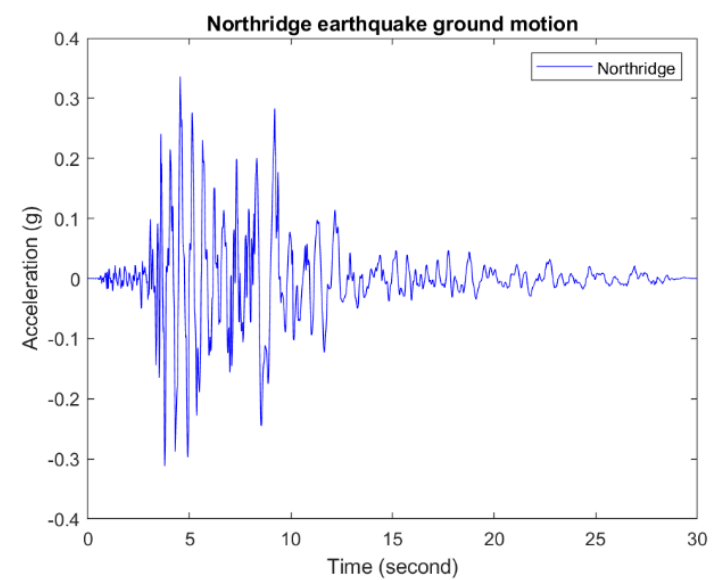

(a)

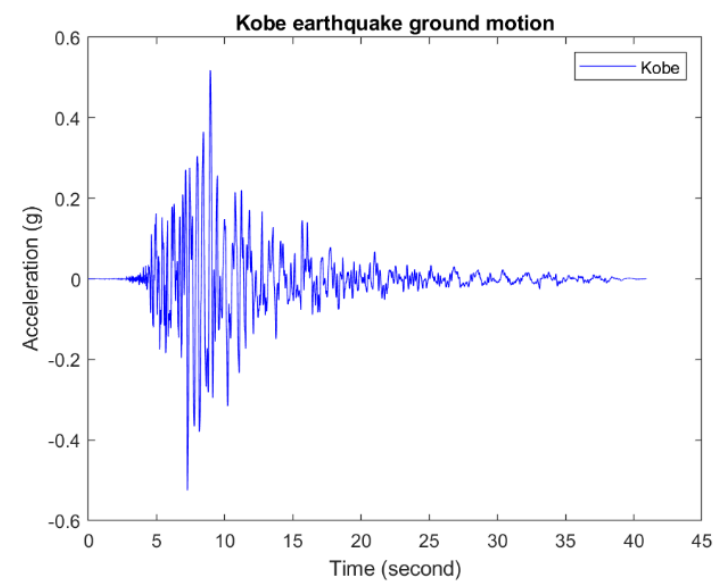

(c)

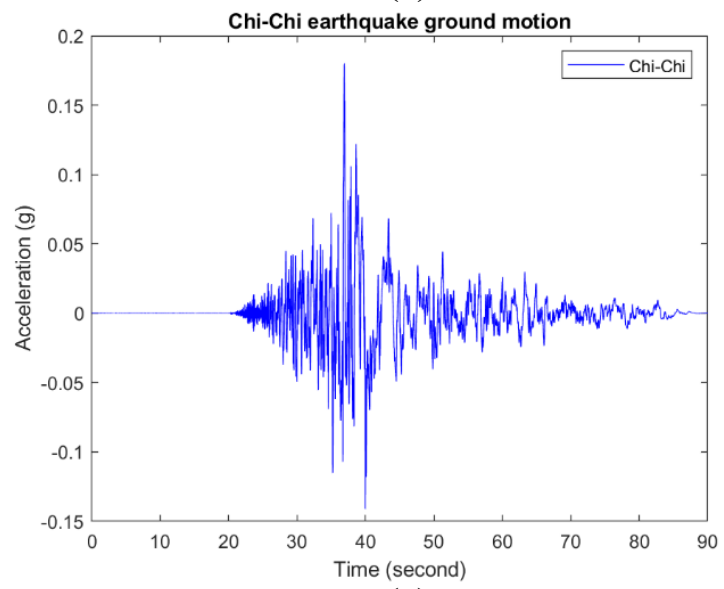

(e)

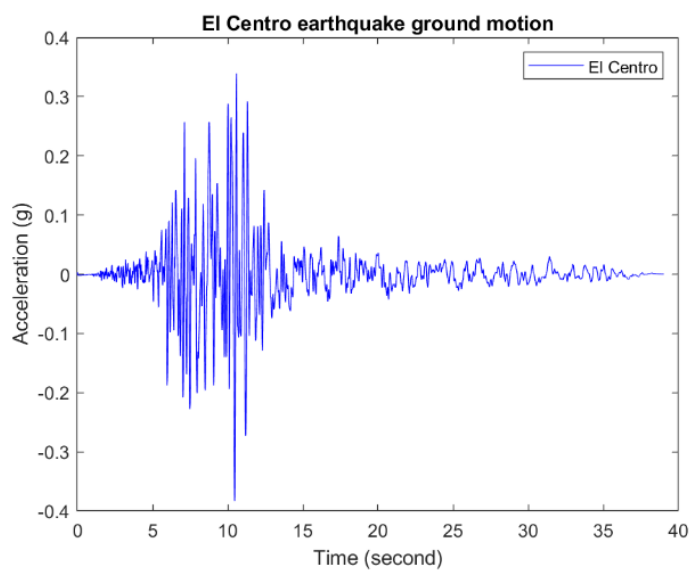

(b)

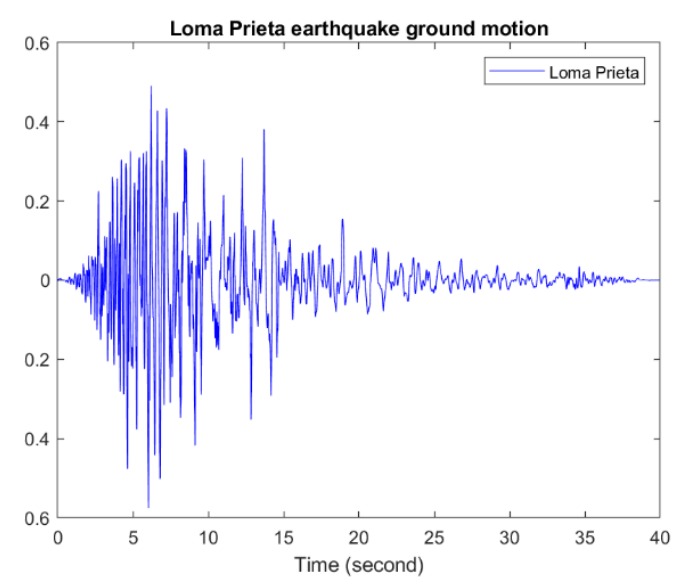

(d)

Figure 4.4 Normalized ground motions from ATC (a) Northridge ground motion (b) El Centro ground motion (c) Kobe ground motion (d) Loma Prieta ground motion (e) Chi-Chi ground motion 


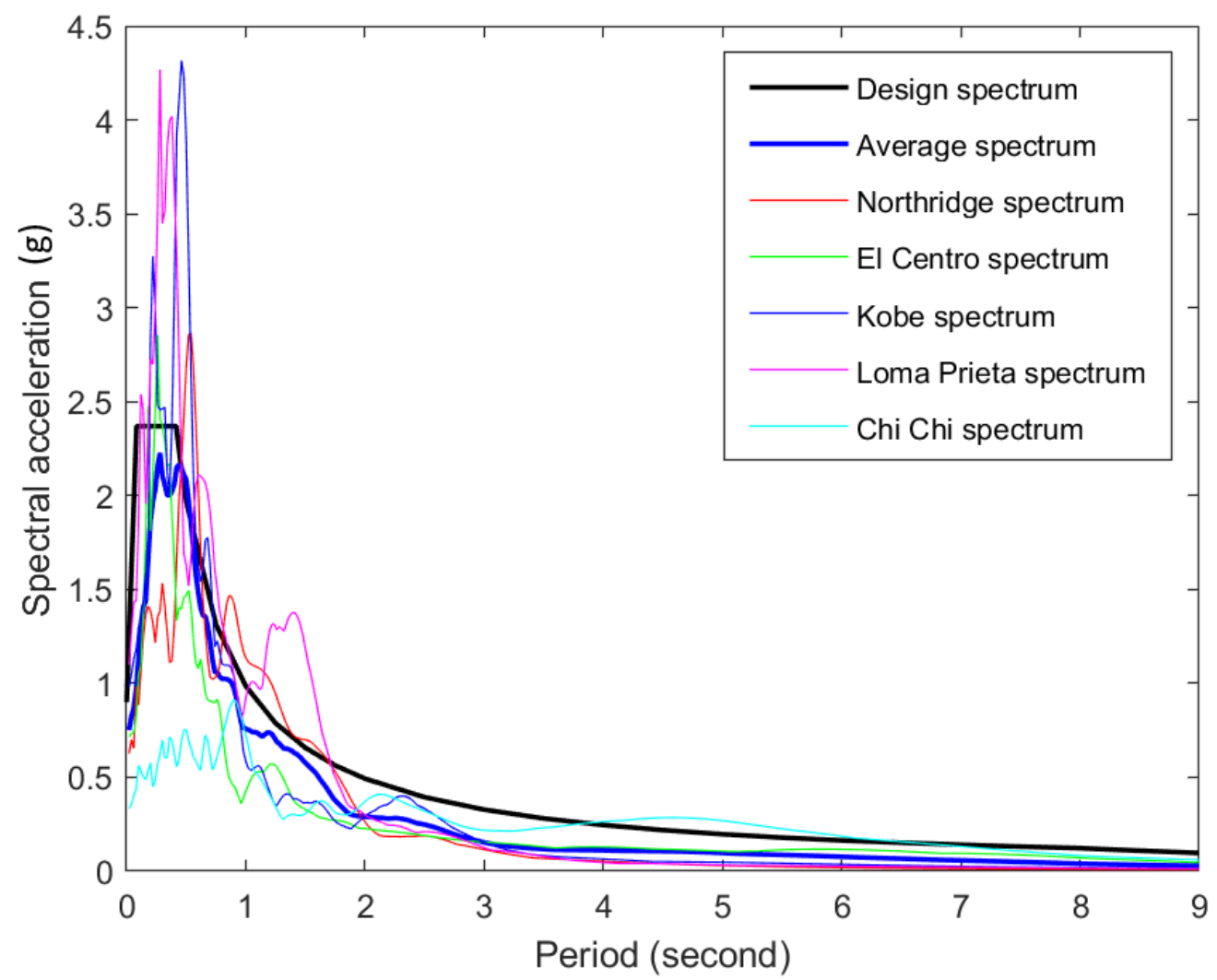

Figure 4.5 Design response spectrum and five earthquake spectrums scaled to the MCE hazard level.

The aim of the present study is to assess the performance of steel building under a realistic fire scenario which includes both heating and cooling phases of the fire load effects. Not necessary as the most severe case. Therefore, the fire exposure is taken to be the parametric fire curve as a representative fire load effect of the fire hazard scenario as discussed in Section 2.2. The shape, maximum temperature reached, time duration and other properties of a parametric fire curve are influenced by a number of parameters of the building's exterior and interior characteristics, such as opening, ventilation and lining materials. Because the prototype building is not a real building and thus this information is not available for precisely determining the specific parametric fire curve which must be used in the fire following earthquake simulation studies here. Since the purpose of the 
investigation here is to assess the validity of the proposed numerical simulation methodology, which parametric fire curve is selected for the investigation would not affect the finding of the research. For determining the parametric fire curve used in the present investigation, the dimensionless factor associated with opening and the thermal absorptivity of surrounding surfaces of the fire compartment, $\Gamma$, is taken to be equal to 1.0. The heating phase ends at 22 min where the temperature of the fire peaks at 800 degree Celsius (1073.15 Kelvin). The applied steel temperature history as shown in Figure 4.6 is calculated using the step-by-step method (CEN, 2005) for unprotected steel. The calculation details are presented in Appendix A. The fire scenarios in three different locations are illustrated in Figure 4.7.

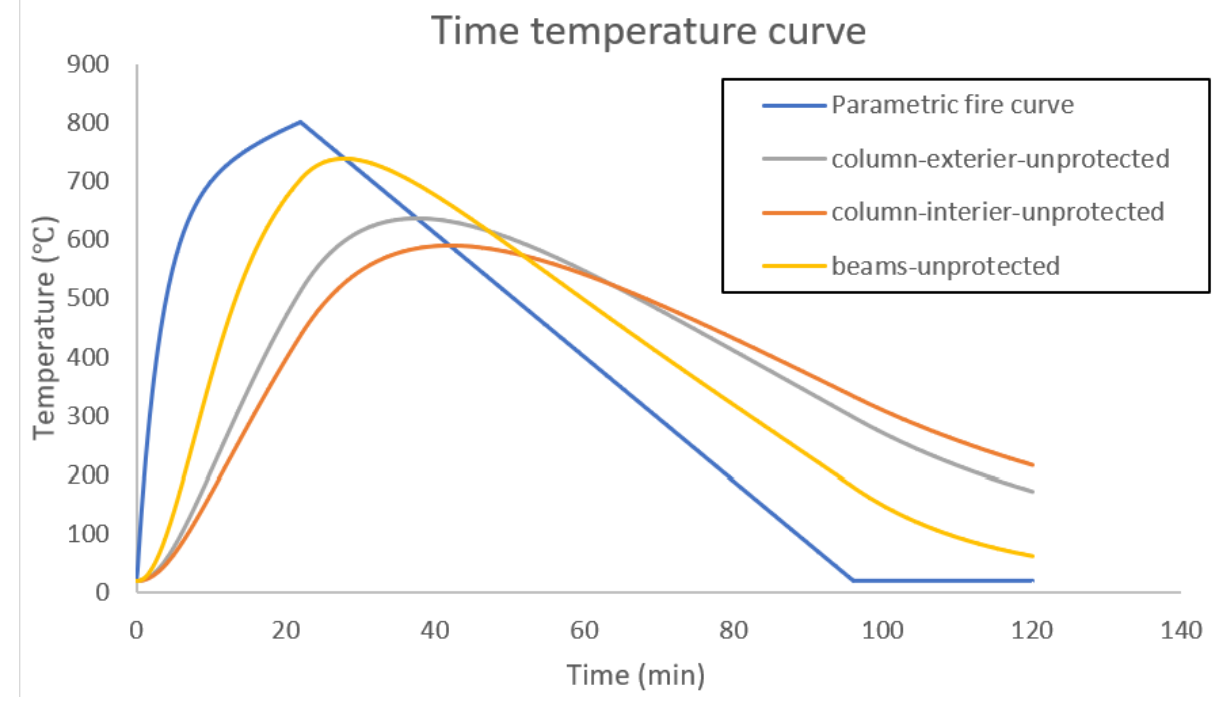

Figure 4.6 Time temperature curve for parametric fire and steel temperature in beams and columns. 


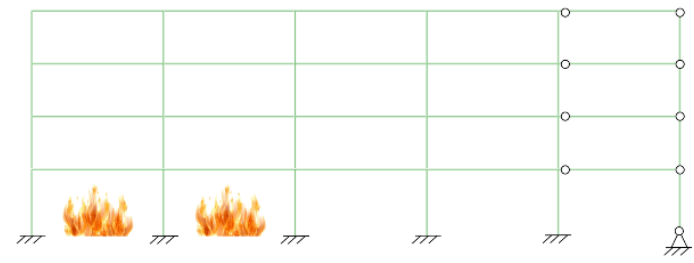

(a)

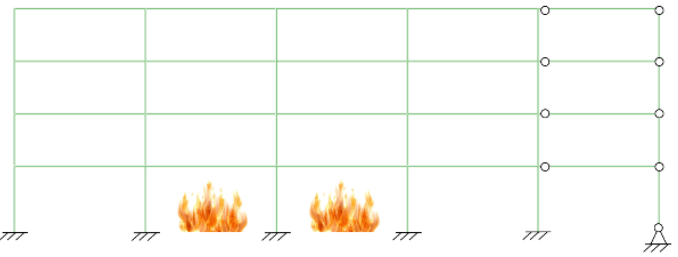

(b)

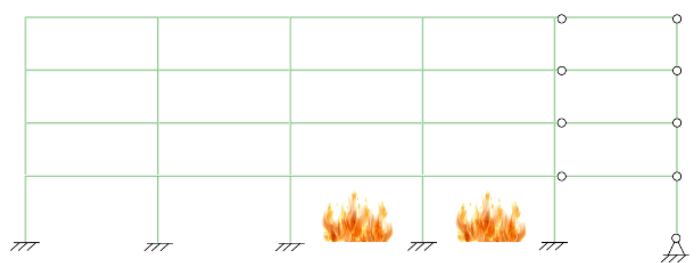

(c)

Figure 4.7 Three considered fire hazard scenarios on the first storey of the building (a) fire located in the two left bays (b) fire located in the two middle bays and (c) fire located in the two right bays.

\subsection{Results and Discussion}

When the structure is subjected to only fire hazard, as shown in Figure 4.8 and Figure 4.9, the maximum and residual interstorey drift ratio (IDR) at the first two floors are significantly greater than these of the upper floors. The large deformations at the lower floors are due to the thermal expansion in the heated columns and beams where the elevated temperatures are applied.

In the time history analysis where the building is subjected to earthquake ground motion alone, the maximum base shear was $6190 \mathrm{kN}$ under the Northridge earthquake as summarized in Table 4.3. In this case, as shown in Figure 4.10 and Figure 4.11 and in contrast to the fire response of the building, the maximum and residual IDR appears at the top fourth floor level of the building. This is because of the seismic force distribution from earthquake is generally highest at the top of a building. In the design of the prototype structure, the fourth-floor column section is relatively weaker compared to the sections of 
the beam and column on the third floor, resulting in a weak storey at the top floor of the prototype building.

\begin{tabular}{cccccc}
\hline Earthquake & Northridge & El Centro & Kobe & Loma Prieta & Chi-Chi \\
\hline Base shear $(\mathrm{kN})$ & 6190 & 5470 & 5100 & 6100 & 5310
\end{tabular}

Table 4.3 Base shear of the building under five earthquakes.

The maximum and residual IDR for the structure under fire following earthquake hazards and with the fire occurring in three different locations are shown from Figures 4.12 to Figure 4.17. The fire only and earthquake only results are also plotted in Figures 4.12, 4.14 and 4.16 to show the effects of the multi-hazard scenarios of fire following earthquake. The maximum IDR values of the upper two floors are typically higher for the FFE hazard scenarios compared to the hazard scenarios of fire alone, but they are considerably lower than the case of earthquake alone. On the other hand, the maximum IDR values of the lower two floors in the FFE scenarios are larger than both scenarios when earthquake and fire are applied to the building separately. These results show that the combination effects of fire and earthquake introduce more damage in the prototype steel building than the two hazards are considered individually. To better illustrate the influences of the fire locations to the behaviour of the building, the results of FFE for the Kobe earthquake are plotted again in Figures 4.18 and 4.19. The effect of fire locations is more pronounced at the lower floors where they are close to the fire as compared to the upper floors. In addition, it can be observed that there is a significant jump in the residual interstorey drift at the top floor at the end of the earthquake. 
Figure 4.20 shows the moment curvature result of a reduced beam section on the first floor of the building where a plastic hinge is formed. Figure 4.21 presents the moment curvature result at the base of the exterior column of the ground floor. The results indicate that the beam experiences large hysteresis nonlinear behaviour during the earthquake but much smaller hysteresis behaviour during the post-earthquake fire. The opposite trends are shown in the selected column section. These results show that when the prototype steel building is subjected to earthquake, the RBS connections in the beams are mainly responsible for dissipating seismic energy. However, during the post-earthquake fire analysis, the thermally induced load effects have more significant impact on the deformations of the column than the beam, which potentially may result in the total collapse of the building in the case of FFE hazards. 


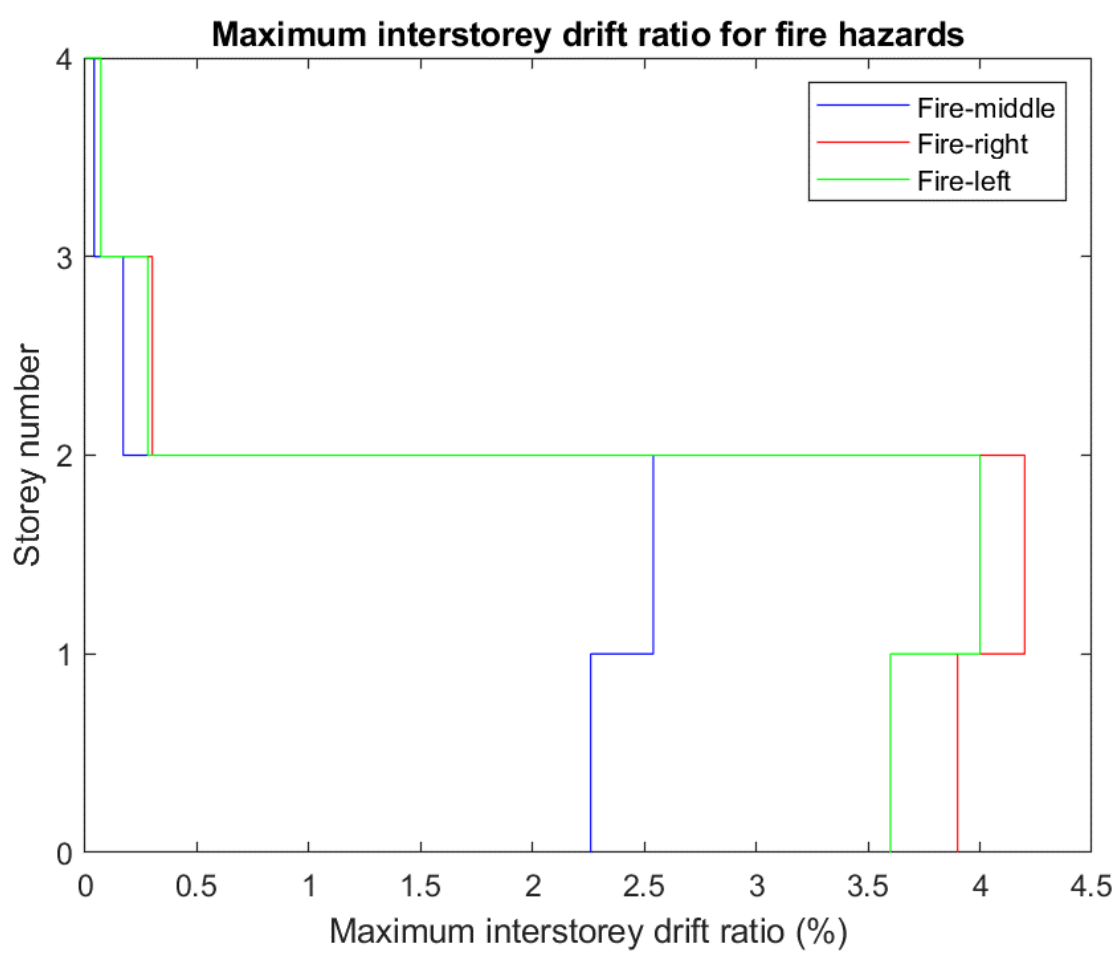

Figure 4.8 Maximum interstorey drift ratio of the building under fire hazards.

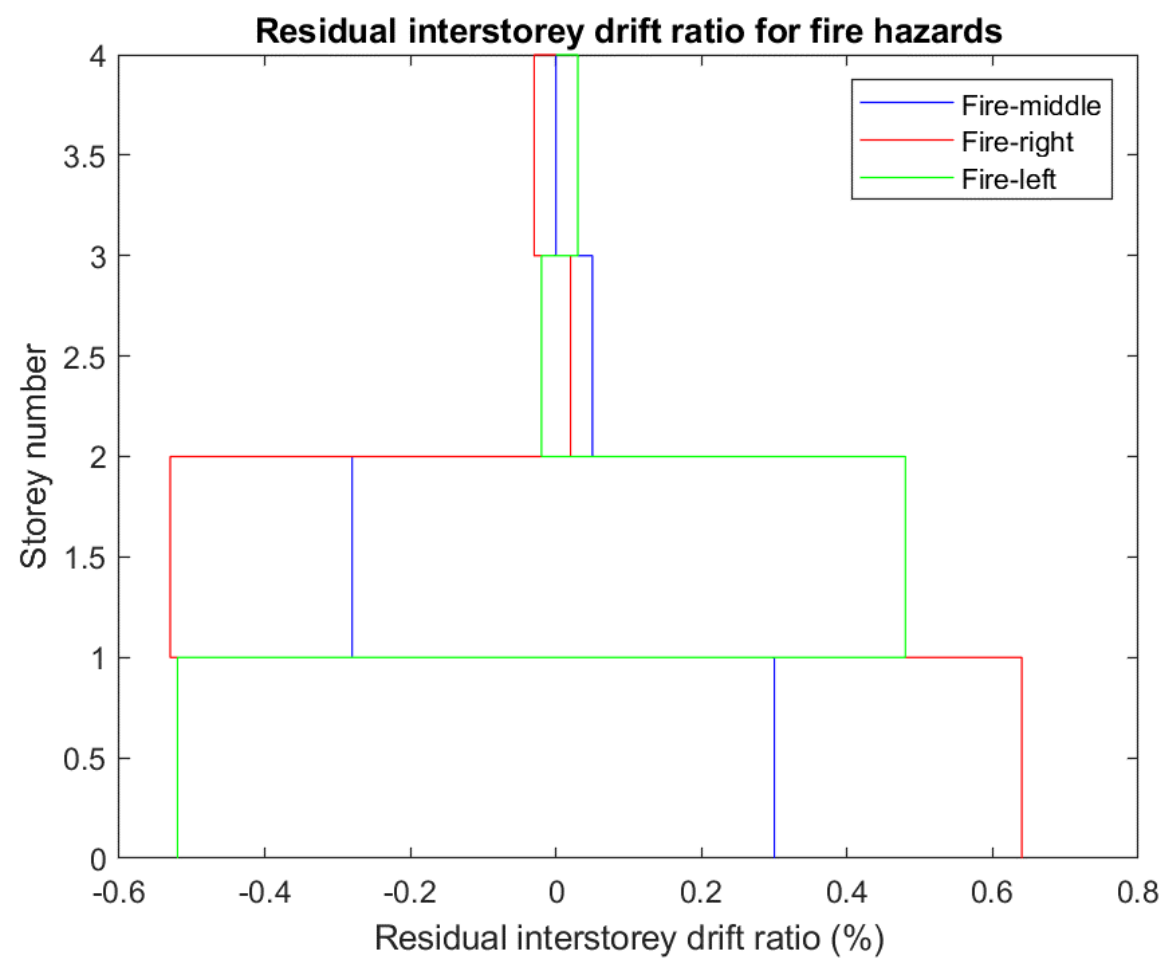

Figure 4.9 Residual interstorey drift ratio of the building under fire hazards. 


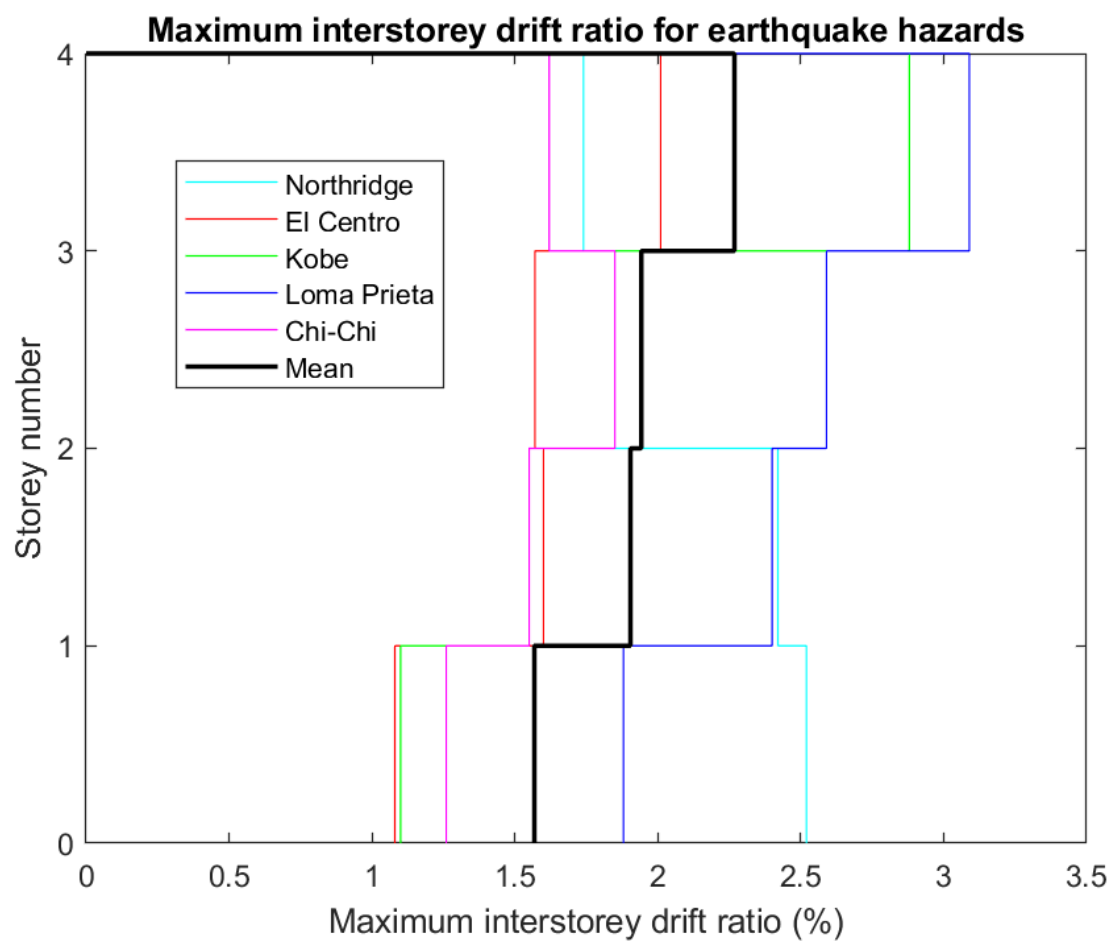

Figure 4.10 Maximum interstorey drift ratio of the building under earthquake hazards.

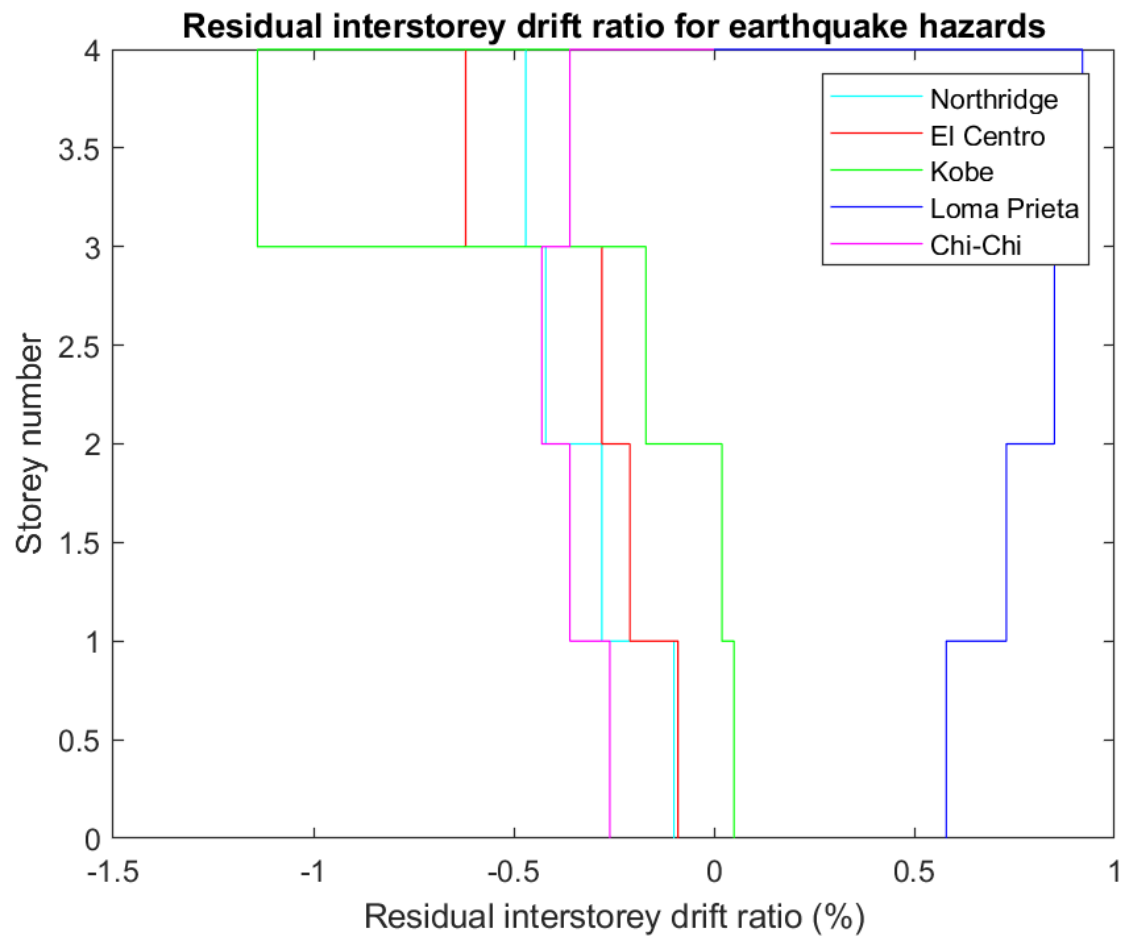

Figure 4.11 Residual interstorey drift ratio of the building under earthquake hazards. 


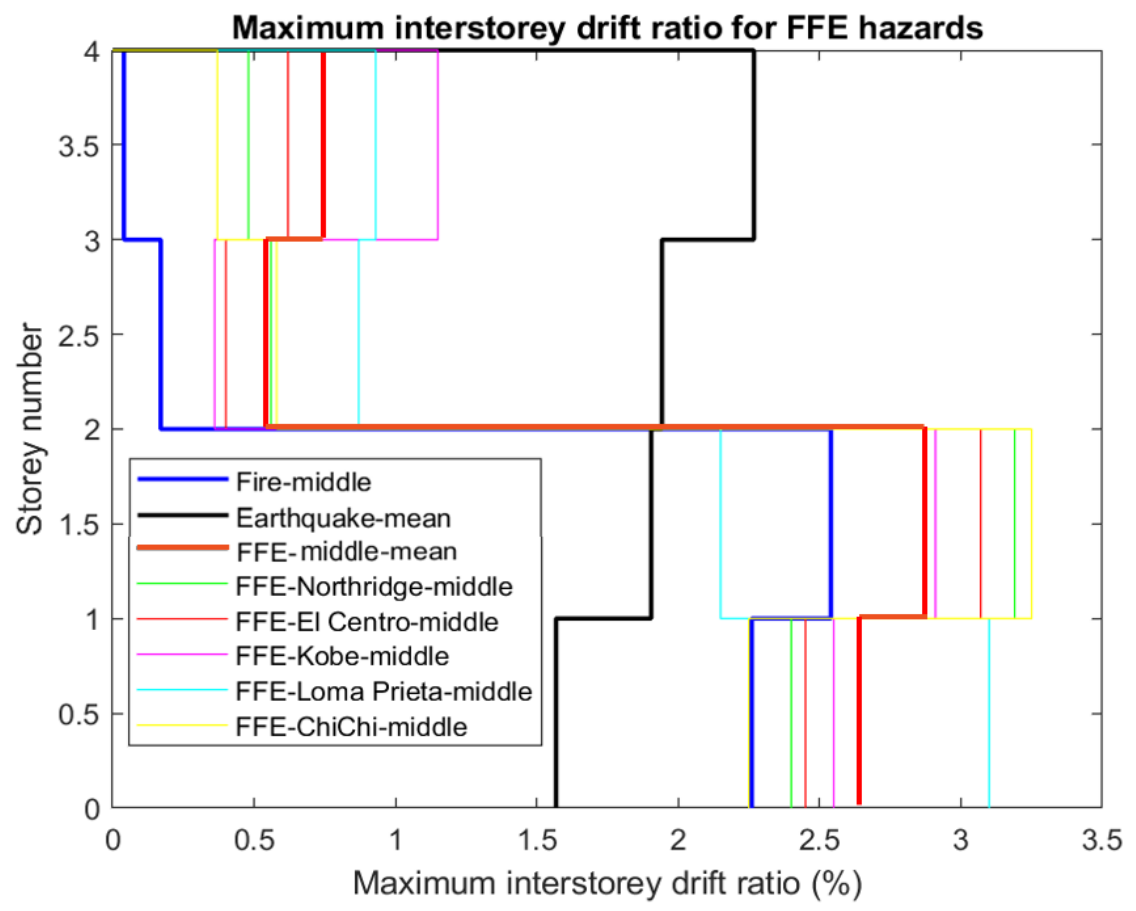

Figure 4.12 Maximum interstorey drift ratio of the building under FFE hazards.

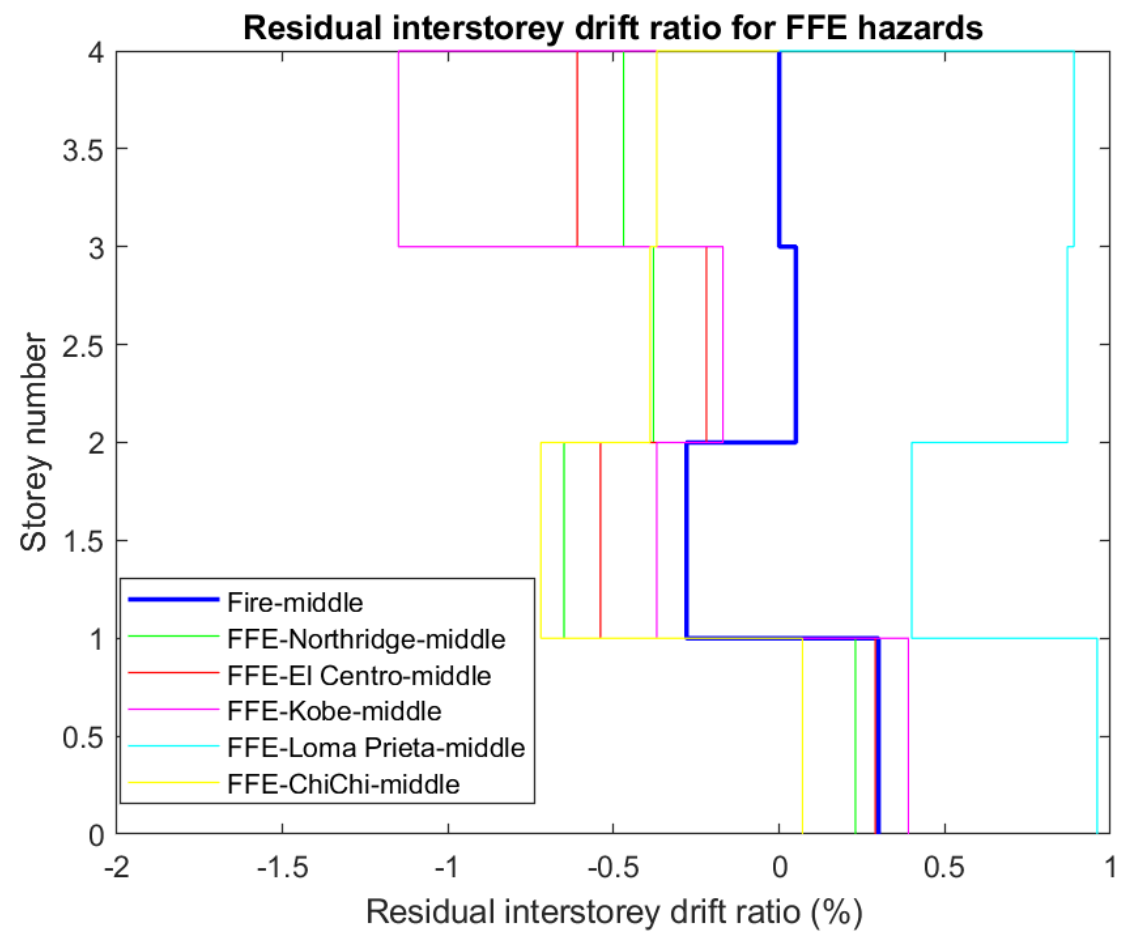

Figure 4.13 Residual interstorey drift ratio of the building under FFE hazards. 


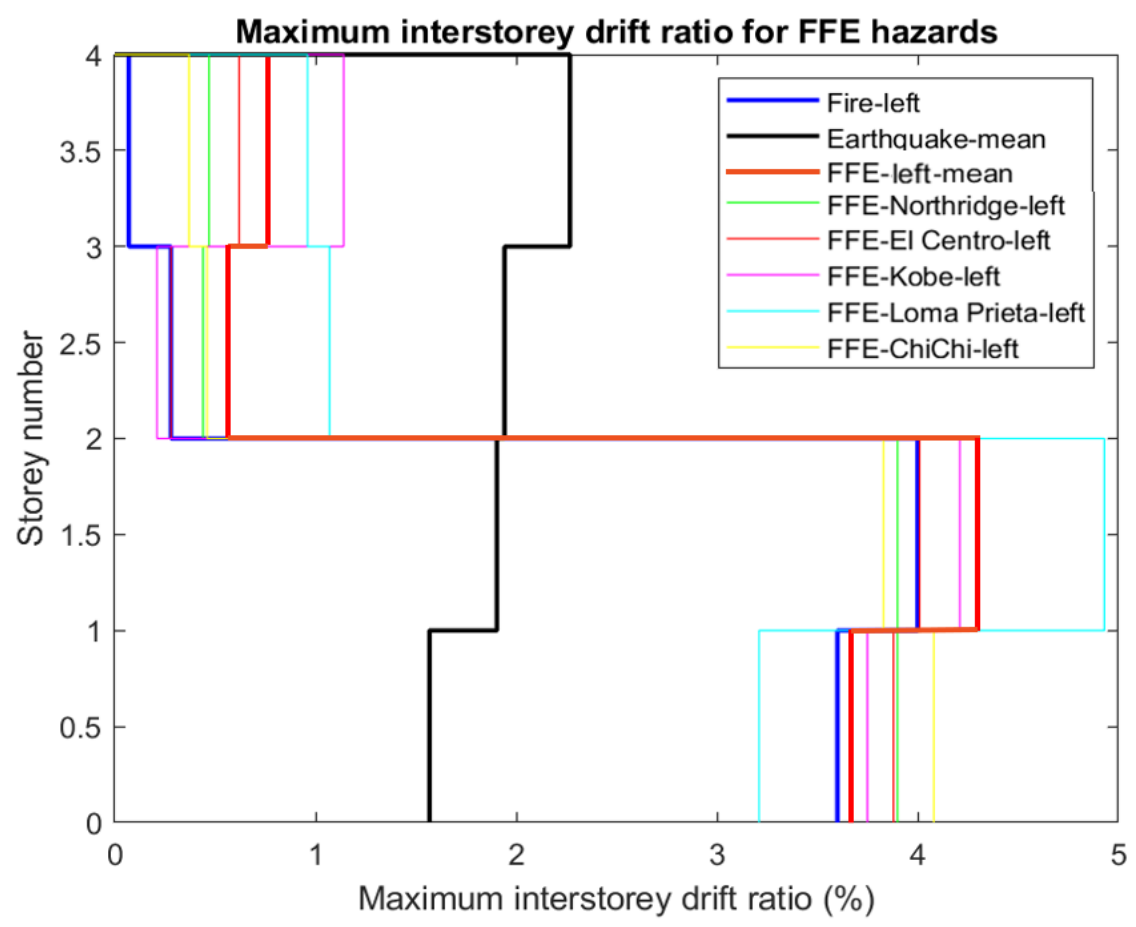

Figure 4.14 Maximum interstorey drift ratio of the building under FFE hazards.

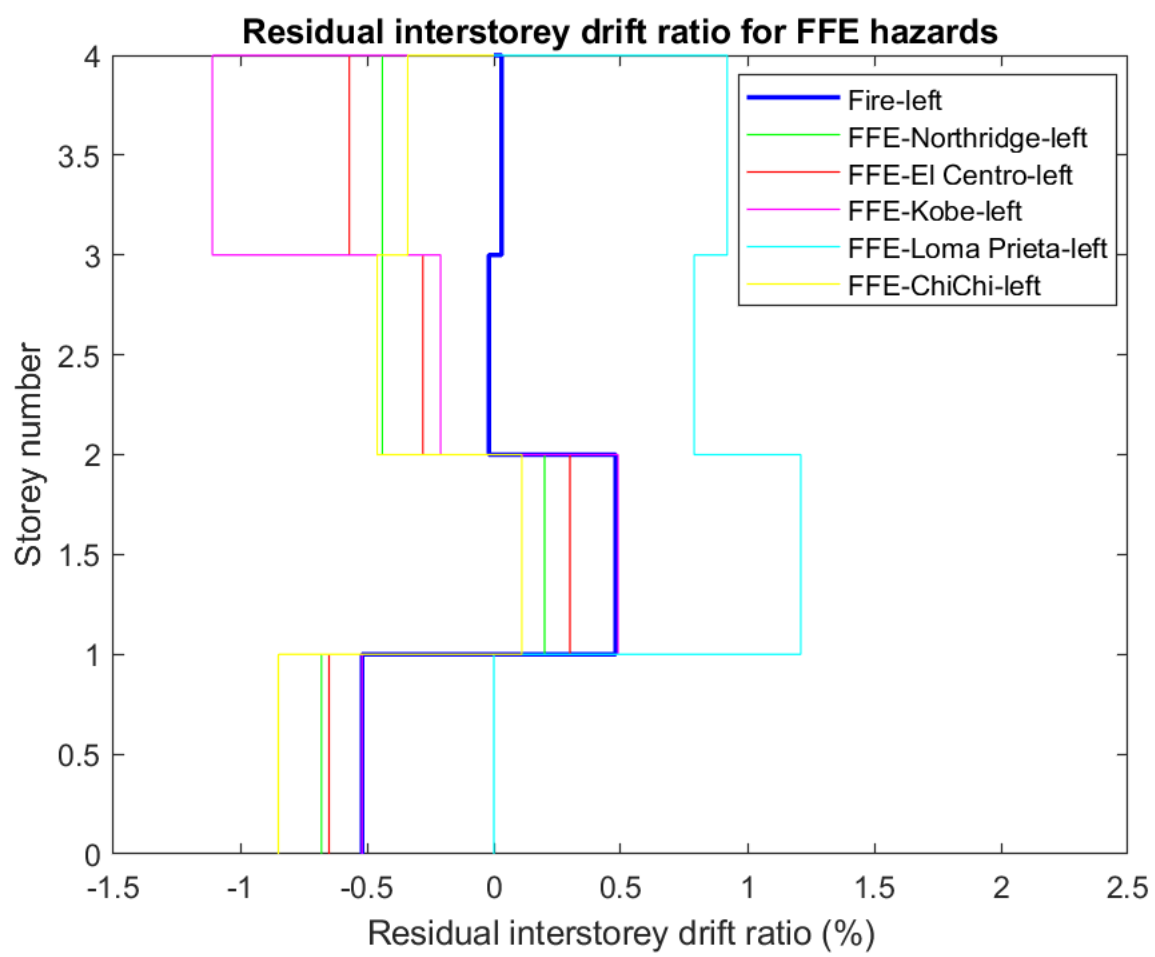

Figure 4.15 Residual interstorey drift ratio of the building under FFE hazards. 


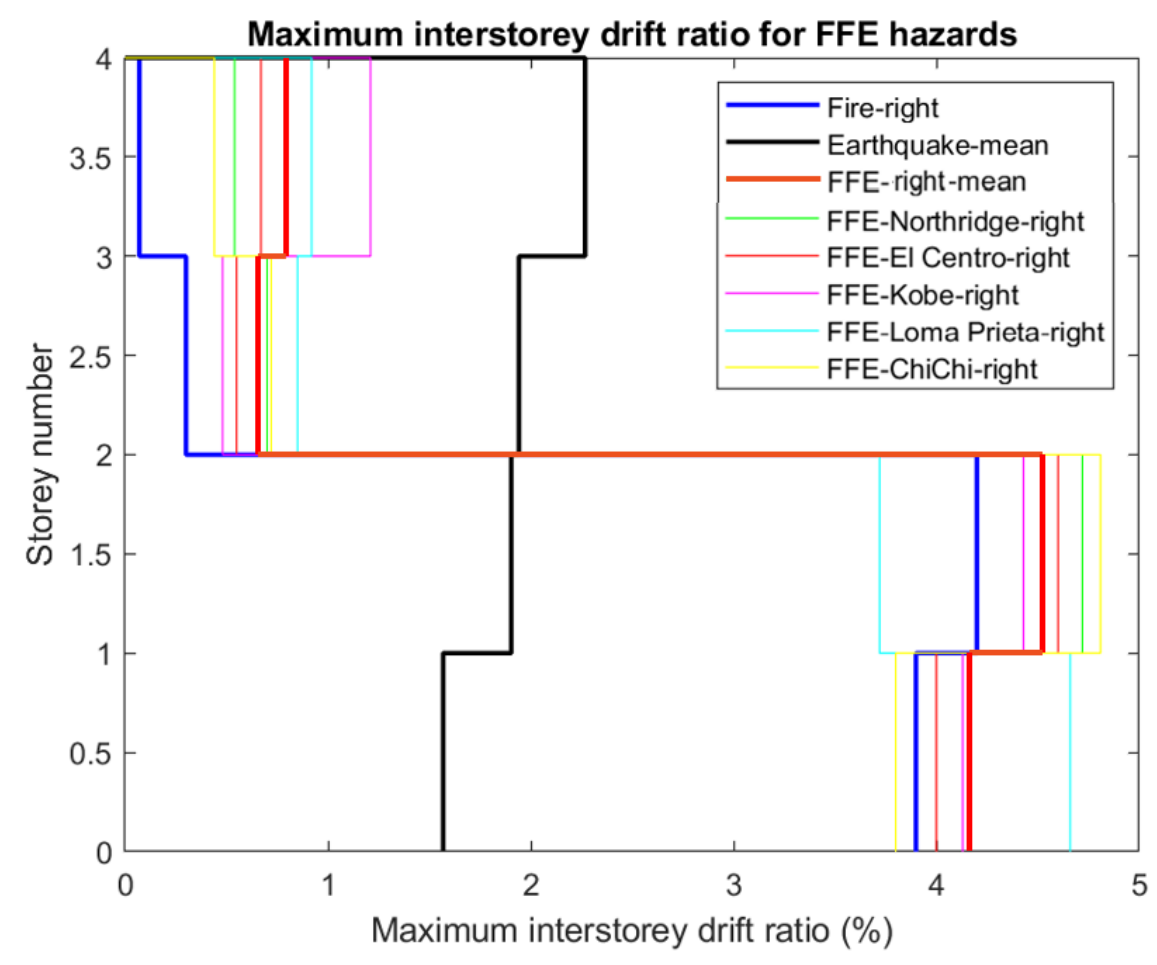

Figure 4.16 Maximum interstorey drift ratio of the building under FFE hazards.

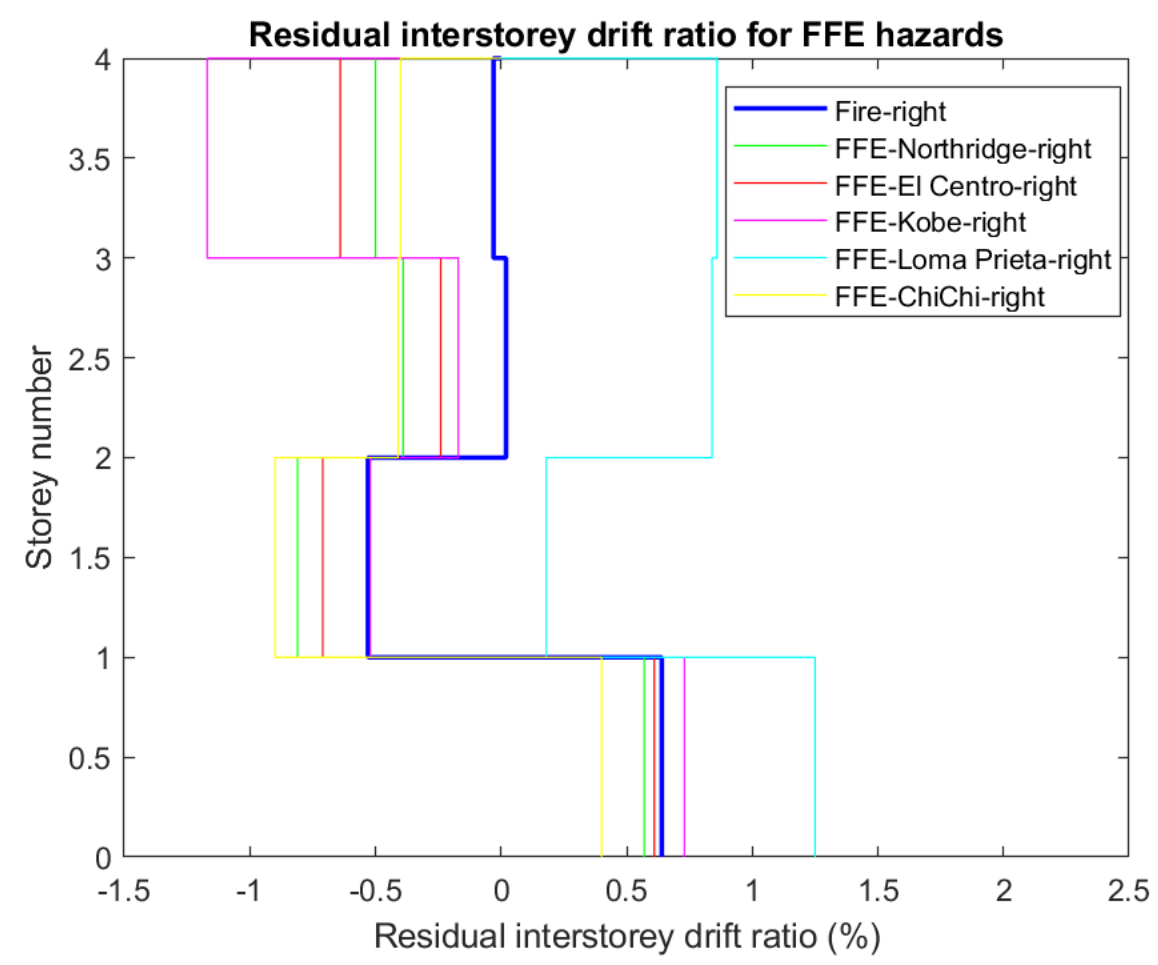

Figure 4.17 Residual interstorey drift ratio of the building under FFE hazards. 


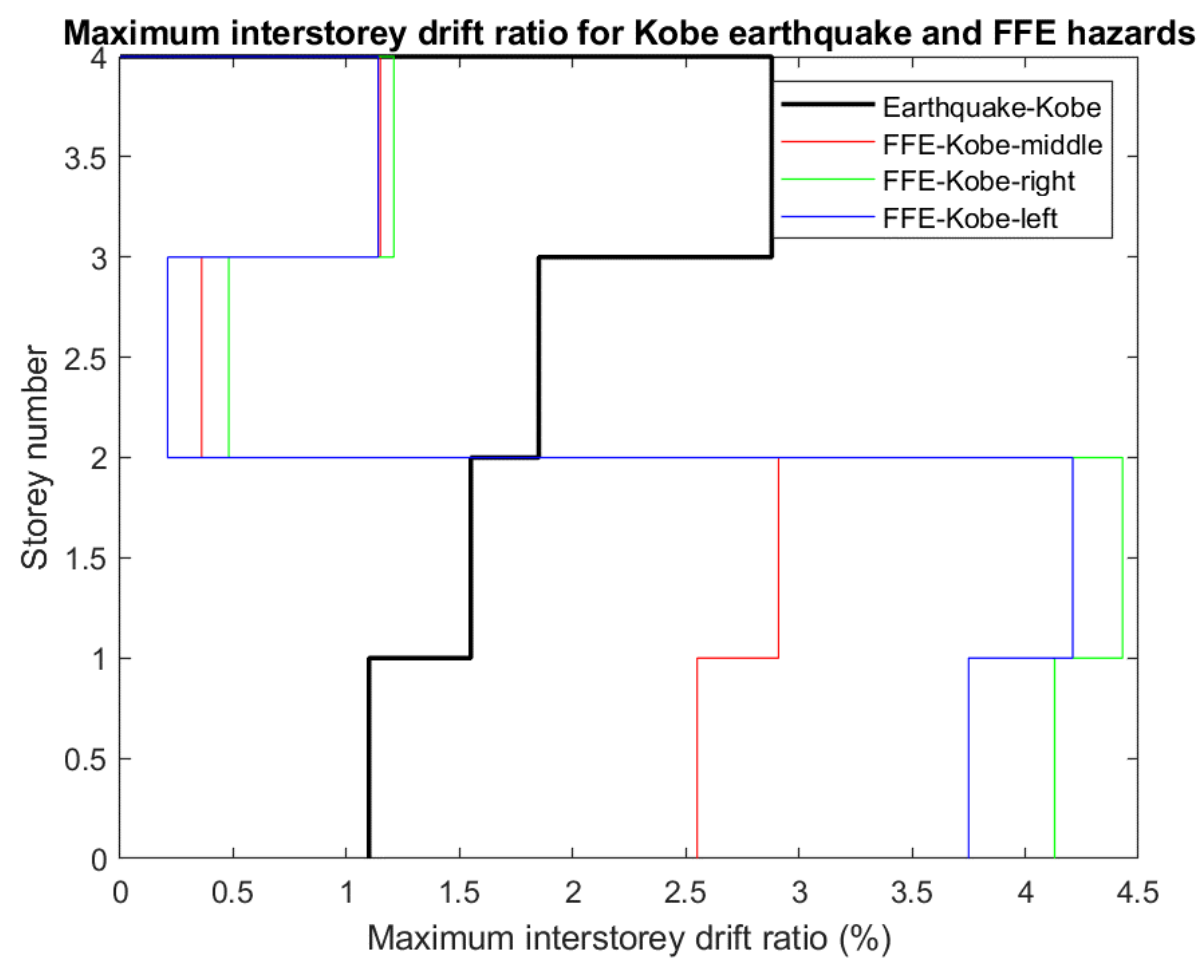

Figure 4.18 Maximum interstorey drift ratio of the building under FFE hazards.

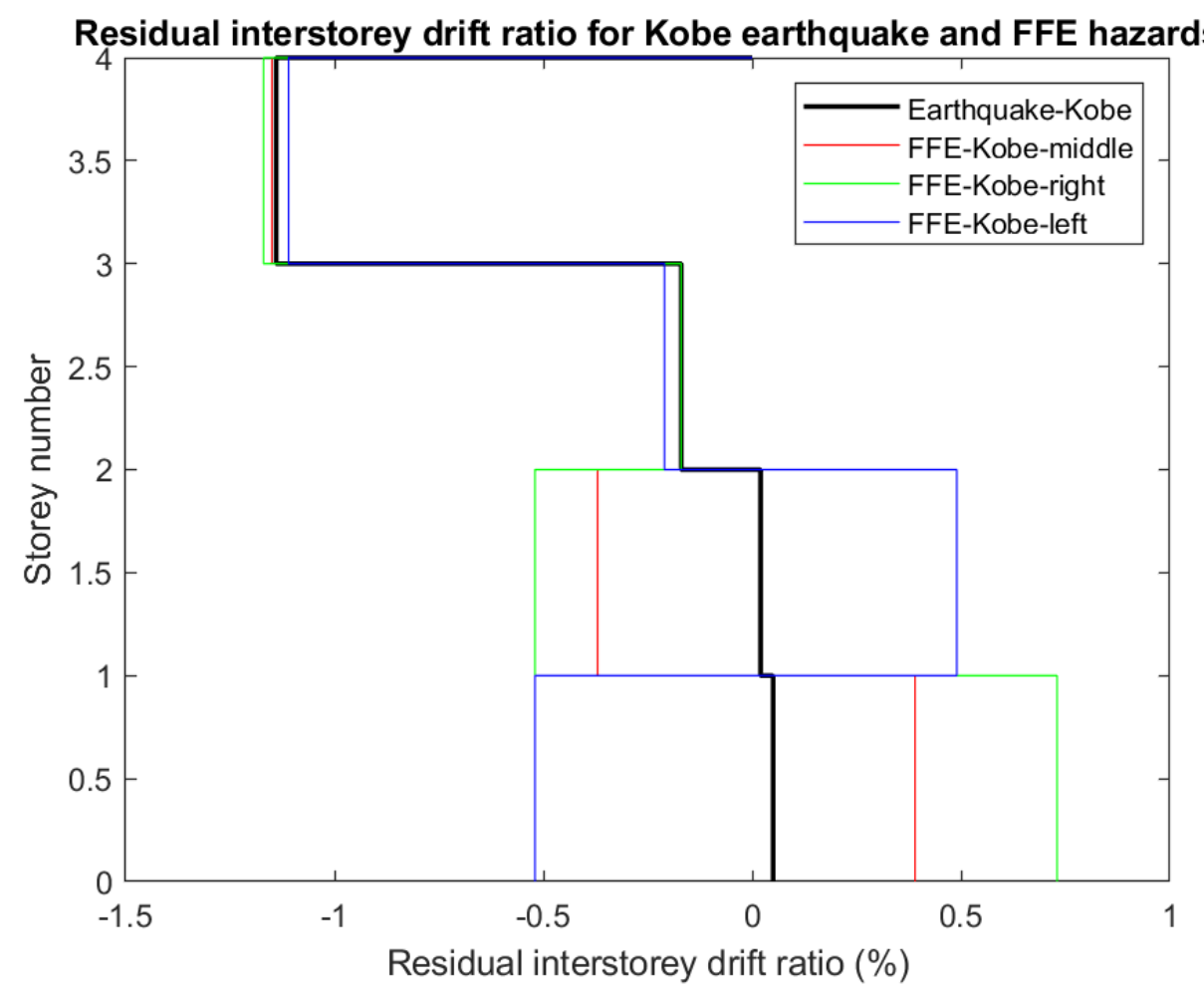

Figure 4.19 Residual interstorey drift ratio of the building under FFE hazards. 


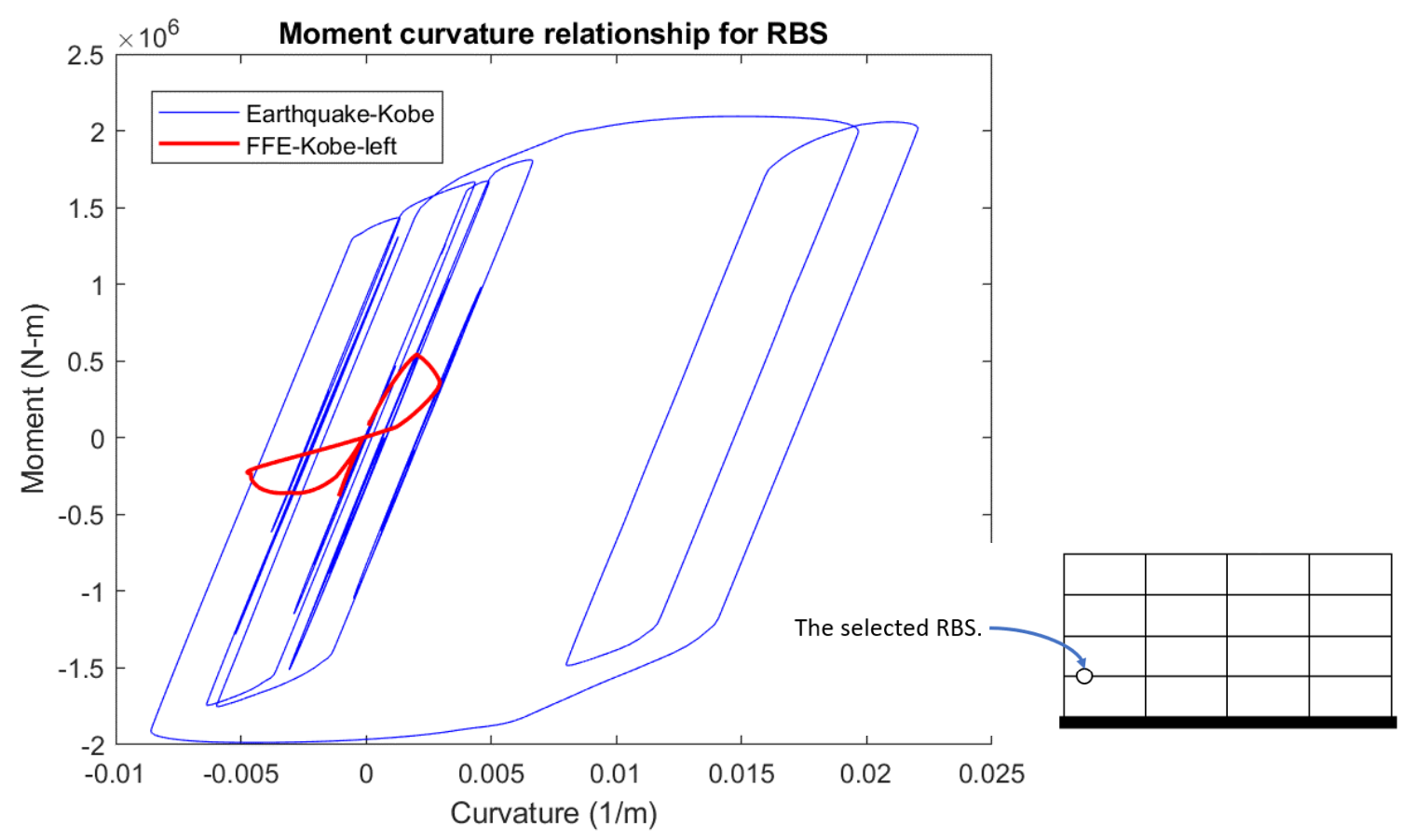

Figure 4.20 Moment curvature relationship of a beam with RBS on the first floor.

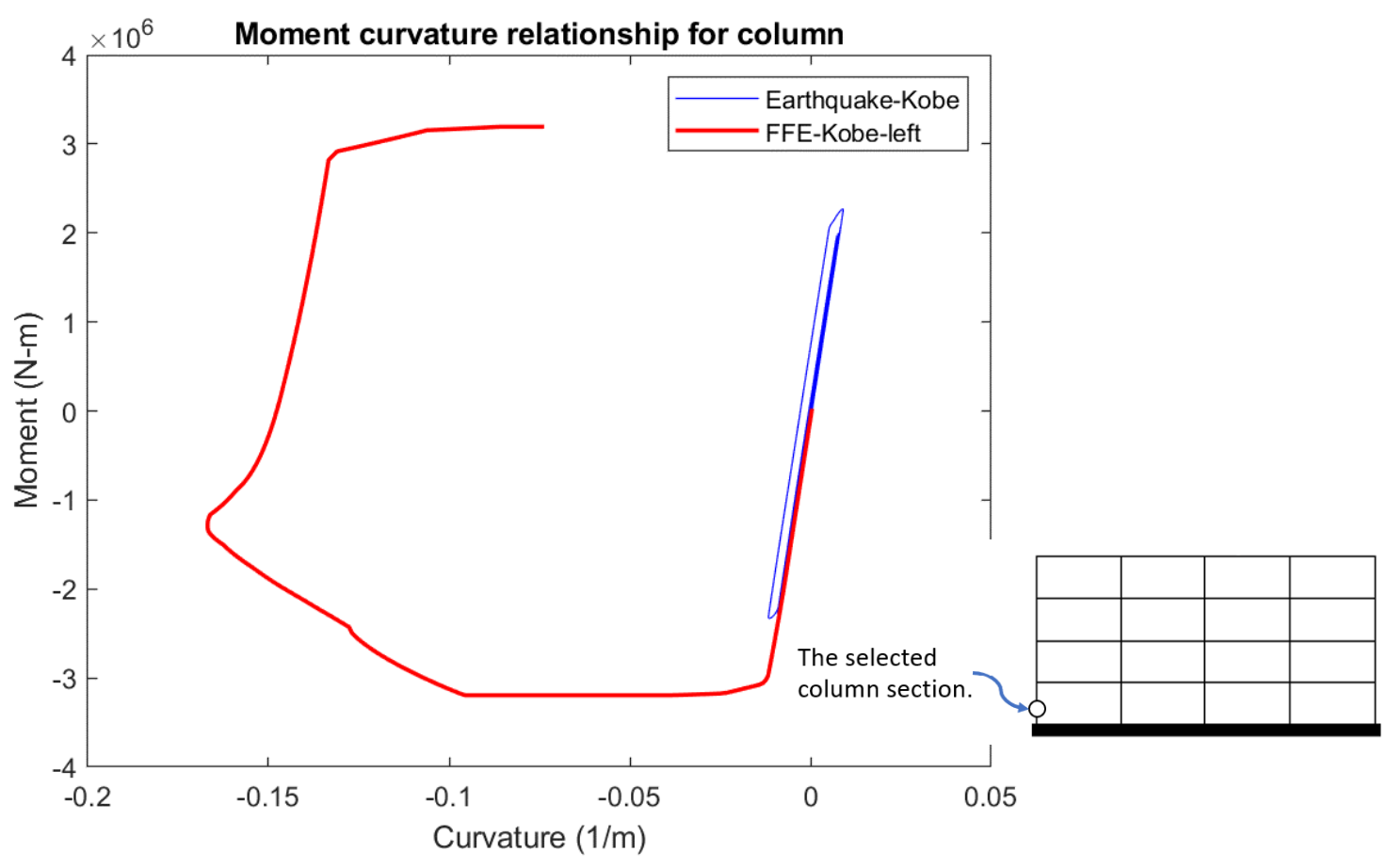

Figure 4.21 Moment curvature relationship of an exterior column on the first floor. 


\section{Chapter 5: Summary, Conclusions and Future Research}

\subsection{Summary}

A framework for assessing the risks of large-scale structures in fire and fire following earthquake through hybrid simulation is proposed and demonstrated in this research by conducting a numerical simulation example. Full interactions between the thermal and mechanical behaviour of the structures are considered in the assessment.

For the multi-hazard risk, a numerical study on the performance of a 4-storey steel moment resisting frame subjected to fire following earthquake is also presented in this research.

\subsection{Conclusions}

The hybrid fire simulation numerical study validated the feasibility of the proposed HFS framework. It is noted that both thermal and mechanical full information exchange at the interface between numerical and physical domains is important in capturing the behaviour and performance of complete structural systems.

In the FFE numerical simulation study, the results show that the sequential combination multi-hazard effect of fire following earthquake can introduce more damage to the example building when compared to the case of damage due to fire hazard alone. The risk of total collapse of the building is high in the post-earthquake fire hazard due to the high nonlinear behaviour in the columns. Therefore, it is necessary to develop design methods for structures against such multi-hazard events. 


\subsection{Future Research}

The suggested improvements and extensive studies in the future are listed as following:

- For the study on the performance of steel buildings under fire following earthquake: (1) include post-earthquake fire ignition model for determining a more realistic fire following earthquake scenario; (2) generate more accurate temperature profile for the heated structural members by doing heat transfer analysis or obtain from CFD.

- Future studies on the hybrid fire simulation: (1) conduct fully automatic hybrid fire simulation tests in the laboratory; (2) consider fire spread scenarios in hybrid fire simulation tests by using multiple furnaces in the laboratory.

- For the application of hybrid simulation on fire following earthquake multihazard scenarios: (1) adopt more comprehensive numerical analysis tools and models; (2) improve the interface platform for such multi-hazard hybrid simulation; (3) conduct numerical and physical test to validate the fire following earthquake hybrid simulation methodology. 


\section{Appendix A: Calculation of properties of unprotected steel temperature exposed to fire}

The step-by-step calculation method for determining the properties of unprotected steel temperature under fire is given by Eurocode 3 (CEN, 2005). Assuming the entering heat equals to the heat to raise the temperature of the unprotected steel. The temperature increase within a given time step $\Delta t$ in an unprotected steel member can be calculated by equation A.1.

$$
\Delta T_{s}=k_{s h} \frac{(F / V)}{\rho_{s} c_{s}}\left[h_{c}\left(T_{f}-T_{s}\right)+\sigma \varepsilon\left(T_{f}{ }^{4}-T_{s}^{4}\right)\right] \Delta t
$$

where $\rho_{\mathrm{s}}$ is the density of steel $\left(\mathrm{kg} / \mathrm{m}^{3}\right), \rho_{\mathrm{s}}=7850 \mathrm{~kg} / \mathrm{m}^{3}$;

$\mathrm{c}_{\mathrm{s}}$ is the specific heat of steel $(\mathrm{J} / \mathrm{kgK}), \mathrm{c}_{\mathrm{s}}$ values are taken from Figure A.1;

$\Delta \mathrm{T}_{\mathrm{s}}$ is the change in steel temperature in the time step $\left({ }^{\circ} \mathrm{C}\right.$ or $\left.\mathrm{K}\right)$;

$h_{c}$ is the convective heat transfer coefficient $\left(\mathrm{W} / \mathrm{m}^{2} \mathrm{~K}\right), \mathrm{h}_{\mathrm{c}}=25 \mathrm{~W} / \mathrm{m}^{2} \mathrm{~K}$;

$\sigma$ is the Stefan-Boltzmann constant $\left(56.7 \times 10^{-12} \mathrm{~kW} / \mathrm{m}^{2} \mathrm{~K}^{4}\right)$;

$\varepsilon$ is the resultant emissivity, $\varepsilon=0.5$;

$\mathrm{T}_{\mathrm{f}}$ is the temperature in the fire environment $(\mathrm{K})$,

$\mathrm{T}_{\mathrm{s}}$ is the temperature of the steel $(\mathrm{K})$,

$\mathrm{k}_{\mathrm{sh}}$ is a correction factor for shadow effects, $\mathrm{k}_{\mathrm{sh}}=1.0$;

$\mathrm{F}$ is the surface area of the member per unit length $\left(\mathrm{m}^{2} / \mathrm{m}\right)$;

$\mathrm{V}$ is the volume of the member per unit length $\left(\mathrm{m}^{3} / \mathrm{m}\right)$;

$\mathrm{F} / \mathrm{V}$ is the section factor for unprotected steel members $(1 / \mathrm{m})$, the $\mathrm{F} / \mathrm{V}$ values for different sections are given in Table A.1. 


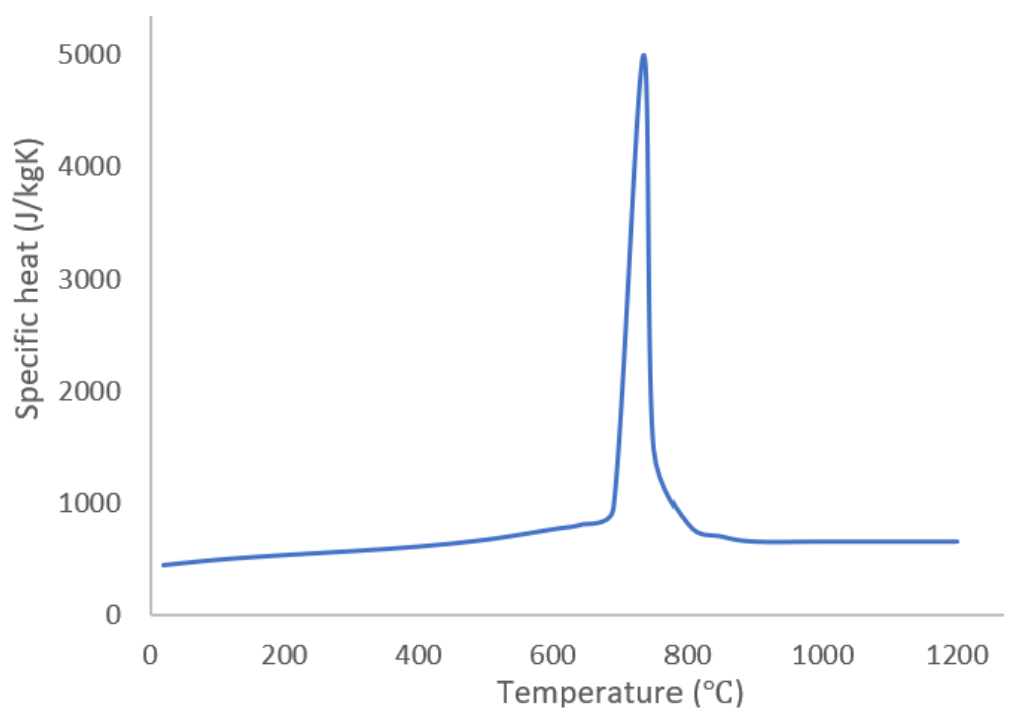

Figure A.1 Specific heat of steel calculated based on Eurocode 3 (CEN, 2005).

\begin{tabular}{ccccc}
\hline Section & W18 $\times 65$ & W14 $\times 233$ & W $14 \times 311$ & $\begin{array}{c}\text { W } 33 \times 130 \\
\text { with } 40 \% \text { flange width reduction }\end{array}$ \\
\hline F/V $(1 / \mathrm{m})$ & 136.4 & 54.0 & 41.5 & 120.0 \\
\hline
\end{tabular}

Table A.1 Section factor for different sections.

Further details on the determination of the properties of unprotected steel are given in Eurocode 3 (CEN, 2005). 


\section{References}

ASCE/SEI 7-16 (2017). Minimum design loads for buildings and other structures. American Society of Civil Engineers/Structural Engineering Institute, Reston, VA, USA.

ASCE/SEI 41-17 (2017). Seismic evaluation and retrofit of existing buildings. American Society of Civil Engineers/Structural Engineering Institute/Society of Fire Protection Engineers, Reston, VA, USA.

ASCE/SEI/SFPE 29-05 (2007). Standard calculation methods for structural fire protection. American Society of Civil Engineers/Structural Engineering Institute/Society of Fire Protection Engineers, Reston, VA, USA.

ASTM (2016). American Society for Testing and Materials. Standard test methods for fire tests of building construction and materials. ASTM E119-16a. Prepared by the ASTM, Reston, VA, USA.

Braxtan, N.L. and Pessiki, P.S. (2011). "Post-earthquake fire performance of sprayed fireresistive material on steel moment frames." Journal of Structural Engineering, 137(9), pp. 946-953.

Buchanan A.H., Abu A.K. (2017). Structural design for fire safety. Wiley, Hoboken, USA.

CAN/ULC. (2014). Canada/Underwriters' Laboratories of Canada. Standard methods of fire endurance tests of building construction and materials. CAN/ULC-S101. Prepared by ULC, Toronto, Canada.

CEN. (2002). "Eurocode 1: Actions on Structures - Part 1-2: General actions - Actions on structures exposed to fire." European Committee for Standardization.

CEN. (2005). "Eurocode 3: Design of steel structures - Part 1-2: General rules - Structural fire design." European Committee for Standardization.

Della Corte, G., Faggiano, G. and Mazzolani, F.M. (2005). "On the structural effects of fire following earthquake." COST C12 Final Conference Proceedings 2005, Innsbruck, Austria.

Franssen J.M., Gernay T., (2017). "Modeling structures in fire with SAFIR®: theoretical background and capabilities". Journal of Structural Fire Engineering, Vol. 8 No. 3, pp. 300323.

FEMA 350. (2000). "Recommended seismic design criteria for new steel moment-frame buildings.” Federal Emergency Management Agency, Washington, DC. 
FEMA P695. (2009). "Quantification of building seismic performance factors." Federal Emergency Management Agency, Washington, DC.

ISO (2014). International Organization for Standardization. Fire resistance tests-Elements of building construction-Part 11: Specific requirements for the assessment of fire protection to structural steel elements. ISO 834-11:2014. By ISO, Geneva, Switzerland.

Izzuddin B., Moore D.B. (2008). "Lessons from a full scale fire test". Accessed 4 May 2018. https://core.ac.uk/download/pdf/295458.pdf.

Jin J., El-Tawil S. (2004). "Seismic performance of steel frames with reduced beam section connections". Journal of Constructional Steel Research. Vol. 61, pp. 453-471.

Johnson, G.R. and Cook, W.H. (1985). "Fracture characteristics of three metals subjected to various strains, strain Rates, temperatures and pressures." Engineering Fracture Mechanics, Vol. 21 No. 1, pp. 31-48.

Khan M.A., Jiang L., Cashell K.A., Usmani A. (2018). “Analysis of restrained composite beams exposed to fire using a hybrid simulation approach". Engineering Structures. Vol. 172, pp. 956-966.

Khorasani N.E. A probabilistic framework for multi-hazard evaluations of buildings and communities subjected to fire and earthquake scenarios. Princeton, New Jersey. Princeton University; 2015.

Khorasani N.E., Garlock M., Gardoni P., (2016). "Probabilistic performance-based evaluation of a tall steel moment resisting frame under post-earthquake fires", Journal of Structural Fire Engineering, Vol. 7 No. 3, pp. 193-216.

Kildashti K., Mirghaderi R. (2009). "Assessment of seismic behaviour of SMRFs with RBS connections by means of mixed-based state-space approach". The Structural Design of Tall and Special Buildings, Vol. 18, pp. 485-505.

Kim J.K., Meacham B.J., Park H., Hutchinson T., Pantoli E. (2014). "Fire performance of a full-scale building subjected to earthquake motions: test specimen, seismic motions and performance of fire protection systems". The $11^{\text {th }}$ international symposium on fire safety science, Canterbury, New Zealand, 1 November 2013.

Korzen M., Magonette G., Buchet Ph. (1999). "Mechanical loading of columns in fire tests by means of the substructuring method". Zeitschrift Fur Angewandte Mathematic Und Mechanik. Vol. 79, pp. 617-618.

Korzen M., Ziener K.U., Riemer S. (2002). "Some remarks on the substructuring method applied to fire resistance tests of columns". World congress on housing, Coimbra, Portugal, 9-13 September 2002. 
Kwon O.S., (2016). "UT-SIM". Accessed 4 May 2018. https://www.ut-sim.ca/.

McCrum D.P., Williams M.S., (2016). "An overview of seismic hybrid testing of engineering structures”. Engineering Structures, Vol. 118, pp. 240-261.

McGrattan, K. B., McDermott, R. J., Weinschenk, C. G., and Forney, G. P. (2013). Fire Dynamics Simulator, Technical Reference Guide. NIST.

Memari M. Performance of steel structures subjected to fire following earthquake. Fort Collins, Colorado. Colorado State University; 2016.

Memari M., Mahmoud H. (2018). "Framework for a performance-based analysis of fires following earthquakes". Engineering Structures, Vol. 171, pp. 794-805.

Mergny E., Drion G., Gernay T., Franssen J.M. (2018). "A PI-controller for hybrid testing in a non-linear environment". The $10^{\text {th }}$ international conference on structures in fire, Belfast, UK, 6-8 June 2018.

Mostafaei H. (2013). "Hybrid fire testing for assessing performance of structures in firemethodology". Fire Safety Journal, Vol. 58, pp. 170-179.

Mostafaei H. (2013). "Hybrid fire testing for assessing performance of structures in fireapplication”. Fire Safety Journal, Vol. 56, pp. 30-38.

NBC. (2015). National Building Code of Canada. Canadian Commission on Building and Fire Codes, National Research Council Canada (NRC), Ottawa, Canada.

NRC (2019). National Research Council Canada. https://nrc.canada.ca/en

OpenFresco. (2015). "Open framework for experimental setup and control”. University of California, Berkeley. http://openfresco.berkeley.edu/

OpenSees. (2015). "Open system for earthquake engineering simulation”. University of California, Berkeley. http://opensees.berkeley.edu/

Qureshi R., Khorasani N.E., (2018). "Instantaneous stiffness correction for hybrid fire testing". The $10^{\text {th }}$ international conference on structures in fire, Belfast, UK, 6-8 June 2018.

Robert F., Rimlinger S., Collignon C. (2010). "Structure fire resistance: a joint approach between modelling and full scale testing (substructuring system)". The $3^{\text {rd }}$ fib congress. Washington DC, USA, 29 May-2 June 2010.

Robertson J.N., Mehaffey J.R. (2000). "Accounting for fire following earthquakes in the development of performance based building codes". The $12^{\text {th }}$ world conference on earthquake engineering, Auckland, New Zealand, 4 February 2000. 
Sauca A., Gernay T., Robert F., Tondini N., Franssen J.M. (2016). "Stability in hybrid fire testing". The $9^{\text {th }}$ international conference on structures in fire, Princeton University, USA, 8-10 June 2016.

Schulthess P., Neuenschwander M., Fontana M., Knobloch M. (2016). "Consolidated fire testing: coupled thermo-mechanical modelling for analysis of the global structural fire behavior". $6^{\text {th }}$ International conference on structural engineering, mechanics and computation, Cape Town, South Africa, 5-7 September 2016.

SFPE (2004). Society of Fire Protection Engineers. Engineering guide: fire exposures to structural elements. Prepared by SFPE, Bethesda, USA.

SIMULIA Corp. (2013) ABAQUS/Standard User's Manual, Version 6.13. Providence, USA.

Tondini N., Abbiati G., Possidente L., Stojadinovic B. (2016). "Hybrid simulation applied to fire testing: a newly conceived numerical framework". The $6^{\text {th }}$ European conference on structural control, Sheffield, England, 11-13 July 2016.

Tondini N., Vassart O., Franssen J.M. (2012). "Development of an interface between CFD and FE software". The $7^{\text {th }}$ international conference on structures in fire, Zurich, Switzerland, 6-8 June 2012.

Usmani A., Zhang J., Jiang J., Jiang Y., May I. (2012). "Using OpenSees for structures in fire". Journal of structural fire engineering, Vol. 3 No. 1, pp. 57-70.

Wang X., Kim R.E., Kwon O.S., Yeo I. (2018). "Hybrid simulation method for a structure subjected to fire and its application to a steel frame". Journal of Structural Engineering, ISSN 0733-9445.

Whyte C.A., Mackie K.R., Stojadinovic B. (2014). "Experimental modeling of the structural response to fire loads using the hybrid simulation technique". $10^{\text {th }}$ U.S. national conference on earthquake engineering, Anchorage, USA, 21-25 July 2014.

Yu Z., Lau D., Erochko J., Kwon OS., Kashef A. (2019). "Methodology for fire following earthquake hybrid simulation". 12 ${ }^{\text {th }}$ Canadian Conference on Earthquake Engineering, Quebec City, QC, Canada,17-20 June 2019. 